Cochrane Database of Systematic Reviews

\title{
Postoperative epidural analgesia versus systemic analgesia for thoraco-lumbar spine surgery in children (Review)
}

Guay J, Suresh S, Kopp S, Johnson RL

Guay J, Suresh S, Kopp S, Johnson RL.

Postoperative epidural analgesia versus systemic analgesia for thoraco-lumbar spine surgery in children.

Cochrane Database of Systematic Reviews 2019, Issue 1. Art. No.: CD012819.

DOI: 10.1002/14651858.CD012819.pub2.

www.cochranelibrary.com 
TABLE OF CONTENTS

ABSTRACT

PLAIN LANGUAGE SUMMARY

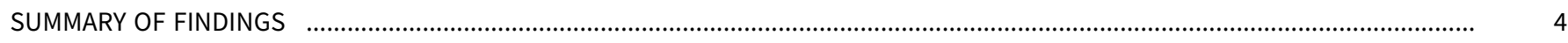

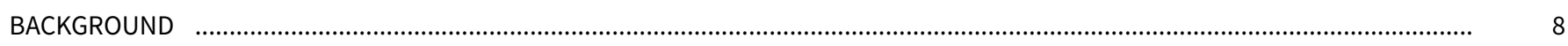

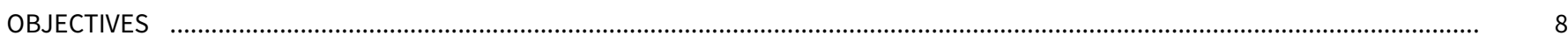

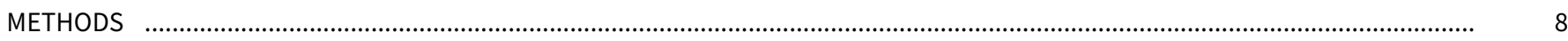

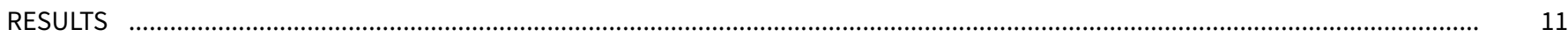

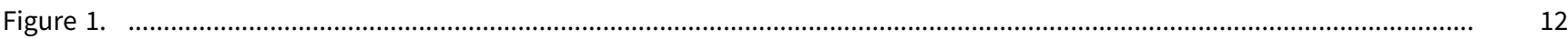

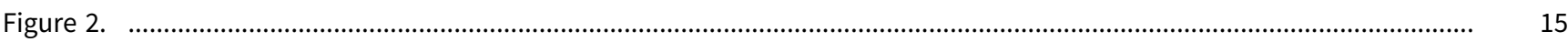

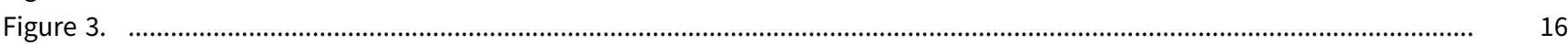

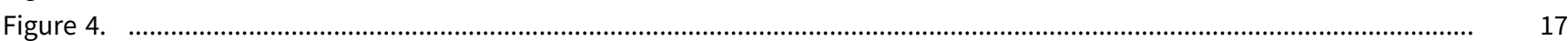

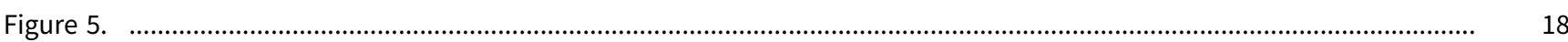

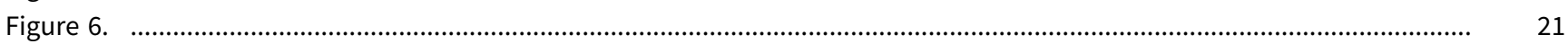

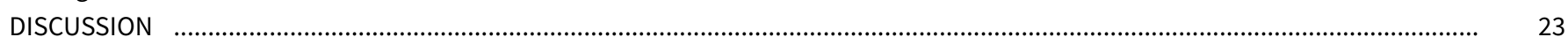

AUTHORS' CONCLUSIONS

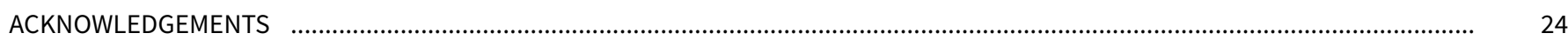

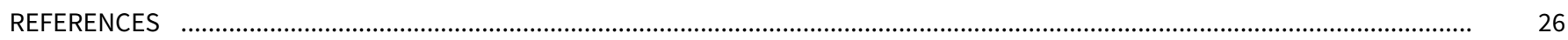

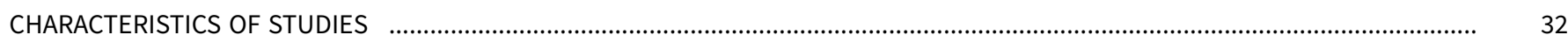

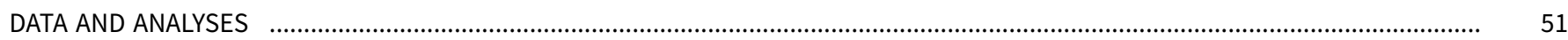

Analysis 1.1. Comparison 1 Epidural analgesia versus systemic analgesia for postoperative pain after back surgery in children, 53

Outcome 1 Pain at rest at 6-8 hours.

Analysis 1.2. Comparison 1 Epidural analgesia versus systemic analgesia for postoperative pain after back surgery in children, Outcome 2 Pain at rest at 20-32 hours.

Analysis 1.3. Comparison 1 Epidural analgesia versus systemic analgesia for postoperative pain after back surgery in children, Outcome 3 Pain on movement at 24 hours.

Analysis 1.4. Comparison 1 Epidural analgesia versus systemic analgesia for postoperative pain after back surgery in children, Outcome 4 Pain at rest at 48 hours.

Analysis 1.5. Comparison 1 Epidural analgesia versus systemic analgesia for postoperative pain after back surgery in children, Outcome 5 Pain on movement at 48 hours.

Analysis 1.6. Comparison 1 Epidural analgesia versus systemic analgesia for postoperative pain after back surgery in children, Outcome 6 Pain at rest at 72 hours.

Analysis 1.7. Comparison 1 Epidural analgesia versus systemic analgesia for postoperative pain after back surgery in children, Outcome 7 Pain on movement at 72 hours.

Analysis 1.8. Comparison 1 Epidural analgesia versus systemic analgesia for postoperative pain after back surgery in children, Outcome 8 Vomiting up to 48 hours after surgery.

Analysis 1.9. Comparison 1 Epidural analgesia versus systemic analgesia for postoperative pain after back surgery in children, Outcome 9 Return of gastrointestinal function: number of participants with bowel movement at 48 hours.

Analysis 1.10. Comparison 1 Epidural analgesia versus systemic analgesia for postoperative pain after back surgery in children, Outcome 10 Return of gastrointestinal function: time to first liquid ingestion.

Analysis 1.11. Comparison 1 Epidural analgesia versus systemic analgesia for postoperative pain after back surgery in children, Outcome 11 Hospital length of stay.

Analysis 1.12. Comparison 1 Epidural analgesia versus systemic analgesia for postoperative pain after back surgery in children, Outcome 12 Participant satisfaction.

Analysis 1.13. Comparison 1 Epidural analgesia versus systemic analgesia for postoperative pain after back surgery in children, Outcome 13 Respiratory depression.

Analysis 1.14. Comparison 1 Epidural analgesia versus systemic analgesia for postoperative pain after back surgery in children, Outcome 14 Wound infection.

Analysis 1.15. Comparison 1 Epidural analgesia versus systemic analgesia for postoperative pain after back surgery in children, Outcome 15 Epidural abscess.

Analysis 1.16. Comparison 1 Epidural analgesia versus systemic analgesia for postoperative pain after back surgery in children, Outcome 16 Neurological complications.

ADDITIONAL TABLES 
[Intervention Review]

\section{Postoperative epidural analgesia versus systemic analgesia for thoraco- lumbar spine surgery in children}

Joanne Guay1,2,3, Santhanam Suresh ${ }^{4}$, Sandra Kopp 5 , Rebecca L Johnson 5

1Department of Anesthesiology, Faculty of Medicine, University of Sherbrooke, Sherbrooke, Canada. ${ }^{2}$ Teaching and Research Unit, Health Sciences, University of Quebec in Abitibi-Temiscamingue, Rouyn-Noranda, Canada. ${ }^{3}$ Department of Anesthesiology and Critical Care, Faculty of Medicine, Laval University, Quebec City, Canada. ${ }^{4}$ Department of Pediatric Anesthesiology, Ann \& Robert H. Lurie Children's Hospital of Chicago Research Center, Chicago, IL, USA. ${ }^{5}$ Department of Anesthesiology and Perioperative Medicine, Mayo Clinic College of Medicine, Rochester, MN, USA

Contact: Joanne Guay, Department of Anesthesiology, Faculty of Medicine, University of Sherbrooke, Sherbrooke, Quebec, Canada. joanneguay@bell.net, joanneguay@att.net.

Editorial group: Cochrane Anaesthesia Group.

Publication status and date: New, published in Issue 1, 2019.

Citation: Guay J, Suresh S, Kopp S, Johnson RL. Postoperative epidural analgesia versus systemic analgesia for thoraco-lumbar spine surgery in children. Cochrane Database of Systematic Reviews 2019, Issue 1. Art. No.: CD012819. DOI: 10.1002/14651858.CD012819.pub2.

Copyright ( 2019 The Cochrane Collaboration. Published by John Wiley \& Sons, Ltd.

\section{A B S T R A C T}

\section{Background}

Spine surgery may be associated with severe acute postoperative pain. Compared with systemic analgesia alone, epidural analgesia may offer better pain control. However, epidural analgesia has sometimes been associated with rare but serious complications. Therefore, it is critical to quantify the real benefits of epidural analgesia over other modes of pain treatment.

\section{Objectives}

To assess the effectiveness and safety of epidural analgesia compared with systemic analgesia for acute postoperative pain control after thoraco-lumbar spine surgery in children.

\section{Search methods}

We searched the Cochrane Central Register of Controlled Trials (CENTRAL), MEDLINE, Embase and Cumulative Index to Nursing and Allied Health Literature on 14 November 2018, together with the references lists of related reviews and retained trials, and two trials registers.

\section{Selection criteria}

We included all randomized controlled trials performed in children undergoing any type of thoraco-lumbar spine surgery comparing epidural analgesia with systemic analgesia for postoperative pain. We applied no language or publication status restriction.

\section{Data collection and analysis}

We assessed risk of bias of included trials using the Cochrane tool. We analysed data using random-effects models. We rated the quality of the evidence according to the GRADE scale.

\section{Main results}

We included 11 trials (559 participants) in the review, and seven trials (249 participants) in the analysis: 140 participants received epidural analgesia and 109 received systemic analgesia.

Most studies included adolescents. Three trials included in the analysis contained some participants older than 18 years. The types of surgery were posterior spinal fusion for idiopathic scoliosis (nine trials), anterior correction for idiopathic scoliosis (one trial), or selective 
dorsal rhizotomy in children with cerebral palsy (one trial). The mean numbers of vertebrae operated on were between nine and 14.5 and the mean numbers of spinal levels were between three and four and a half. The length of surgery varied between three and six and a half hours.

Compared with systemic analgesia, epidural analgesia reduced pain at rest at all time points. At six to eight hours, the mean pain score on a 0 to 10 scale with systemic analgesia was 3.1 (standard deviation 0.7 ) and with epidural analgesia was -1.32 points (95\% confidence interval (Cl) -1.83 to -0.82 ; 4 studies, 116 participants; moderate-quality evidence). At 72 hours, the mean pain score with epidural analgesia was equivalent to a -0.8 point reduction on a 0 to 10 scale (standardized mean difference (SMD) $-0.65,95 \% \mathrm{Cl}-1.19$ to $-0.10 ; 5$ studies, 157 participants; moderate-quality evidence).

\section{Return of gastrointestinal function}

There was no difference for nausea and vomiting between groups (risk ratio (RR) $0.87,95 \% \mathrm{Cl} 0.58$ to $1.30 ; 6$ studies, 215 participants; low-quality evidence). One study found epidural analgesia with local anaesthetics may have increased the number of participants who had their first flatus within 48 hours (RR $1.63,95 \% \mathrm{Cl} 1.08$ to $2.47 ; 30$ participants; very low-quality evidence). Two studies found epidural analgesia with local anaesthetics may have increased the number of participants in whom first bowel movement occurred within 48 hours (RR $11.52,95 \% \mathrm{Cl} 2.36$ to 56.26; 60 participants; low-quality evidence). It was uncertain whether epidural analgesia reduced the time to first bowel movement (MD 0.09 days, $95 \% \mathrm{Cl}-0.32$ to $0.50 ; 1$ study, 60 participants; very low-quality evidence) and time to first liquid ingestion following epidural infusion of an opioid alone or a local anaesthetic plus an opioid (mean difference (MD) $-5.02 \mathrm{hours}, 95 \% \mathrm{Cl}-13.15$ to 3.10; 2 studies, 56 participants; very low-quality evidence). Epidural analgesia with local anaesthetics may have increased the risk of having first solid food ingestion within 48 hours (RR $7.00,95 \% \mathrm{Cl} 1.91$ to 25.62 ; 1 study, 30 participants; very low-quality evidence).

\section{Secondary outcomes}

It was uncertain whether there was a difference in time to ambulate (MD 0.08 days, $95 \% \mathrm{Cl}-0.24$ to $0.39 ; 1$ study, 60 participants; very lowquality evidence) and hospital length of stay (MD -0.29 days, $95 \% \mathrm{Cl}-0.69$ to $0.10 ; 2$ studies, 89 participants; very low-quality evidence). Two studies found participants were more satisfied when treated with epidural analgesia (MD 1.62 on a scale from 0 to $10,95 \% \mathrm{Cl} 1.26$ to 1.97; 60 participants; very low-quality evidence). It was unclear whether there was a difference in parent satisfaction for epidural analgesia with an opioid alone (MD 0.60, $95 \% \mathrm{Cl}-0.81$ to $2.01 ; 1$ trial, 27 participants; very low-quality evidence).

\section{Complications}

It was uncertain whether there was a difference in the risk of complications such as: respiratory depression (risk difference (RD) -0.05, $95 \% \mathrm{Cl}-0.16$ to $0.05 ; 4$ studies, 126 participants; very low-quality evidence); wound infection (RD $0.01,95 \% \mathrm{Cl}-0.05$ to $0.08 ; 2$ trials, 93 participants; very low-quality evidence); epidural abscess (RD 0,95\% Cl -0.05 to $0.05 ; 3$ trials, 120 participants; very low-quality evidence); and neurological complications ( $\mathrm{RD} 0.01,95 \% \mathrm{Cl}-0.04$ to 0.06 ; 4 studies, 151 participants; very low-quality evidence).

\section{Authors' conclusions}

There is moderate- and low-quality evidence that there may be a small additional reduction in pain up to 72 hours after surgery with epidural analgesia compared with systemic analgesia. Two very small studies showed epidural analgesia with local anaesthetic alone may accelerate the return of gastrointestinal function. The safety of this technique in children undergoing thoraco-lumbar surgery is uncertain due to the very low-quality of the evidence. The study in 'Studies awaiting classification' may alter the conclusions of the review once assessed.

\section{PLAIN LANGUAGE SUMMARY}

\section{Epidural analgesia for postoperative pain after spinal surgery in children}

\section{Review question}

We tried to determine if epidural analgesia offers some advantages over systemic (vein, skin or muscles) analgesia for treating postoperative pain in children undergoing spine surgery.

\section{Background}

Some children need extensive spinal bone surgery. This is a very painful procedure. Traditionally, this pain has mostly been treated with an opioid such as systemic morphine (or morphine like medicine) given via an in injection into the veins, skin or muscles. Epidural analgesia involves giving pain relief medicine into a catheter inserted in the spine to block pain transmission to the brain. The catheter is a small tube usually placed by the surgeon, at the end of the surgery, in the space in the spinal canal known as the epidural space.

\section{Study characteristics}


The evidence is current to 14 November 2018. We included 11 trials with 559 participants in the review, and seven trials with 249 participants in the analysis. The trials were funded by departmental resources (five trials), or in part by industry and partly by charity (one trial). Five trials did not mention the source of funding. Three of the trials included in the analysis contained some participants older than 18 years.

\section{Key results}

There may be a small additional reduction in pain up to 72 hours after surgery with epidural analgesia compared with systemic analgesia. After an extensive spine surgery, the gut is paralysed for a certain amount of time leading to nausea (feeling sick), vomiting (being sick), inability to ingest liquid or food, and no stools excretion. Two very small studies showed epidural analgesia with local anaesthetic alone may have accelerated the return of gut function. If confirmed, this would mean that children would be able to resume normal liquid and solid food intake faster after extensive spine surgery. Children in two small studies were more satisfied with epidural analgesia compared with children in the systemic analgesia group. However, it was unclear whether their parents were more satisfied with epidural analgesia or systemic analgesia. The safety of this technique in children undergoing spine surgery was uncertain because there was insufficient information to determine whether there was a difference in the rate of complications between epidural analgesia and systemic analgesia and an analysis of small trials might not be the best methodology to evaluate this aspect.

\section{Quality of the evidence}

The quality of evidence was moderate, low or very low for reduced pain and low or very low for all other measurements.

Imperfections in the trials and low number of available trials were the main problems leading to rating the quality of evidence as low or very low. 


\section{SUMMARY OF FINDINGS}

Summary of findings for the main comparison. Epidural analgesia compared to systemic analgesia for postoperative analgesia after thoraco-lumbar spine surgery in children

\section{Epidural analgesia compared to systemic analgesia for postoperative analgesia after thoraco-lumbar spine surgery in children}

Patient or population: children having undergone thoraco-lumbar spine surgery. 3 trials included in the analysis contained participants older than 18 years: Blumenthal 2005 (10-30 years; mean age 17 years), Klatt 2013 (10-21 years), and O'Hara 2004 (13-21 years)

Settings: university hospitals in Russia (1 trial), Switzerland (2), and USA (5)

Intervention: epidural analgesia. Local anaesthetic were used alone (2 trials) or in combination with an opioid ( 8 trials). Opioids alone were infused for one trial

Comparison: systemic analgesia. The comparator was continuous intravenous morphine (2 trials), intravenous patient-controlled analgesia with morphine (4 trials), intravenous patient-controlled analgesia with hydromorphone ( 2 trials), intravenous patient-controlled analgesia with an opioid ( 1 trial), intravenous nurse-controlled analgesia with morphine (1 trial), or unspecified (1 trial)

\begin{tabular}{|c|c|c|c|c|c|c|}
\hline \multirow[t]{3}{*}{ Outcomes } & \multicolumn{2}{|c|}{ Illustrative comparative risks ${ }^{\star}(95 \% \mathrm{Cl})$} & \multirow{3}{*}{$\begin{array}{l}\text { Relative effect } \\
(95 \% \mathrm{CI})\end{array}$} & \multirow{3}{*}{$\begin{array}{l}\text { No of partici- } \\
\text { pants } \\
\text { (studies) }\end{array}$} & \multirow{3}{*}{$\begin{array}{l}\text { Quality of the } \\
\text { evidence } \\
\text { (GRADE) }\end{array}$} & \multirow[t]{3}{*}{ Comments } \\
\hline & Assumed risk & Corresponding risk & & & & \\
\hline & Systemic analgesia & Epidural analgesia & & & & \\
\hline \multirow{7}{*}{$\begin{array}{l}\text { Pain } \\
\text { Assessed with: } \\
\text { scale: } 0-10 \text { (0 } \\
\text { = no pain, } 10= \\
\text { worst pain) }\end{array}$} & \multicolumn{2}{|c|}{ Pain scores at rest at 6-8 hours after surgery } & \multirow[t]{2}{*}{-} & \multirow{2}{*}{$\begin{array}{l}116 \\
\text { (4 studies) }\end{array}$} & \multirow{2}{*}{$\begin{array}{l}\oplus \oplus \oplus \ominus \\
\text { Moderate } a\end{array}$} & \multirow[t]{2}{*}{-} \\
\hline & $\begin{array}{l}\text { Mean pain score in the control } \\
\text { groups was } 3.1 \pm 0.7 \text { (mean } \pm \\
\text { SD) }\end{array}$ & $\begin{array}{l}\text { Mean pain score with epidural analgesia } \\
\text { was } 1.32 \text { lower } \\
\text { ( } 1.83 \text { to } 0.82 \text { lower) }\end{array}$ & & & & \\
\hline & \multicolumn{2}{|c|}{ Pain scores at rest at $20-32$ hours after surgery } & \multirow[t]{2}{*}{-} & \multirow{2}{*}{$\begin{array}{l}208 \\
\text { (6 studies) }\end{array}$} & \multirow{2}{*}{$\begin{array}{l}\oplus \oplus \oplus \ominus \\
\text { Moderate }^{a}\end{array}$} & \multirow[t]{2}{*}{-} \\
\hline & $\begin{array}{l}\text { Mean pain score in the control } \\
\text { groups was } 3.5 \pm 1.0 \text { (mean } \pm \\
\text { SD) }\end{array}$ & $\begin{array}{l}\text { Mean pain score with epidural analgesia } \\
\text { was } 1.06 \text { lower } \\
\text { (1.56 to } 0.57 \text { lower) }\end{array}$ & & & & \\
\hline & \multicolumn{2}{|c|}{ Pain scores on movement at 24 hours after surgery } & \multirow[t]{2}{*}{-} & \multirow[t]{2}{*}{$\begin{array}{l}87 \\
\text { (3 studies) }\end{array}$} & \multirow[t]{2}{*}{$\begin{array}{l}\oplus \oplus \ominus \ominus \\
\text { Low } b\end{array}$} & \multirow{2}{*}{$\begin{array}{l}\text { Equivalent to - } \\
1.2 \text { on a } \\
\text { scale from } 0 \text { to } \\
10\end{array}$} \\
\hline & \multicolumn{2}{|c|}{$\begin{array}{l}\text { Mean pain score with epidural analgesia was } \\
\text { 1.51 SDs lower } \\
\text { ( } 2.27 \text { to } 0.76 \text { lower) }\end{array}$} & & & & \\
\hline & \multicolumn{2}{|c|}{ Pain scores at rest at $\mathbf{4 8}$ hours after surgery } & - & $\begin{array}{l}148 \\
\text { (5 studies) }\end{array}$ & $\begin{array}{l}\oplus \oplus \oplus \ominus \\
\text { Moderate } a\end{array}$ & - \\
\hline
\end{tabular}




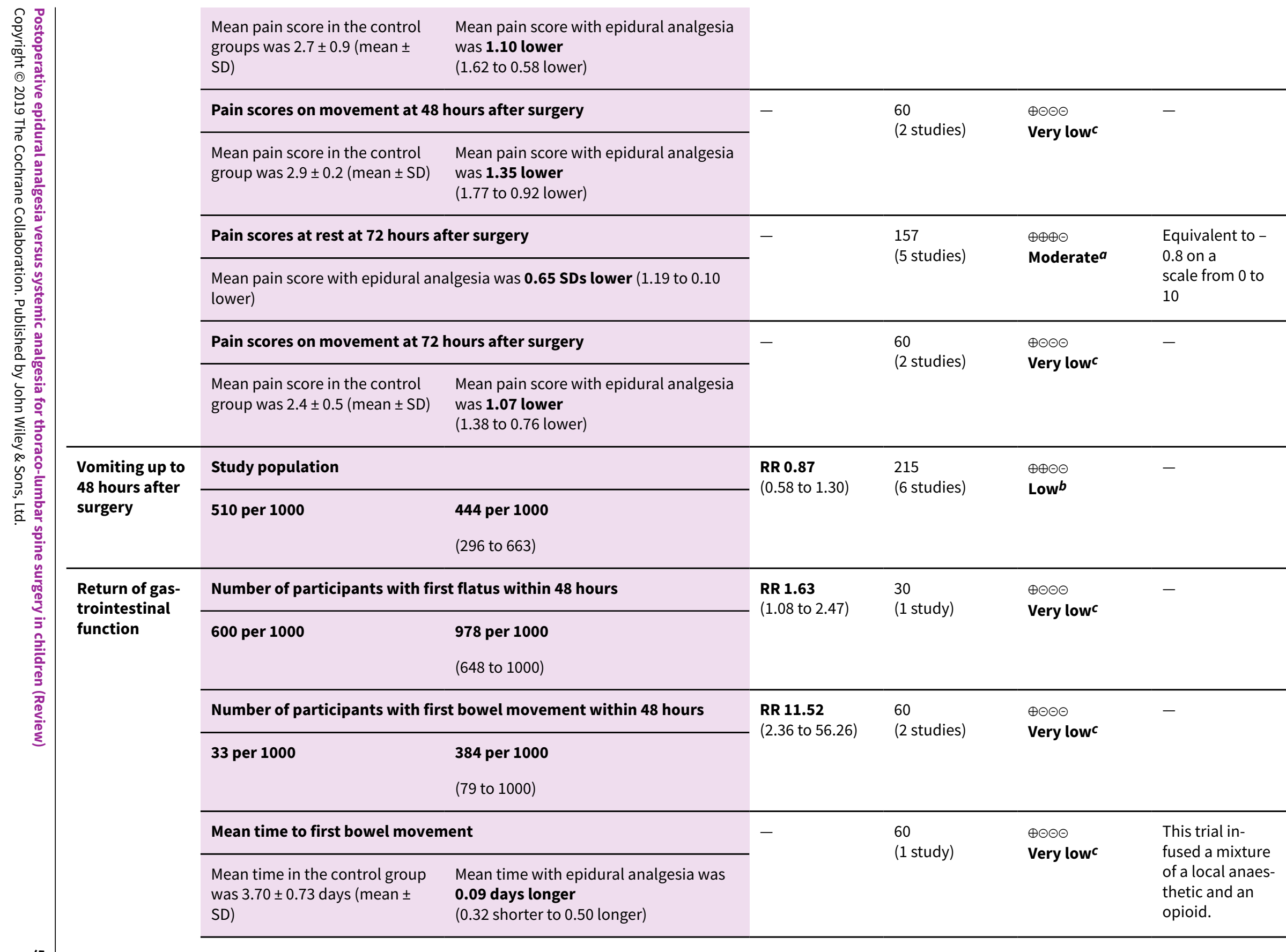




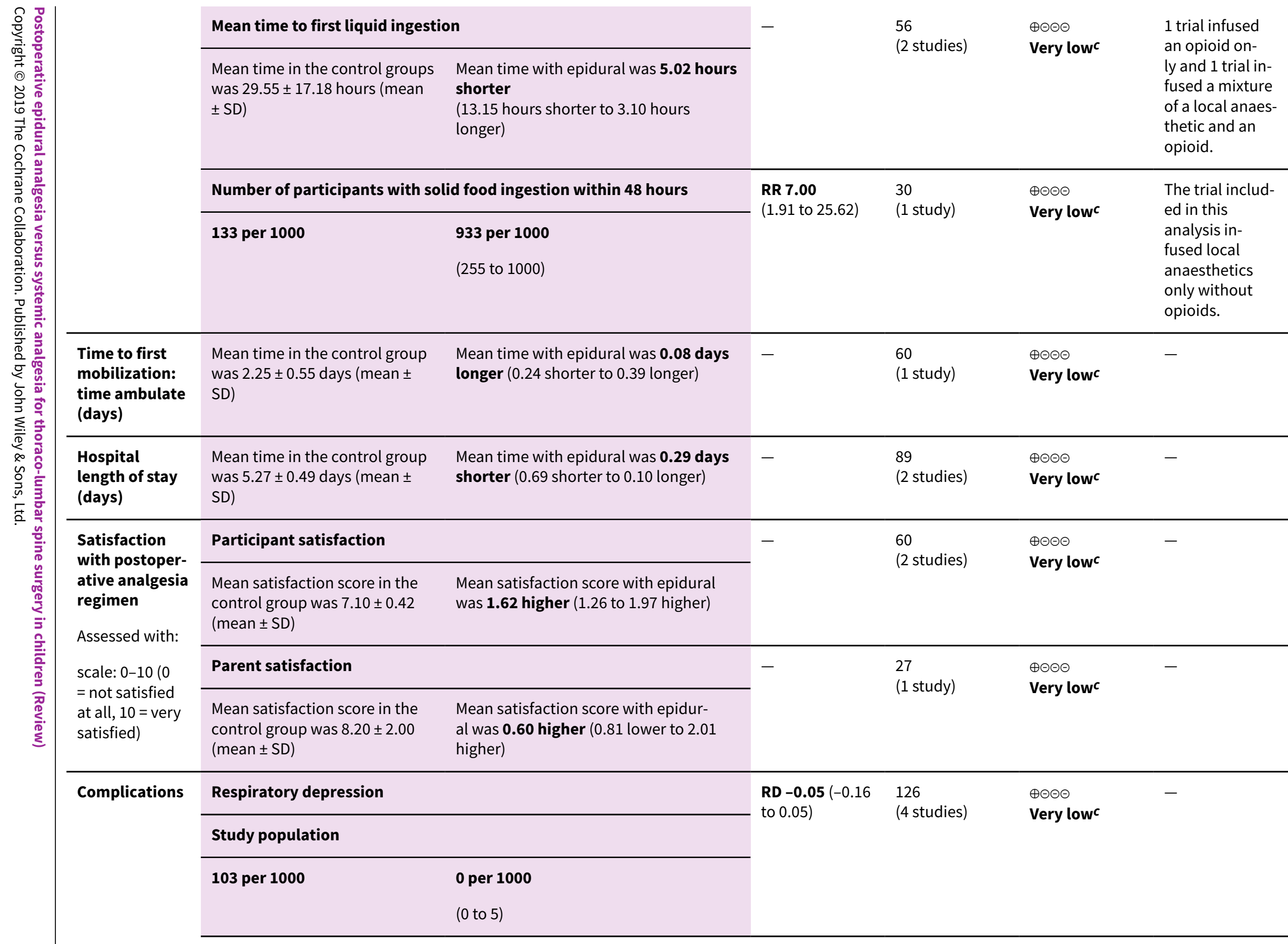




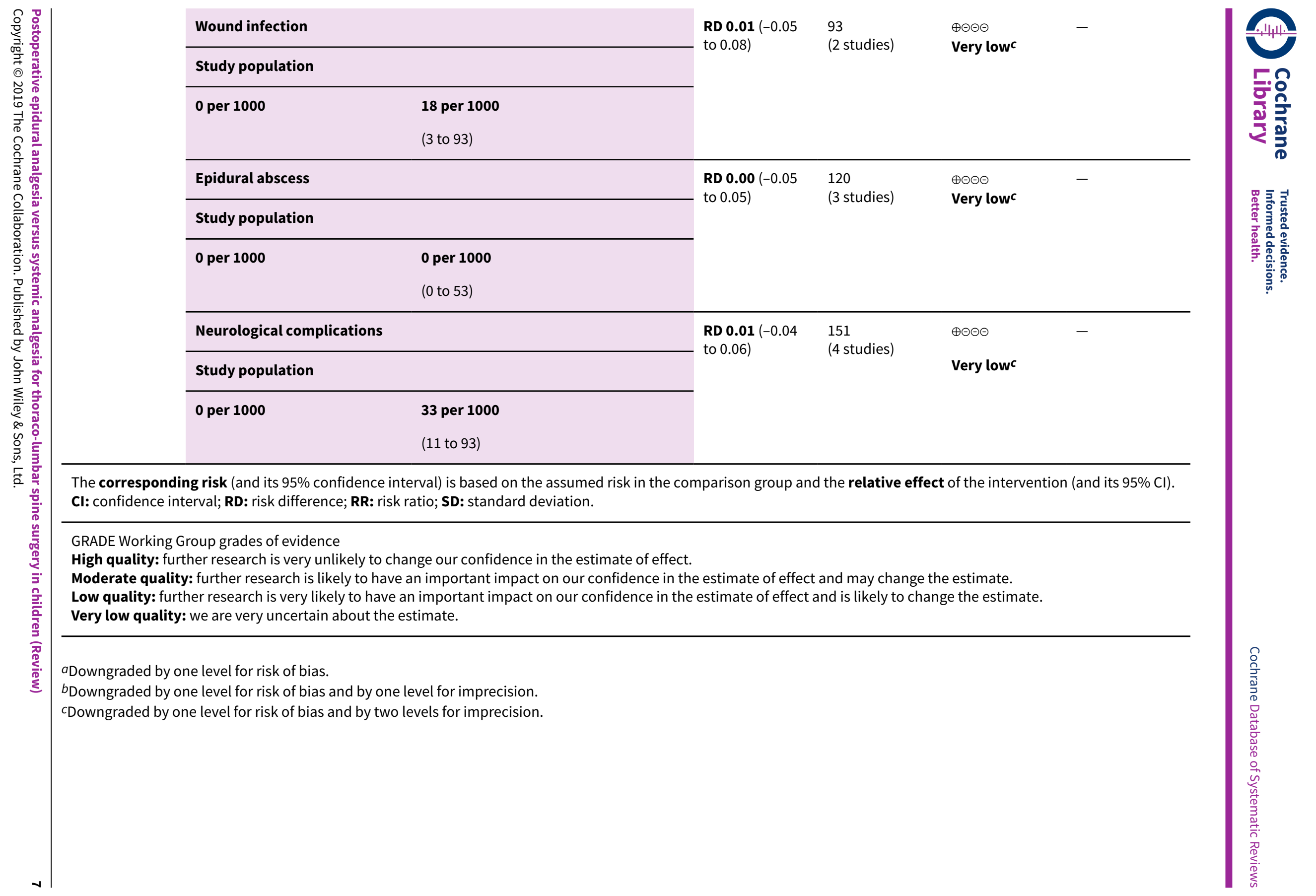




\section{B A C K G R O U N D}

\section{Description of the condition}

Idiopathic scoliosis is the most common spinal deformity encountered by general orthopaedic surgeons (Sud 2013). Scoliosis is a disease in which the spine is curved in three dimensions. Although the condition may have various causes (i.e. congenital, neurological, or musculoskeletal disorders), in children (defined as 18 years of age or less for the purpose of this review), idiopathic scoliosis is the most common form (approximately $70 \%$ to $80 \%$ of all cases) (McNicol 2016; Negrini 2015). The prevalence of idiopathic scoliosis is estimated to be between $0.9 \%$ and $12 \%$ of the general population, with up to $0.1 \%$ at risk of requiring a surgical intervention (Negrini 2015). A severe form is more commonly found in female adolescents (80\% to 90\%) (Negrini 2015). Problems related to scoliosis include reduced quality of life, disability, pain, cosmetic deformity, functional limitations, and pulmonary problems (Negrini 2015). For idiopathic scoliosis, most surgeons agree that surgical treatment should be considered in skeletally mature people with curves greater than $50^{\circ}$ (thoracic Cobb curve angle as measured on x-rays) because of the risk of progression into adulthood (Agabegi 2015). Surgical treatment includes decompression, instrumented fusion, and deformity correction. In children, spinal fusion (with or without thoracotomy) is common and expensive. In the USA, the mean cost of each procedure is USD 28,696, and total annual expenses for spinal fusions in children was estimated to be about USD 600 million in 2013 (Center for Disease Control and Prevention 2015).

Spinal surgery may also be required for treatment of traumatic injuries and infectious, inflammatory, or neoplastic diseases. Around the world, the incidence of traumatic spinal cord injuries varies from 3.6 to 195.4 per million in the general population (Jazayeri 2015). Females are at greatest risk in adolescence (World Health Organization 2013).

Orthopaedic surgeries, including spine surgery, are among the most painful surgical procedures and are frequently associated with severe acute postoperative pain (Borgeat 2008; Gramke 2007). Adequate treatment of acute postoperative pain is considered a human fundamental right (White 2007). Treatment of acute postoperative pain in people undergoing spine surgery may be complicated by the fact that some of these people are experiencing chronic pain and may be opioid tolerant. Modalities that have been proposed to treat acute postoperative pain after spine surgery include systemic opioids, non-steroidal anti-inflammatory drugs, gabapentinoids, N-methyl-D-aspartate (NMDA) antagonists, and neuraxial blocks (Sharma 2012). Systemic opioids for acute postoperative pain may increase postoperative nausea and vomiting and gastrointestinal ileus, and may prolong hospitalization, potentially increasing hospital costs (Guay 2016). Pulmonary function may also be affected in children with scoliosis deformity, particularly among children with nonidiopathic scoliosis or those with idiopathic scoliosis and a thoracic deformity (Chua 2016; Ran 2016), making them more susceptible to respiratory depression from systemic opioids. Non-steroidal anti-inflammatory drugs, gabapentinoids, and NMDA antagonists, although useful, are usually considered as co-analgesic drugs (added to systemic opioids or neuraxial blocks) that are insufficient to be used alone. Neuraxial blocks, including single-injection intrathecal opioids or continuous epidural analgesia with one or two catheters, have been proposed as an alternative.

\section{Description of the intervention}

Epidural analgesia, which consists of injection of a solution into the spine outside the dura mater, can be used for surgery as the sole anaesthetic or as a supplement to general anaesthesia for postoperative analgesia (De Rojas 2014). The solution may contain a local anaesthetic alone, an opioid alone, or local anaesthetic plus opioid. Various adjuvants may be added to improve efficacy or prolong duration of the solution. The solution may be administered as a single injection (single shot block) or as a loading dose followed by a continuous infusion (through an epidural catheter) to control postoperative pain for the first few days after surgery, when pain is most intense. For scoliosis surgery, the surgeon usually inserts an epidural catheter at the end of surgery. Injection of a local anaesthetic before surgical incision or at the start of surgery could potentially interfere with the neurological spinal cord monitoring required during this type of surgery (Loughman 1995).

\section{How the intervention might work}

When compared with a systemic opioid-based regimen, epidural analgesia with local anaesthetics has been reported to decrease postoperative pain, hasten gastrointestinal transit return, and decrease hospital length of stay for open abdominal surgery (Guay 2016). It has been postulated that faster return of gastrointestinal transit may be due to sympathetic blockade by the epidural, reduced opioid requirements, or local anaesthetics themselves (Guay 2016). Specifically for scoliosis surgery, one non-Cochrane review suggested that epidural analgesia may have improved pain control, hastened gastrointestinal transit return, and improved patient satisfaction (Borgeat 2008).

\section{Why it is important to do this review}

It is unknown whether epidural analgesia improves pain control; accelerates return of gastrointestinal transit; or reduces risk of respiratory depression, length of hospitalization, and costs of care among children. Epidural analgesia is more complex to administer than systemic analgesia and is associated with rare but serious adverse events such as epidural haematoma or abscess. it is important to justify epidural use with clear documentation of superiority compared with systemic opioidbased postoperative analgesia. This is the lone Cochrane Review comparing epidural analgesia versus systemic analgesia (opioids or others) for postoperative pain after thoraco-lumbar spine surgery in children.

\section{O B J E C T I VES}

To assess the effectiveness and safety of epidural analgesia compared with systemic analgesia for acute postoperative pain control after thoraco-lumbar spine surgery in children.

\section{METHODS}

\section{Criteria for considering studies for this review}

\section{Types of studies}

We included only randomized controlled trials (RCTs) evaluating epidural analgesia for postoperative pain, and comparing epidural analgesia with any form of systemic analgesia by any route. We excluded observational studies, quasi-randomized trials, crossover trials, and cluster-randomized trials (Higgins 2011). We 
placed no restrictions on the basis of language of publication or publication status.

\section{Types of participants}

We included studies performed on children (aged 0 to 18 years) undergoing thoracic, lumbar, or thoraco-lumbar spine surgery for any condition while under general anaesthesia. We included studies using any surgical approach: minimally invasive or not, posterior or anterior or both, and located at the thoracic or lumbar or thoraco-lumbar level.

\section{Types of interventions}

We included studies comparing a group of participants with epidural analgesia used for postoperative analgesia versus a group of participants receiving systemic analgesia (opioid based or others) used for postoperative analgesia. We included studies in which investigators administered epidural analgesia as a single shot block or as a continuous infusion for any duration and containing a local anaesthetic alone (extended duration or not) or in combination with an opioid (extended duration or not) or an opioid alone. We included studies in which trialists added an adjuvant to the solution or not. We excluded studies in which investigators added substances directly in the epidural space without the use of an epidural needle/catheter, such as steroids or other substances (gelfoam soaked or microfibrillar collagen or other). We excluded studies in which researchers administered the local anaesthetic or the opioid intrathecally. We excluded trials comparing nerve blocks versus systemic analgesia.

For the comparator, we included all forms of systemic analgesia (opioid-based regimen or other) regardless of the route of administration (intravenous (IV) with or without a proxy- or selfadministered patient-controlled device), intramuscular or oral analgesia, or other).

\section{Types of outcome measures}

\section{Primary outcomes}

1. Pain (at rest and on movement up to 72 hours after surgery). We included pain measured on any ascending or descending scale as provided by study authors.

2. Vomiting up to 48 hours after surgery (number of participants with event). We extracted data on this outcome as the number of participants who experienced vomiting episodes.

3. Return of gastrointestinal function measured as time to first:
a. flatus (hours);
b. bowel movement (hours);
c. liquid ingestion (hours);
d. solid food ingestion (hours).

\section{Secondary outcomes}

1. Time to first mobilization (days).

2. Hospital length of stay (days).

3. Satisfaction with postoperative analgesia regimen (any ascending or descending scale as provided by study authors):

a. participant satisfaction (any ascending or descending scale as provided by study authors);

b. parent satisfaction (any ascending or descending scale as provided by study authors).
4. Complications (related to analgesic techniques (epidural or systemic analgesia), including respiratory depression, hospital inpatient falls, and infections (e.g. wound infection, epidural abscess) within 30 days of surgery) and neurological complications.

\section{Search methods for identification of studies}

\section{Electronic searches}

We searched the Cochrane Central Register of Controlled Trials (CENTRAL) in the Cochrane Library (2018, Issue 9); MEDLINE Ovid: Epub Ahead of Print, In-Process and Other Non-Indexed Citations, Ovid MEDLINE(R) Daily, and Ovid MEDLINE(R) (from 1946 to 14 November 2018); Embase Ovid (from 1974 to 14 November 2018); and the Cumulative Index to Nursing and Allied Health Literature (CINAHL) (from 1981 to 14 November 2018). Our search strategies are displayed in Appendix 1, Appendix 2, Appendix 3, and Appendix 4 (Higgins 2011).

\section{Searching other resources}

We searched the World Health Organization International Clinical Trials Registry Platform (www.who.int/trialsearch), and ClinicalTrials.gov (www.clinicaltrials.gov), to identify trials in progress.

We scanned the reference lists and citations of all included trials and of any relevant systematic reviews identified to obtain further references to additional trials. We screened the conference proceedings of anaesthesiology societies from 2012 to 2017, as published in three major anaesthesiology journals: British Journal of Anaesthesiology,European Journal of Anaesthesiology, and Regional Anesthesia and Pain Medicine (European Society of Regional Anesthesia (ESRA) 2012 to 2017 and American Society of Regional Anesthesia (ASRA) 2012 to 2016). We also looked for abstracts on the websites of the American Society of Anesthesiologists for the same years and of the American Society of Regional Anesthesia 2017. We contacted all trial authors for additional information.

We also searched ProQuest Dissertations and Thesis Global (14 November 2018) as a source of grey literature (Appendix 5).

\section{Data collection and analysis}

\section{Selection of studies}

Two review authors (JG and RLJ) independently screened the list of all titles and abstracts identified by the search. We retrieved and independently read potential articles to determine their eligibility for inclusion. We resolved discrepancies by discussion, or with the help of a third review author (SK) when required. Two review authors (of JG, RLJ, and SK) examined potential trials found from sources other than electronic databases for classification (included, excluded, or awaiting classification). We documented the selection process in sufficient detail to complete a PRISMA flow diagram (Moher 2009). We listed all reasons for exclusion in the Characteristics of excluded studies table.

\section{Data extraction and management}

Two review authors (JG and SK) independently extracted data. When necessary, we sought the help of a third review author $(R L J)$ to resolve discrepancies. For selected studies, we entered the following parameters onto our data extraction form: risk 
of bias as measured with the Cochrane tool; and outcomes and factors chosen a priori for assessment of heterogeneity (Schünemann 2011). We extracted dichotomous data as the number of participants experiencing the event and the total number of participants in each treatment group. We extracted continuous data as means, standard deviations (SDs), and total numbers of participants. When data were not available in these formats, we extracted data as $P$ values, numbers of participants, and direction of effect. We did not consider medians as equivalent to means, and did not estimate SDs from quartiles or ranges. We entered first the site where the study was performed and the date of data collection (to facilitate exclusion of duplicate publications), then whether the study was included in the review or the reason for exclusion. After reaching agreement, one review author entered the data into the comprehensive meta-analysis and moderators for heterogeneity exploration (Comprehensive MetaAnalysis 2007). Also, after reaching agreement, we entered the risk of bias evaluation into Review Manager 5 (Review Manager 2014). We resolved disagreements by discussion or with the help of a third review author (RLJ), and contacted study authors to request additional information when required. We transferred data for analysis to Review Manager 5 in the format required to include the maximal number of studies (events and the total numbers of participants for each group; means, SDs, and numbers of participants included in each group; or generic inverse variance, if necessary). When possible, we entered the data into an intentionto-treat (ITT) analysis.

\section{Assessment of risk of bias in included studies}

We assessed the quality of included studies using the Cochrane 'Risk of bias' tool (Schünemann 2011), to examine random sequence generation, allocation concealment, blinding of participants and personnel, blinding of outcome assessment, incomplete outcome data, selective reporting, and other bias. We resolved disagreements by discussion or with the help of a third review author. We assessed risk of bias on the basis of information presented in the reports, while making no assumptions.

\section{Measures of treatment effect}

We reported results as risk ratios (RRs) and 95\% confidence intervals (95\% Cls) for dichotomous data (vomiting and number of participants with bowel movement within 48 hours) (McColl 1998). Due to the high number of trials with zero cells, we analysed complications (respiratory depression, wound infection, epidural abscess, and neurological complications) as risk differences (RD). We reported results as mean differences (MDs) and 95\% Cls for continuous data (pain scores, hospital length of stay, participant or parent satisfaction as much as feasible. If some of the continuous data used different scales (pain scores), or if only $\mathrm{P}$ values were extractable, we presented results as standardized mean differences (SMDs) and $95 \% \mathrm{Cls}$, and gave equivalence on a clinical scale. For SMDs, we considered 0.2 a small effect, 0.5 a medium effect, and 0.8 a large effect (Pace 2011). For time-to-event data (time to return of gastrointestinal transit, time to first mobilization), we contacted trial authors to try to obtain data as hazard ratios (HRs) for analysis but this proved impossible due to no response from some study authors and unavailability of data in this format for others. As planned in the published protocol (Guay 2017), as an alternative solution, we then analysed these data in the format provided by trial authors in their reports and treated them as other continuous data reported as MDs with $95 \% \mathrm{Cls}$. When there was an effect noted, we calculated from the odds ratio a number needed to treat for an additional beneficial outcome (NNTB), or a number needed to treat for an additional harmful outcome (NNTH) (Cates 2016; Deeks 2002). When we were unable to demonstrate an effect, we performed trial sequential analysis to ensure that enough participants were included in the retained studies to justify a conclusion on the absence of effect (Pogue 1998; Thorlund 2018).

\section{Unit of analysis issues}

We included only parallel-group trials. If a study contained more than two groups, we fused the two groups (by using the appropriate formula for adding SDs when required), when we thought they were equivalent according to the criteria of our protocol (taking our factors for heterogeneity exploration into account), or we separated them and split the control group in half if we thought they were different (Guay 2017).

\section{Dealing with missing data}

We contacted study authors when the published articles did not provide enough information for extraction of data. We made no imputations (Deeks 2011).

\section{Assessment of heterogeneity}

We considered clinical heterogeneity before pooling results, and examined statistical heterogeneity before carrying out any metaanalysis. We qualified the amount as low ( $25 \%$ or less), moderate ( $25 \%$ to $74 \%)$ or high ( $75 \%$ or greater) depending of the value obtained for the $1^{2}$ statistic (see 'Summary of findings' table and GRADE'; Higgins 2003).

\section{Assessment of reporting biases}

We assessed publication bias using a funnel plot, followed by Duval and Tweedie's trim and fill technique (Borenstein 2009a; Duval 2000a; Duval 2000b). This technique assessed whether publication bias was likely, and yielded an estimate of effect size after correction for the possibility of publication bias when such bias was suspected.

\section{Data synthesis}

We analysed data using Review Manager 5 and Comprehensive Meta-Analysis Version 2.2.044 with random-effects models (Comprehensive Meta-Analysis 2007; Review Manager 2014). For dichotomous data, we provided results as RRs (values best understood by clinicians; McColl 1998), or RDs (trials with zero cells). For continuous data, if some analyses could not be entered in our favoured format (means, SDs, and numbers of participants), we did not consider a median as equivalent to a mean and did not estimate SDs from quartiles. Instead we entered data as P values, numbers of participants, and direction of effect (using the Review Manager 5 calculator; Review Manager 2014). In such cases, MDs cannot be obtained. We then presented our results as SMDs. For results provided as SMDs, we gave clinical equivalents calculated as follows: SMD multiplied by the SD of a study at low risk of bias, and for which a typical SD on a clinical scale was provided (Schünemann 2011). For results in which the intervention produced an effect, we calculated the NNTB or the NNTH using the odds ratio (Cates 2016). We also calculated classical fail-safe numbers (number of missing trials to bring $P$ value greater than 0.05 , two-tailed test; Comprehensive Meta-Analysis 2007) for all outcome with a P value less than 0.05 and three studies or more. If an effect could not 
be demonstrated, we also calculated optimal information sizes to ensure that enough participants were included in the retained studies to justify a conclusion based on absence of effect (Brant R; Pogue 1998; Thorlund 2018).

\section{Subgroup analysis and investigation of heterogeneity}

We explored any amount of heterogeneity greater than $25 \%$ using Egger's regression intercept (comprehensive meta-analysis; to eliminate a small-study effect), sensitivity analysis, subgrouping, or meta-regression (comprehensive meta-analysis) as appropriate. Small-study effects relate to the fact that small studies may have different effect size than the larger studies (Rucker 2011). Various explanations have been proposed to explain this effect amongst which is the fact that medical journals may be more inclined to accept small studies when results are positive. Other reasons proposed are: heterogeneity, selective outcome reporting bias, a mathematical artefact, or genuine random variation (Rucker 2011). Egger's regression intercept test that hypothesis. When there is an inverse correlation between the size of the study (number of participants included) and the effect size (the smaller the study, the larger the effect size), then there is a possibility that a small-study effect is present in the results. A small-study effect may introduce heterogeneity in the results and may also increase the overall effect size measured. A priori factors for heterogeneity included the following.

1. Cause of the condition (scoliosis (idiopathic or other) versus traumatic versus other).

2. Elective surgery versus urgent surgery.

3. Surgical approach (open posterior only versus open anterior only versus both versus other techniques).

4. Site of surgery (thoracic versus lumbar versus thoraco-lumbar).

5. Number of fused vertebrae.

6. Epidural technique: number of catheters (one versus two).

7. Solution used in the catheter (local anaesthetics versus local anaesthetics plus opioids versus opioids only versus local anaesthetic plus opioids and other adjuvants).

8. Single shot versus continuous infusion (and duration).

9. Comparator (route, substance used, proxy-patient-controlled device versus continuous infusion versus intermittent administration (mandatory or on request)).

10. Mean age of participants.

11.Sex distribution.

Although we examined forest plots for all outcomes with studies placed in order for all potential heterogeneity factors, to avoid multiple comparisons, we performed analysis (sensitivity, subgrouping, or meta-regression) only when forest plots suggested a statistically significant effect. We analysed subgroup differences using Review Manager $5\left(\mathrm{Chi}^{2}\right)$ and considered a P value less than 0.05 significant for subgroup differences (Review Manager 2014).

\section{Sensitivity analysis}

We performed sensitivity analysis (defined as excluding a study on the basis of its risk of bias (allocation concealment or blinding of outcome assessors, or both) or because it appeared as an outlier on a forest plot).

\section{'Summary of findings' table and GRADE}

We judged the quality of the body of evidence according to the GRADE system and presented this assessment in Summary of findings for the main comparison for all outcomes (Schünemann 2013), using the GRADEpro software (GRADEpro GDT). For risk of bias, we judged the quality of evidence as high when we derived most information from studies at low risk of bias, and we downgraded quality by one level when we obtained most information from studies at high or unclear risk of bias (allocation concealment and blinding of outcome assessors), or by two levels when the proportion of information obtained from studies at high risk of bias was sufficient to affect interpretation of results. For inconsistency, we downgraded the quality of evidence by one level when the $1^{2}$ statistic was $50 \%$ or higher without satisfactory explanation, and by two levels when the 12 statistic was $75 \%$ or higher without explanation. We did not downgrade the quality of evidence for indirectness, because outcomes were based on direct comparisons performed mostly on the population of interest and were not surrogate markers. For imprecision, we downgraded the quality of evidence by one level when the $\mathrm{Cl}$ around the effect size was large or overlapped an absence of effect and failed to exclude an important benefit or harm, or when the number of participants was fewer than the optimal information size; and we downgraded the quality by two levels when the $\mathrm{Cl}$ was very wide and included both appreciable benefit and harm. For publication bias, we downgraded the quality of evidence by one level when correcting for the possibility of publication bias as assessed by Duval and Tweedie's trim and fill analysis changed the conclusion. When the quality of the body of evidence is high, further research is very unlikely to change our confidence in the estimate of effect. When quality is moderate, further research is likely to have an important impact on our confidence in the estimate of effect and may change the estimate. When quality is low, further research is very likely to have an important impact on our confidence in the estimate of effect and is likely to change the estimate. When the quality is very low, any estimate of effect is very uncertain. The review contains only one comparison as per our protocol: epidural analgesia versus systemic analgesia. Means of control groups and epidural groups provided in the Summary of findings for the main comparison were calculated using the Prism software (Prism 2007).

\section{RE S U L T S}

\section{Description of studies}

\section{Results of the search}

We identified 1771 records from CENTRAL, 1123 from MEDLINE, 1175 from Embase, 139 from CINAHL, and four from ProQuest Dissertations and Thesis Global. After we removed the duplicates, there were 2734 records left. From these records and from other sources, we retrieved 46 full articles. We excluded 33 trials (see Excluded studies; Characteristics of excluded studies table). Of the 13 other trials, one is an ongoing trial (Characteristics of ongoing studies table), and one is awaiting classification (report not available to date; Characteristics of studies awaiting classification table). Therefore, we included 11 trials in the review (Blumenthal 2005; Blumenthal 2006; Cakar Turhan 2011; Cassady 2000; Ezhevskaya 2012a; Ezhevskaya 2015; Gauger 2009; Klatt 2013; Malviya 1999; O'Hara 2004; Ozturk Mamik 2011).

\section{See Figure 1.}


Figure 1. Study flow diagram.

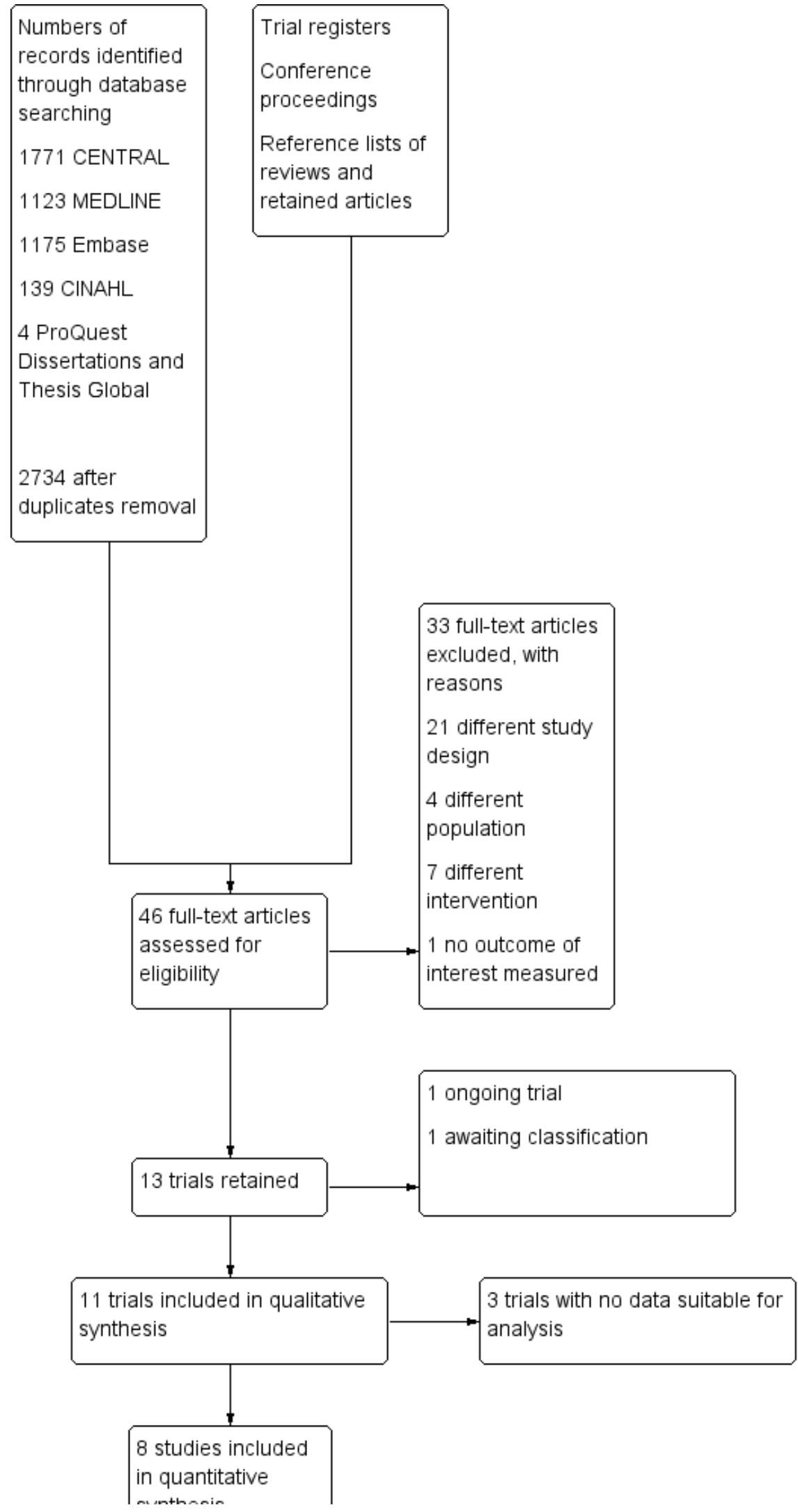


Figure 1. (Continued)

in quantitative
synthesis
(meta-analysis)

\section{Included studies}

We included 11 trials with 559 participants in the review (Blumenthal 2005; Blumenthal 2006; Cakar Turhan 2011; Cassady 2000; Ezhevskaya 2012a; Ezhevskaya 2015; Gauger 2009; Klatt 2013; Malviya 1999; O'Hara 2004; Ozturk Mamik 2011). The 11 included trials were published between 1999 and 2015.

Ten trials with 444 participants reported group distribution: 240 participants were in the epidural analgesia group and 204 participants were in the systemic analgesia group (Blumenthal 2005; Blumenthal 2006; Cakar Turhan 2011; Cassady 2000; Ezhevskaya 2012a; Gauger 2009; Klatt 2013; Malviya 1999; O'Hara 2004; Ozturk Mamik 2011). There were no data suitable for analysis for three trials (Cakar Turhan 2011; Ezhevskaya 2012a; Ozturk Mamik 2011), and one trial did not report the number of participants per group (Ezhevskaya 2015). Therefore, we included seven trials with 249 participants in the analysis (Blumenthal 2005; Blumenthal 2006; Cassady 2000; Gauger 2009; Klatt 2013; Malviya 1999; O'Hara 2004): 140 to epidural analgesia and 109 to systemic analgesia (Characteristics of included studies table).

\section{Source of funding}

Five of the trials reported funding by departmental resources (Blumenthal 2005; Blumenthal 2006; Klatt 2013; Malviya 1999; O'Hara 2004). One trial reported funding in part by industry and part by a charity (Cassady 2000). Five trials did not specify the source of funding (Cakar Turhan 2011; Ezhevskaya 2012a; Ezhevskaya 2015; Gauger 2009; Ozturk Mamik 2011).

\section{Setting}

Nine trials were conducted in university hospitals (Blumenthal 2005; Blumenthal 2006; Cassady 2000; Ezhevskaya 2012a; Ezhevskaya 2015; Gauger 2009; Klatt 2013; Malviya 1999; O'Hara 2004). Two trials did not specify the exact setting (Cakar Turhan 2011; Ozturk Mamik 2011).

The trials were conducted in Russia (two: Ezhevskaya 2012a; Ezhevskaya 2015); Switzerland (two; Blumenthal 2005; Blumenthal 2006); Turkey (two: Cakar Turhan 2011; Ozturk Mamik 2011); and the USA (five: Cassady 2000; Gauger 2009; Klatt 2013; Malviya 1999; O'Hara 2004).

\section{Participants}

The types of surgery performed were: posterior spinal fusion for idiopathic scoliosis (Blumenthal 2005; Cakar Turhan 2011; Cassady 2000; Ezhevskaya 2012a; Ezhevskaya 2015; Gauger 2009; Klatt 2013; O'Hara 2004; Ozturk Mamik 2011); anterior correction for idiopathic scoliosis (Blumenthal 2006); or selective dorsal rhizotomy in children with cerebral palsy (Malviya 1999).

Table 1 provides information on the types of surgeries.
Four trials included participants older than 18 years: Blumenthal 2005 (10 to 30 years; mean age 17 years); Ezhevskaya 2012a (12 to 25 years); Klatt 2013 (10 to 21 years); and O'Hara 2004 (13 to 21 years).

\section{Intervention}

In nine trials, the surgeons inserted catheters for continuous infusions at the end of surgery (Blumenthal 2005; Blumenthal 2006; Cassady 2000; Ezhevskaya 2015; Gauger 2009; Klatt 2013; Malviya 1999; O'Hara 2004; Ozturk Mamik 2011). In one trial, there were additional loading doses administered at two thoracic levels before the surgery (Ezhevskaya 2012a). One trial administered a bolus of solution before surgery and used infiltration for postoperative analgesia (Cakar Turhan 2011). Trials used local anaesthetic alone (Blumenthal 2005; Blumenthal 2006); or in combination with an opioid (Cakar Turhan 2011; Cassady 2000; Ezhevskaya 2012a; Ezhevskaya 2015; Gauger 2009; Klatt 2013; O'Hara 2004; Ozturk Mamik 2011). One trial infused an opioid without any local anaesthetic (Malviya 1999). Two trials started the infusion only on postoperative day one, instead of at wound closure (Blumenthal 2005; Blumenthal 2006). Infusions were administered at one level (Cakar Turhan 2011; Cassady 2000; Ezhevskaya 2015; Gauger 2009; Malviya 1999; O'Hara 2004; Ozturk Mamik 2011); or two levels (Blumenthal 2005; Blumenthal 2006; Ezhevskaya 2012a). Klatt 2013 compared one versus two levels versus systemic analgesia.

The types of local anaesthetics used were: ropivacaine (Blumenthal 2005; Blumenthal 2006; Ezhevskaya 2012a; Ezhevskaya 2015); levobupivacaine (Cakar Turhan 2011; Ozturk Mamik 2011); or bupivacaine (Cassady 2000; Gauger 2009; Klatt 2013; O'Hara 2004). Opioids used were: morphine (Cakar Turhan 2011; Malviya 1999; Ozturk Mamik 2011); fentanyl (Cassady 2000; Ezhevskaya 2012a; Ezhevskaya 2015; Klatt 2013; O'Hara 2004); or fentanyl plus hydromorphone (Gauger 2009). Two trials added epinephrine (adrenaline) to the solution (Cassady 2000; Ezhevskaya 2012a). Table 2 shows details of postoperative analgesia.

\section{Comparator}

Studies compared epidural analgesia with: continuous IV morphine (Blumenthal 2005; Blumenthal 2006); IV patient-controlled analgesia with morphine (Cakar Turhan 2011; Cassady 2000; O'Hara 2004; Ozturk Mamik 2011); IV patient-controlled analgesia with hydropmorphone (Gauger 2009; Klatt 2013); IV patient-controlled analgesia with an opioid (Ezhevskaya 2012a); or IV nurse-controlled analgesia with morphine (Malviya 1999). One trial did not specify the comparator (Ezhevskaya 2015).

\section{Excluded studies}

We excluded 33 trials for the following reasons: different study design (21 trials; Adu-Gyamfi 1995; Aizenberg 2011; Amaranath 1989; Arms 1998; Ekatodramis 2002; Ezhevskaya 2012b; Ezhevskaya 2012c; Khinkover 2006; Lowry 2001; Milbrandt 2009; Nóbrega 2017; Pham 2008; Ravish 2012; Saudan 2008; Shaw 1996; Sparkes 1989; Sucato 2005; Sundarathiti 2010; Tobias 2001; Turner 2000; Van 
Boerum 2000); different study population (four trials; Bernard 1995a; Ezhevskaya 2014a; Goodarzi 1993; Sekar 2004); different intervention (seven trials; Akin Takmaz 2011; Cohen 2017; Erdogan 2017; Eshevskaya 2013; Ezhevskaya 2014b; Goodarzi 1999; Lawhorn 1994); and no outcome of interest measured (one trial; Loughnan 1990).

See Characteristics of excluded studies table for more details.

\section{Studies awaiting classification}

We have one trial awaiting classification (Kick 1995). This potential trial came from the reference list of a review article (Bernard 1995b). To date, we have been unable to locate this article despite requests at two different university libraries.
See Characteristics of studies awaiting classification table for more details.

\section{Ongoing studies}

We found one potential ongoing trial (EUCTR2008-001642-19$\mathrm{SE})$. This trial aims to compare epidural analgesia with fentanyl, bupivacaine, and epinephrine versus IV analgesia with s-ketamine and morphine. The trial was registered in 2008, and last refreshed in March 2012. There is no contact information provided.

See Characteristics of ongoing studies table for more details.

\section{Risk of bias in included studies}

Figure 2 and Figure 3 show the risk of bias of included trials. 
Figure 2. Risk of bias summary: review authors' judgements about each risk of bias item for each included study.

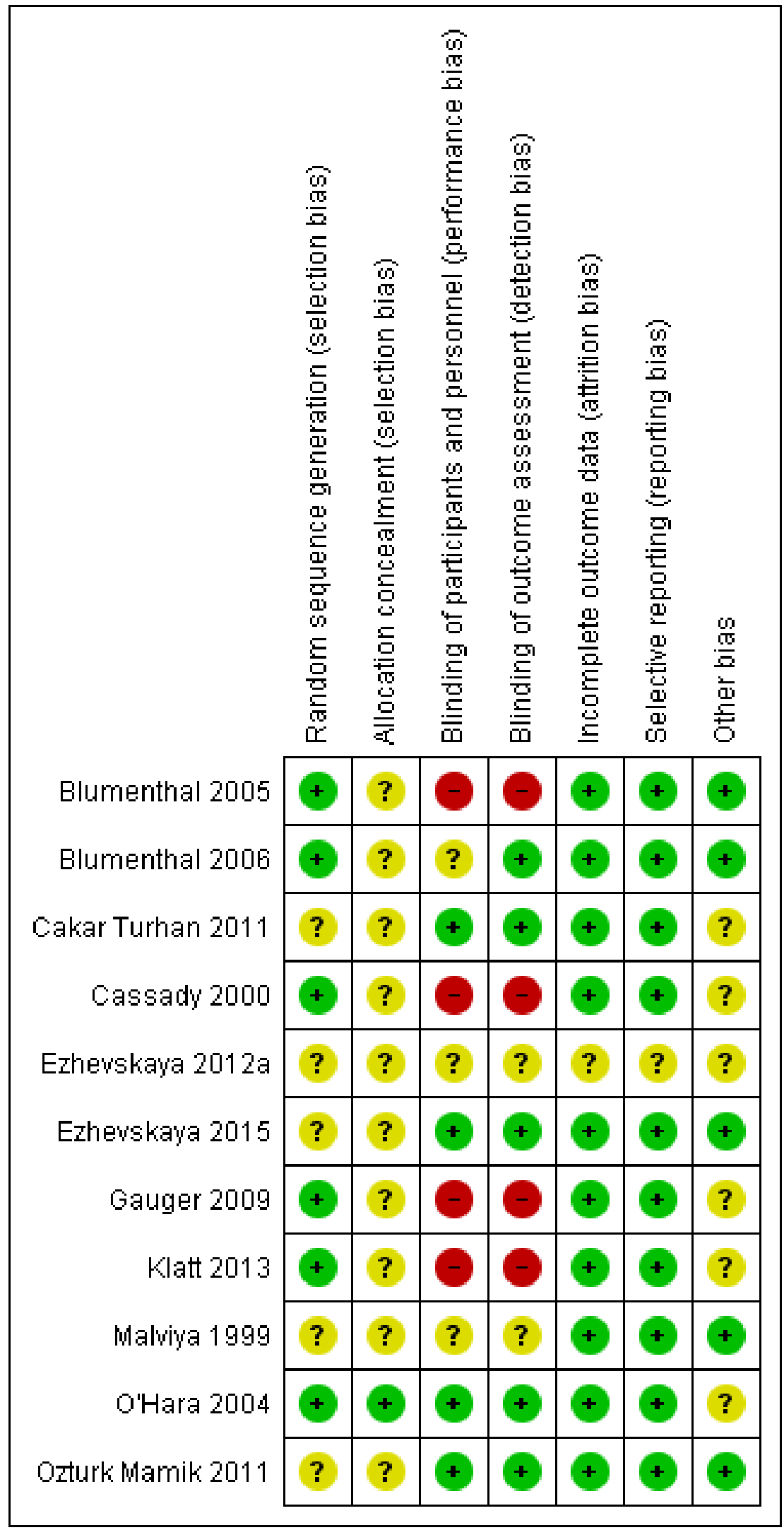

Postoperative epidural analgesia versus systemic analgesia for thoraco-lumbar spine surgery in children (Review) 
Figure 3. Risk of bias graph: review authors' judgements about each risk of bias item presented as percentages across all included studies.

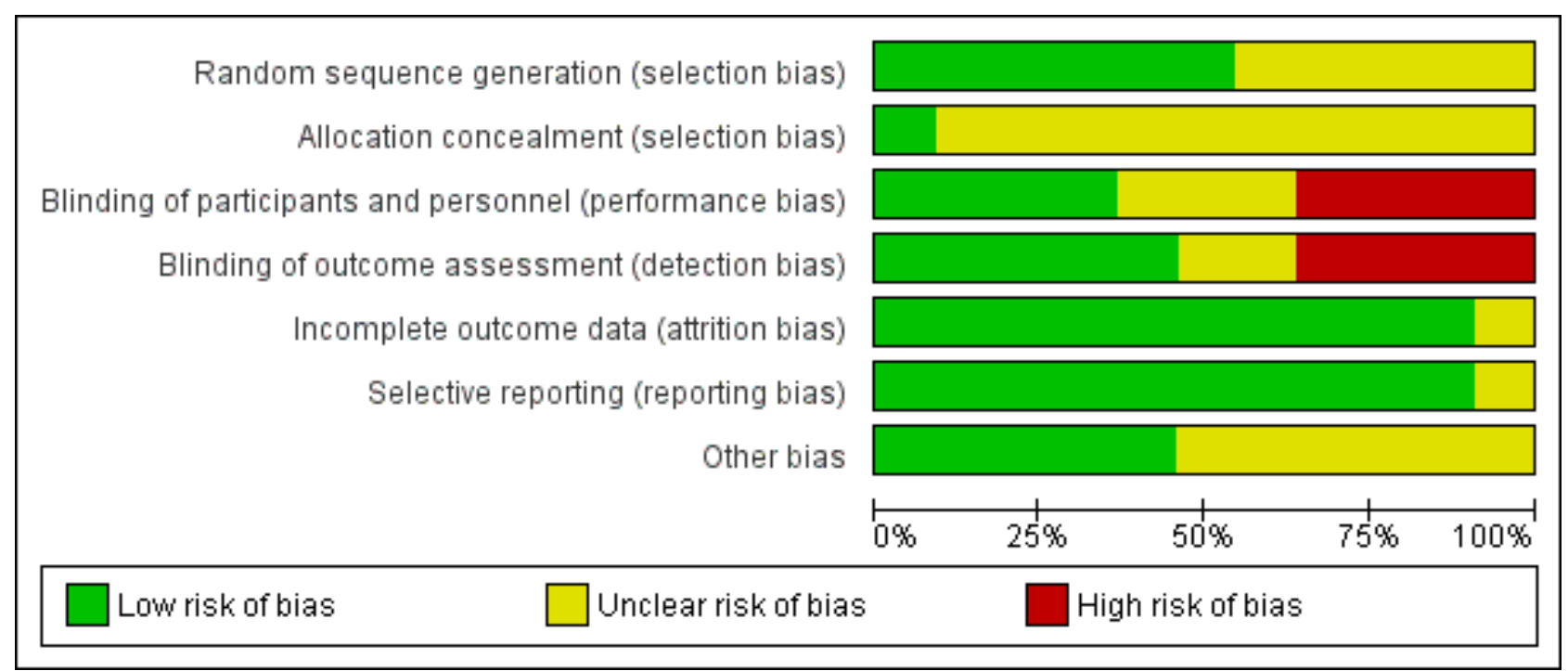

Random sequence generation was at low risk of bias for six trials (Blumenthal 2005; Blumenthal 2006; Cassady 2000; Gauger 2009; Klatt 2013; O'Hara 2004), and at unclear risk of bias for the other five trials.

\section{Allocation}

We judged allocation concealment bias at low risk for one trial (O'Hara 2004), and at unclear risk for the remaining 10 trials.

\section{Blinding}

We judged blinding of participants and personnel taking care of participants at low risk of bias for four trials (Cakar Turhan 2011; Ezhevskaya 2015; O'Hara 2004; Ozturk Mamik 2011). We rated this domain at high risk of bias for four trials (Blumenthal 2005; Cassady 2000; Gauger 2009; Klatt 2013). For three trials, there was not enough information in the report to enable us to judge this domain (Blumenthal 2006; Ezhevskaya 2012a; Malviya 1999).

We judged blinding of outcome assessment at low risk of bias for five trials (Blumenthal 2006; Cakar Turhan 2011; Ezhevskaya 2015; O'Hara 2004; Ozturk Mamik 2011). We judged this domain at high risk of bias for four trials (Blumenthal 2005; Cassady 2000; Gauger 2009; Klatt 2013). For two trials, there was not enough information in the report to allow us to judge this domain (Ezhevskaya 2012a; Malviya 1999).

\section{Incomplete outcome data}

We judged attrition bias at low risk for 10 trials (Blumenthal 2005; Blumenthal 2006; Cakar Turhan 2011; Cassady 2000; Ezhevskaya 2015; Gauger 2009; Klatt 2013; Malviya 1999; O'Hara 2004; Ozturk Mamik 2011). For Ezhevskaya 2012a, we judged attrition bias at unclear risk. The numbers of participants retained in the analysis by the study authors in one of the conference abstract were 45 and 35 (Ezhevskaya 2012a). There was no explanation provided for apparent loss of 10 participants in the control group. The other conference abstract related to this trial reported that the number of participants retained was 70 and 65 (Ezhevskaya 2012a).

\section{Selective reporting}

We judged reporting bias at low risk for 10 trials (Blumenthal 2005; Blumenthal 2006; Cakar Turhan 2011; Cassady 2000; Ezhevskaya 2015; Gauger 2009; Klatt 2013; Malviya 1999; O'Hara 2004; Ozturk Mamik 2011). Ezhevskaya 2012a was reported as conference abstracts only and no data were provided.

\section{Other potential sources of bias}

We judged five trials at low risk for other risks of bias (Blumenthal 2005; Blumenthal 2006; Ezhevskaya 2015; Malviya 1999; Ozturk Mamik 2011). We judged the other six trials at unclear risk of other bias. Cakar Turhan 2011 performed wound infiltration in addition to epidural analgesia for one group only, thus generating a potential bias for the present review. Cassady 2000; Gauger 2009; Klatt 2013; and O'Hara 2004 were not analysed by ITT. Ezhevskaya 2012a was published as conference abstracts only and there were no details provided on demographic characteristics.

\section{Effects of interventions}

See: Summary of findings for the main comparison Epidural analgesia compared to systemic analgesia for postoperative analgesia after thoraco-lumbar spine surgery in children

\section{Primary outcomes}

\section{Pain (at rest and on movement up to 72 hours after surgery)}

\section{Pain at rest at six to eight hours after surgery}

Four trials with 116 participants reported on pain at rest at six to eight hours after surgery (Blumenthal 2005; Blumenthal 2006; Cassady 2000; Malviya 1999). Pain scales were visual analogue pain scale from 0 to 10 or FLACC (Face, Legs, Activity, Cry, Consolability; Malviya 1999; Appendix 6). We judged random sequence generation at low risk of bias for three trials (Blumenthal 2005; Blumenthal 2006; Cassady 2000), and at unclear risk of bias for one trial (Malviya 1999). We judged allocation concealment unclear for the four trials. Blinding of participants and personnel taking care of participants was at high/unclear risk for the four trials. Blinding of outcome 
assessment was at unclear/high risk for three trials (Blumenthal 2005; Cassady 2000; Malviya 1999), and at low risk for one trial (Blumenthal 2006). Attrition bias and reporting bias were at low risk for the four trials. We judged other risk of bias at unclear risk for one trial (Cassady 2000), and at low risk for the other three trials.
We found that epidural analgesia reduced pain at rest at six to eight hours after surgery (MD $-1.32,95 \% \mathrm{Cl}-1.83$ to -0.82 ; Analysis 1.1; Figure 4; Summary of findings for the main comparison). If data were analysed as SMD to take into account the fact that not all authors used the same pain scale then the SMD was $-0.81(95 \% \mathrm{Cl}$ -1.35 to -0.28$)$.

Figure 4. Forest plot of comparison: 1 Epidural analgesia versus systemic analgesia for postoperative pain after back surgery in children, outcome: 1.1 Pain at rest at 6 to 8 hours.

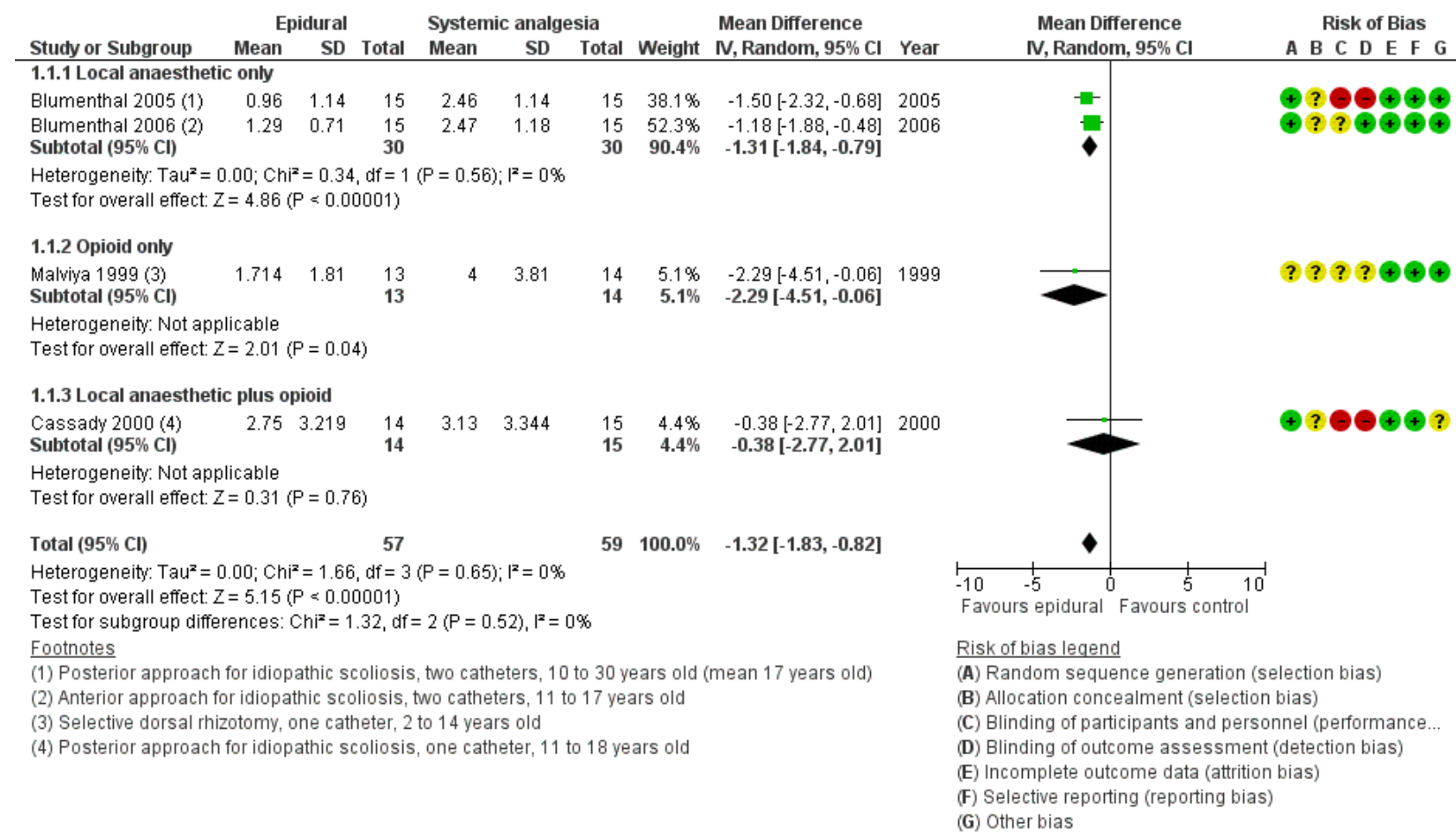

We found no evidence of a small-study effect. The impact of asymmetry in the funnel plot led to a trim and fill estimate MD of $-1.28(95 \% \mathrm{Cl}-1.77$ to -0.79$)$. The classical fail-safe number was 19. Trial sequential analysis indicated that 60 participants were required to find a 1-point difference in pain (alpha 0.05 ; power $80 \%$; two-sided test; variance based on studies with blinded assessors; heterogeneity model variance based). We downgraded the quality of evidence by one level for risk of bias and rated it moderate.

\section{Pain at rest at 20 to 32 hours}

Six trials with 208 participants reported on pain at rest at 20 to 32 hours (Blumenthal 2005; Blumenthal 2006; Cassady 2000; Klatt 2013; Malviya 1999; O'Hara 2004). Pain scales used were visual analogue pain scale from 0 to 10 or Wong-Baker (Klatt 2013), or FLACC (Malviya 1999; Appendix 6). We judged random sequence generation at unclear risk of bias for one trial (Malviya 1999), and at low risk of bias for the other five trials. We judged allocation concealment at low risk of bias for one trial (O'Hara 2004), and at unclear risk of bias for the other five trials. Blinding of participants and personnel taking care of participants was at low risk for one trial (O'Hara 2004), and at unclear/high risk for the other five trials. Blinding of outcome assessment was at unclear/high risk for four trials (Blumenthal 2005; Cassady 2000; Klatt 2013; Malviya 1999), and at low risk for two trials (Blumenthal 2006; O'Hara 2004).

We found that epidural analgesia reduced pain at rest at 20 to 32 hours (MD $-1.06,95 \% \mathrm{Cl}-1.56$ to -0.57 ; Analysis 1.2; Figure 5; Summary of findings for the main comparison). If data were analysed as SMD to take into account the fact that not all authors used the same pain scale then the SMD was $-0.54(95 \% \mathrm{Cl}-1.00$ to $-0.09)$. We found no evidence of a small-study effect. The impact of asymmetry in the funnel plot led to a trim and fill estimate MD of $-1.15(95 \% \mathrm{Cl}-1.74$ to -0.56$)$. The classical fail-safe number was 28. Trial sequential analysis indicated that 141 participants were required to find a 1-point difference in pain (alpha 0.05; power $80 \%$; two-sided test; variance based on studies with blinded assessors; heterogeneity model variance based) and that the $Z$ curve crossed the boundary in favour of epidural analgesia. We downgraded the quality of evidence by one level for risk of bias and rated it moderate. 
Figure 5. Forest plot of comparison: 1 Epidural analgesia versus systemic analgesia for postoperative pain after back surgery in children, outcome: 1.2 Pain at rest at 20 to 32 hours.

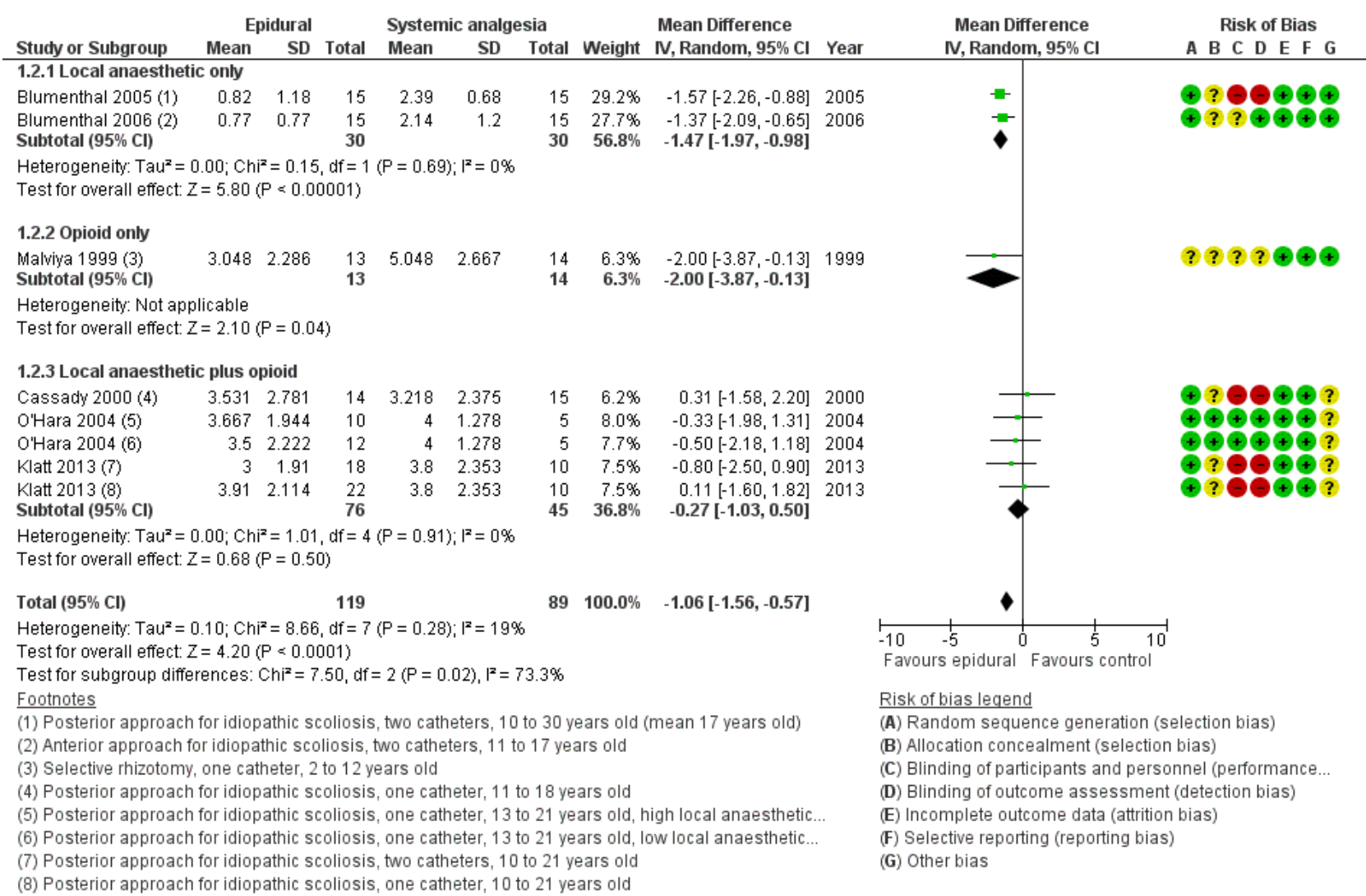

\section{Pain on movement at 24 hours}

Three trials with 87 participants reported on pain on movement at 24 hours (Blumenthal 2005; Blumenthal 2006; Malviya 1999). One trial (Malviya 1999), was at unclear risk of bias for random sequence generation and the two other trials were at low risk of bias for this domain. The three trials were at unclear/high risk of bias for allocation concealment and blinding of participants and personnel taking care of the participants. Blinding of outcome assessment was at low risk for one trial (Blumenthal 2006), and at unclear/high risk for two trials (Blumenthal 2005; Malviya 1999). The three trials were at low risk of bias for attrition bias, reporting bias, and risks of other bias.

Pain on movement at 24 hours was lower for participants treated with epidural analgesia (SMD $-1.51,95 \% \mathrm{Cl}-2.27$ to -0.76 ; Analysis 1.3; Summary of findings for the main comparison). There was no evidence of a small-study effect or publication bias. Based on Blumenthal 2005 (SD 0.81), this would be equivalent to 1.22 on a scale from 0 to 10 . The classical fail-safe number was 28 . We downgraded the quality of evidence by one level for risk of bias and by one level for imprecision, and rated it low.

\section{Pain at rest at 48 hours}

Five trials with 148 participants reported on pain at rest at 48 hours (Blumenthal 2005; Blumenthal 2006; Cassady 2000; Malviya 1999; O'Hara 2004). Pain scales used were visual analogue pain scale from 0 to 10 or FLACC (Malviya 1999; Appendix 6). Random sequence generation was at unclear risk of bias for one trial (Malviya
1999), and at low risk of bias for the other four trials. Allocation concealment was at low risk of bias for one trial (O'Hara 2004), and at unclear risk for the other four trials. Blinding of participants and personnel taking care of participants was at low risk of bias for one trial (O'Hara 2004), and at unclear/high risk for the other four trials. Blinding of outcome assessment was at low risk for two trials (Blumenthal 2006; O'Hara 2004), and at unclear/high of bias for the other three trials. The five trials were at low risk of bias for attrition bias and reporting bias. Other risks of bias were at low risk for three trials (Blumenthal 2005; Blumenthal 2006; Malviya 1999), and at unclear risk of bias for the other two trials.

Pain at rest at 48 hours was lower for participants treated with epidural analgesia (MD $-1.10,95 \% \mathrm{Cl}-1.62$ to -0.58 ; Analysis 1.4; Summary of findings for the main comparison). If data were analysed as SMD to take into account the fact that not all authors used the same pain scale then the SMD was $-0.66(95 \% \mathrm{Cl}-1.22$ to $-0.10)$. There was no evidence of a small-study effect. The impact of asymmetry in the funnel plot led to a trim and fill estimate MD of $-1.37(95 \% \mathrm{Cl}-2.00$ to -0.75$)$. Trial sequential analysis indicated that 163 participants were required to find a 1-point difference in pain (alpha 0.05; power 80\%; two-sided test; variance based on studies with blinded assessors; heterogeneity model variance based) but that the $Z$ curve crossed the boundary in favour of epidural analgesia. We downgraded the quality of evidence by one level for risk of bias and rated it moderate. 


\section{Pain on movement at $\mathbf{4 8}$ hours}

Two trials with 60 participants reported on pain on movement at 48 hours (Blumenthal 2005; Blumenthal 2006)

Random sequence generation was at low risk of bias for the two trials. Allocation concealment was at unclear risk of bias for the two trials. Blinding of participants and personnel taking care of the participants was at unclear risk of bias for Blumenthal 2006, and at high risk for Blumenthal 2005. Blinding of outcome assessment was at low risk of bias for Blumenthal 2006, and at high risk of bias for Blumenthal 2005. All other domains were at low risk of bias for the two trials.

Epidural analgesia reduced pain on movement at 48 hours (MD $1.35,95 \% \mathrm{Cl}-1.77$ to -0.92 ; Analysis 1.5 ; Summary of findings for the main comparison). The classical fail-safe number was 23 . Trial sequential analysis indicated that 57 participants were required to find a 1-point difference in pain (alpha 0.05; power 80\%; twosided test; variance based on studies with blinded assessors; heterogeneity model variance based) and that the $Z$ curve crossed the boundary in favour of epidural analgesia. We downgraded the quality of evidence by one level for risk of bias and by two levels for imprecision, and rated it very low.

\section{Pain at rest at 72 hours}

Five trials with 157 participants reported on pain at rest at 72 hours (Blumenthal 2005; Blumenthal 2006; Gauger 2009; Malviya 1999; O'Hara 2004). Random sequence generation was at unclear risk for one trial (Malviya 1999), and at low risk of bias for the other four trials. Allocation concealment was at low risk of bias for one trial (O'Hara 2004), and at unclear risk of bias for the other four trials. Blinding of participants and personnel taking care of the participants was at low risk of bias for one trial (O'Hara 2004), and at unclear/high risk of bias for the other four trials. Blinding of outcome assessment was at low risk of bias for two trials (Blumenthal 2006; O'Hara 2004), and at unclear/high risk of bias for the other three trials. The five trials were at low risk of attrition bias and reporting bias. Other risks of bias were at low risk for three trials (Blumenthal 2005; Blumenthal 2006; Malviya 1999), and at unclear/ high risk for the other two trials (Gauger 2009; O'Hara 2004).

Epidural analgesia reduced pain at rest at 72 hours (SMD -0.65 , $95 \% \mathrm{Cl}-1.19$ to -0.10 ; Analysis 1.6; Summary of findings for the main comparison). Heterogeneity was high when all trials were included $\left(1^{2}=61 \%\right)$ but absent $\left(I^{2}=0 \%\right)$ when Blumenthal 2006 was excluded. Blumenthal 2006 studied participants undergoing anterior spinal correction while the other four trials studied participants undergoing posterior spinal correction. Excluding Blumenthal 2006, the SMD was $-0.46(95 \% \mathrm{Cl}-0.82$ to -0.10$)$. There was no evidence of a small-study effect. The impact of asymmetry in the funnel plot led to a trim and fill estimate SMD of $-0.75(95 \%$ $\mathrm{Cl}-1.26$ to -0.24 ). Based on Blumenthal 2006 (SD 1.2) the difference would be equivalent to 0.8 on a scale from 0 to 10 . The classical failsafe number was 17 . We downgraded the quality of evidence by one level for risk of bias and rated it moderate.

\section{Pain on movement at 72 hours}

Two trials with 60 participants reported on pain on movement at 72 hours (Blumenthal 2005; Blumenthal 2006). Random sequence generation was at low risk of bias for the two trials. Allocation concealment was at unclear risk of bias for the two trials. Blinding of participants and personnel taking care of the participants was at unclear risk of bias for Blumenthal 2006, and at high risk of bias for Blumenthal 2005. Blinding of outcome assessment was at low risk of bias for Blumenthal 2006, and at high risk of bias for Blumenthal 2005. All other domains were at low risk of bias for the two trials.

Epidural analgesia reduced pain on movement at 72 hours (MD $1.07,95 \% \mathrm{Cl}-1.38$ to -0.76 ; Analysis 1.7 ; Summary of findings for the main comparison). Trial sequential analysis indicated that 57 participants were required to find a 1-point difference in pain (alpha 0.05 ; power $80 \%$; two-sided test; variance 1.5 ; heterogeneity model variance based) and that the $Z$ curve crossed the boundary in favour of epidural analgesia. We downgraded the quality of evidence by one level for risk of bias and by two levels for imprecision, and rated it very low.

\section{Vomiting up to 48 hours after surgery (number of participants with event)}

Six trials with 215 participants reported on nausea and vomiting after surgery (Blumenthal 2005; Blumenthal 2006; Cassady 2000; Gauger 2009; Klatt 2013; Malviya 1999). Available data (closest to 48 hours) suitable for extraction for cumulative number of participants having experienced postoperative nausea and vomiting were found at: six hours (Blumenthal 2005; Blumenthal 2006); around 40 hours (Cassady 2000; during use of epidural or IV patient-controlled analgesia which was discontinued upon successful restoration of oral fluid intake and this occurred at a mean time of 39.3 hours for epidural analgesia and 41.7 hours for systemic analgesia), during the first three postoperative days (Gauger 2009), or at an unspecified time point (emesis; Klatt 2013). One trial was at unclear risk of bias for random sequence generation (Malviya 1999); and all other trials were at low risk of bias for this domain (Blumenthal 2005; Blumenthal 2006; Cassady 2000; Gauger 2009; Klatt 2013). Allocation concealment and blinding of participants or personal taking care of the participants were at unclear/high risk for all six trials. Blinding of outcome assessment was at low risk of bias for Blumenthal 2006, and at unclear/high risk for the other five trials. All six trials were at low risk of attrition bias and selective reporting. Blumenthal 2005; Blumenthal 2006; and Malviya 1999 were rated at low risk of other bias. Cassady 2000; Gauger 2009; and Klatt 2013 were at unclear risk for the possibility of other bias.

We did not find a difference for the risk of nausea and vomiting (RR $0.87,95 \% \mathrm{Cl} 0.58$ to 1.30; Analysis 1.8; Summary of findings for the main comparison). There was no evidence of a small-study effect. The impact of asymmetry in the funnel plot led to a trim and fill estimate RR of 1.08 ( $95 \% \mathrm{Cl} 0.70$ to 1.67$)$. Trial sequential analysis calculated that 781 participants were required to eliminate a $25 \%$ difference (alpha 0.05 ; power $80 \%$; two-sided test; incidence in the control arm 51\%; model based variance) and that the Z curve failed to cross the boundaries. We downgraded the quality of the evidence by one level for risk of bias and by one level for imprecision and rated it low.

\section{Return of gastrointestinal function}

None of the trials reported gastrointestinal function as time to event. When contacted, some authors did not reply (Cakar Turhan 2011; Ezhevskaya 2012a; Gauger 2009), or gave us results in the format available (mean and SD (Klatt 2013); or number of participants with and without the event at a certain time point (Blumenthal 2006)); or informed us that their data were no longer available (Blumenthal 2005); or sent text of published abstract 
(Ezhevskaya 2015). Therefore, we analysed this outcome either as the number of participants with and without the event at a certain time point, or as mean and SD of the time when it occurred.

\section{3a. Time to first flatus (hours)}

One trial with 30 participants provided data for first flatus (Blumenthal 2006). Data were available as number of participants who experienced the event within 48 hours. Using a double catheter technique with ropivacaine alone on participants undergoing anterior correction of thoracic scoliosis, Blumenthal and colleagues reported that $15 / 15$ participants with epidural analgesia had their first flatus within 48 hours compared with $9 / 15$ participants for those who had systemic analgesia (RR $1.63,95 \% \mathrm{Cl} 1.08$ to 2.47 ). This trial was at unclear risk of bias for allocation concealment and low risk of bias for all other domains. Trial sequential analysis calculated that 348 participants were required to eliminate a $25 \%$ difference (alpha 0.05; power 80\%; two-sided test; incidence in the control arm 60\%; model-based variance). We downgraded the quality of evidence by one level for risk of bias and by two levels for imprecision, and rated it very low.

\section{3b. Time to first bowel movement (hours)}

Two trials infused local anaesthetic alone through two catheters and reported on the number of participants with or without bowel movement within 48 hours (Blumenthal 2005; Blumenthal 2006; Analysis 1.9). Random sequence generation was at low risk of bias for the two trials. Allocation concealment was at unclear risk of bias for the two trials. Blinding of participants and personnel taking care of the participants was at unclear risk of bias for Blumenthal 2006, and at high risk for Blumenthal 2005. Blinding of outcome assessment was at low risk of bias for Blumenthal 2006, and at high risk of bias for Blumenthal 2005. We judged all other domains at low risk of bias for the two trials.

Epidural analgesia increased the possibility of having first bowel movement within 48 hours (RR $11.52,95 \% \mathrm{Cl} 2.36$ to 56.26; NNTB $3,95 \% \mathrm{Cl} 2$ to 10 ). Trial sequential analysis calculated that 542 participants were required to eliminate a $25 \%$ difference (alpha 0.05; power 80\%; two-sided test; incidence in the intervention arm $60 \%$; model-based variance). We downgraded the quality of evidence by one level for risk of bias and two levels for imprecision, and rated it very low.

One trial infused a mixture of local anaesthetic and an opioid, and reported time to first bowel movement (mean \pm SD; participants with one catheter: $3.82 \pm 0.85$ days; 22 participants; participants with two catheters: $3.75 \pm 0.68$ days; 16 participants; participants with IV patient-controlled analgesia: $3.70 \pm 0.73$ days; 20 participants; Klatt 2013). This would give an MD of 0.09 days (95\% $\mathrm{Cl}-0.32$ to 0.50 ) for epidural analgesia versus systemic analgesia. This trial was at low risk of bias for random sequence generation, attrition bias, and reporting bias. Other domains were at unclear/ high risk of bias. Trial sequential analysis calculated that 48 participants were required to eliminate a one-day difference (alpha 0.05 ; power $80 \%$; empirical variance 1.5 ; model-based variance). We downgraded the quality of evidence by one level for risk of bias and two levels for imprecision, and rated it very low.

\section{3c. Time to first liquid ingestion (hours)}

Two trials with 56 participants reported time to first oral liquid ingestion (Cassady 2000; Malviya 1999). Cassady 2000 infused a mixture of a local anaesthetic and an opioid. Malviya 1999 infused opioids only. Malviya 1999 was at unclear risk of bias for random sequence generation, allocation concealment, blinding of participant and personnel taking care of participant, and for blinding of outcome assessment. Malviya 1999 was at low risk of bias for all other domains. Cassady 2000 was at low risk of bias for random sequence generation, attrition bias, and reporting bias. Cassady 2000 was at unclear/high risk of bias for all other domains.

We did not find a difference in time to first liquid oral intake (MD -5.02 hours, $95 \% \mathrm{Cl}-13.15$ to 3.10 ; Analysis 1.10). Trial sequential analysis calculated that 301 participants were required to eliminate a five-day difference (empirical) (alpha 0.05; power 80\%; twosided test; variance empirical; model variance based heterogeneity correction). We downgraded the quality of evidence by one level for risk of bias and two levels for imprecision, and rated quality of evidence for absence of effect as very low.

\section{3d. Time to first solid food ingestion (hours)}

One trial with 30 participants provided data for time to ingestion of solid foods (Blumenthal 2006). Using a double catheter technique with ropivacaine alone on participants undergoing anterior correction of thoracic scoliosis, Blumenthal and colleagues reported that participants with epidural analgesia were more likely to have their first solid foods ingested within 48 hours (RR 7.00, $95 \% \mathrm{Cl} 1.91$ to 25.62 ). Based on a $13.3 \%$ incidence of solid food intake within 48 hours in the control group, the NNTB would be 2 (95\% Cl 2 to 3). Blumenthal 2006 was at unclear risk of bias for allocation concealment and for blinding of personnel taking care of the participants and at low risk of bias for all other domains. Trial sequential analysis calculated that 150 participants were required to eliminate a $25 \%$ difference (alpha 0.05 ; power $80 \%$; twosided test; $90 \%$ incidence in the intervention arm; model variance based heterogeneity correction). We downgraded the quality of the evidence by one level for risk of bias and by two levels for imprecision and rated it very low.

For Summary of findings for the main comparison for return of gastrointestinal function, we presented all results available. There were no data available as time to event in hours.

\section{Secondary outcomes}

\section{Time to first mobilization (days)}

Data related to this outcome were available only for time to ambulate after surgery. One trial with 60 participants gave results for time to ambulate (MD 0.08 days, $95 \% \mathrm{Cl}-0.24$ to 0.39 ) (Klatt 2013). Klatt 2013 was at unclear/high risk of bias for allocation concealment, blinding of participants and personnel taking care of the participants, blinding of outcome assessment, and other bias, and at low risk of bias for all other domains. Trial sequential analysis calculated that 48 participants were required to eliminate a oneday difference (alpha 0.05; power 80\%; two-sided test; variance 1.5; heterogeneity correction model variance based). We downgraded the quality of the evidence by one level for risk of bias and two levels for imprecision, and rated absence of effect as very low.

\section{Hospital length of stay (days)}

We found no data on time to readiness for discharge. Two trials with 89 participants reported on hospital length of stay (Cassady 2000; Klatt 2013). Random sequence generation and attrition bias were at low risk of bias for the two trials. Allocation concealment, blinding of participants and personnel taking care of the participants, 
blinding of outcome assessment, and other risk of bias were at unclear/high risk of bias for the two trials. Reporting bias was at low risk for Cassady 2000 and at unclear risk for Klatt 2013. We found no difference in hospital length of stay (MD - 0.29 days, 95\% $\mathrm{Cl}-0.69$ to 010 ; Analysis 1.11; Figure 6). Trial sequential analysis calculated that 29 participants were required to eliminate a one- day difference (alpha 0.05; power 80\%; two-sided test; empirical variance; heterogeneity correction model variance based). We downgraded the quality of the evidence by one level for risk of bias and two levels for imprecision, and rated absence of effect as very low quality of evidence.

Figure 6. Forest plot of comparison: 1 Epidural analgesia versus systemic analgesia for postoperative pain after back surgery in children, outcome: 1.11 Hospital length of stay (days).

\begin{tabular}{|c|c|c|c|c|c|c|c|c|c|c|c|}
\hline \multirow[b]{2}{*}{ Study or Subgroup } & \multicolumn{3}{|c|}{ Epidural } & \multicolumn{3}{|c|}{ Control } & \multicolumn{3}{|c|}{ Mean Difference } & \multirow{2}{*}{$\begin{array}{c}\text { Mean Difference } \\
\text { IV, Random, } 95 \% \mathrm{Cl} \text { [days] }\end{array}$} & \multirow{2}{*}{$\begin{array}{c}\text { Risk of Bias } \\
\text { A B C DE F G }\end{array}$} \\
\hline & Mean [days] & SD [days] & Total & Mean [days] & SD [days] & Total & Weight & IV, Random, $95 \% \mathrm{Cl}$ [days] & Year & & \\
\hline Cassady 2000 & 4.7 & 1.1 & 14 & 4.7 & 1.6 & 15 & $16.0 \%$ & $0.00[-0.99,0.99]$ & 2000 & $\longrightarrow$ & ๑? ? \\
\hline Klatt 2013 (1) & 5.19 & 0.68 & 21 & 5.55 & 0.826 & 10 & $45.5 \%$ & $-0.36[-0.95,0.23]$ & 2013 & $\rightarrow$ & †? \\
\hline Klatt 2013 (2) & 5.21 & 0.855 & 19 & 5.55 & 0.826 & 10 & $38.5 \%$ & $-0.34[-0.98,0.30]$ & 2013 & -- & $\odot ? \ominus \ominus \odot \odot ?$ \\
\hline Total $(95 \% \mathrm{Cl})$ & & & 54 & & & 35 & $100.0 \%$ & $-0.29[-0.69,0.10]$ & & & \\
\hline $\begin{array}{l}\text { Heterogeneity: Tau } \\
\text { Test for overall effect }\end{array}$ & $\begin{array}{l}0.00 ; \mathrm{Chi}^{2}=0.4 \\
\mathrm{Z}=1.45(\mathrm{P}=0 .\end{array}$ & $\begin{array}{l}10, d f=2(P \\
15)\end{array}$ & $=0.82)$ & $i_{1}^{2}=0 \%$ & & & & & & $\begin{array}{cccc} & 1 & 1 & 1 \\
-4 & -2 & 0 & 2 \\
\text { Favours epidural } & \text { Favours contr }\end{array}$ & \\
\hline $\begin{array}{l}\text { Footnotes } \\
\text { (1) One catheter } \\
\text { (2) Two catheters }\end{array}$ & & & & & & & & & & $\begin{array}{l}\text { Risk of bias legend } \\
\text { (A) Random sequence generatio } \\
\text { (B) Allocation concealment (selec } \\
\text { (C) Blinding of participants and pe } \\
\text { (D) Blinding of outcome assessm } \\
\text { (E) Incomplete outcome data (attr } \\
\text { (F) Selective reporting (reporting b } \\
\text { (G) Other bias }\end{array}$ & $\begin{array}{l}\text { election bias) } \\
\text { bias) } \\
\text { nnel (performance... } \\
\text { (detection bias) } \\
\text { bias) }\end{array}$ \\
\hline
\end{tabular}

\section{Satisfaction with postoperative analgesia regimen (any ascending or descending scale as provided by study authors)}

\section{3a. Participant satisfaction}

In their methods section, Gauger 2009 mentioned that participants were asked to rate their level of satisfaction with analgesia treatment as very dissatisfied, somewhat dissatisfied, somewhat satisfied, or very satisfied. Their results were reported as only one participant in each group reported dissatisfaction with their pain management. This trial was at low risk of bias for random sequence generation, attrition bias, and reporting bias. Gauger 2009 was at unclear/high risk of bias for all other domains.

Two trials with 60 participants reported a higher score for participant satisfaction with epidural analgesia (MD 1.62, 95\% Cl 1.26 to 1.97; Blumenthal 2005; Blumenthal 2006; Analysis 1.12). Random sequence generation, attrition bias, reporting bias, and other bias were at low risk of bias for the two trials. Allocation concealment and blinding of participants and personnel taking care of participants were at unclear/high risk of bias for the two trials. Blinding of outcome assessment was at low risk of bias for Blumenthal 2006 and at high risk of bias for Blumenthal 2005. Trial sequential analysis calculated that 48 participants were required to eliminate a 1-point difference (alpha 0.05; power 80\%; two-sided test; variance 1.5; heterogeneity correction model variance based) and that the $Z$ curve crossed the boundary in favour of epidural analgesia. We downgraded the quality of the evidence by one level for risk of bias and two levels for imprecision, and rated it very low.

\section{3b. Parent satisfaction}

One trial reported on parent satisfaction score (MD 0.60, 95\% $\mathrm{Cl}-0.81$ to 2.01) (Malviya 1999). Malviya 1999 was at low risk of bias for attrition bias, reporting bias, and other bias, and at unclear risk of bias for all other domains. Trial sequential analysis calculated that 108 participants were required to eliminate a 1point difference (alpha 0.05; power $80 \%$; two-sided test; variance empirical; heterogeneity correction model variance based). We downgraded the quality of the evidence by one level for risk of bias and two levels for imprecision, and rated it very low.

For the 'Summary of findings' table for satisfaction, we presented results available for participant and for parent satisfaction. No trial reported satisfaction at more than one time point.

\section{Complications (related to analgesic techniques (epidural or systemic analgesia), including respiratory depression, hospital inpatient falls, and infections (e.g. wound infection, epidural abscess) within $\mathbf{3 0}$ days of surgery) and neurological complications}

Part of this outcome was reported as a narrative review and we provided additional details in Table 3.

\section{Complications possibly related to epidural analgesia}

\section{Technical issues}

One trial reported a high rate of primary catheter failure $(37 \%)$ (Gauger 2009). Gauger 2009 did not confirm the catheter position with an intraoperative radiography. One trial reported 10 cases of epidural leakage (out of 21 participants with a single catheter and 18 participants with two catheters) causing discontinuation for two participants (Klatt 2013). One trial reported one dislodged catheter during utilization. None of these trials mentioned any precautions taken to prevent catheter dislodgment or leakage, or both (Malviya 1999) (Table 3).

\section{Side effects}

There was transient partial lower limb motor blockade after the initial loading dose for 4/30 participants (Blumenthal 2005); and for 2/30 participants (Blumenthal 2006), in two trials using ropivacaine alone. Motor strength normalized within 180 minutes for all participants. Three trials noted paraesthesia of the lower limbs: Gauger 2009 (1/19 participants), Klatt 2013 (4/21 for participants with one catheter and $1 / 18$ for participants with two catheters), and O'Hara 2004 (7/22 participants) (Table 3). 
One trial reported one participant with hypotension requiring epidural discontinuation (Gauger 2009; Table 3).

\section{Complications}

One participant had respiratory depression (oxygen desaturation less than 90\%) (Gauger 2009; Table 3; Analysis 1.13). There were no neurological complications attributed to epidural analgesia (see below).

\section{Complications possibly related to systemic analgesia}

Two of 19 participants remained intubated and ventilated for several hours (Gauger 2009). Three participants had respiratory depression (oxygen desaturation less than 90\%) in Gauger 2009 and one participant had increased partial pressure of carbon dioxide $\left(\mathrm{PaCO}_{2}\right.$; from $6.5 \mathrm{kPa}$ to $7.8 \mathrm{kPa}$ or $50 \mathrm{mmHg}$ to $60 \mathrm{mmHg}$ ) and decreased respiratory rate ( 6 breaths/minute to 8 breaths/minute) in O'Hara 2004.

\section{4a. Respiratory depression}

Four trials with 126 participants reported on the number of participants with respiratory depression for the two modes of treatment (Cassady 2000; Gauger 2009; Malviya 1999; O'Hara 2004). Random sequence generation was at unclear risk of bias for Malviya 1999 and at low risk of bias for the other three trials. Allocation concealment was at low risk of bias for one trial (O'Hara 2004) and at unclear risk of bias for the other three trials. Blinding of participants and personnel taking care of the participants and blinding of outcome assessment were at low risk of bias for O'Hara 2004, and at unclear/high risk of bias for the other three trials. Attrition and reporting bias were at low risk for the four trials. Other risks of bias were at low risk for Malviya 1999, and at unclear risk for the other three trials.

We did not find a difference in the risk of respiratory depression (RD $-0.05,95 \% \mathrm{Cl}-0.16$ to 0.05 ; Analysis 1.13 ). There was no evidence of small-study effect or publication bias. Trial sequential analysis indicated that the information size for a $25 \%$ relative risk reduction was 12,200 (alpha 0.05 ; power $80 \%$; two-sided test; $10.6 \%$ incidence in the control arm; RD; random-effects model; model variance based). We downgraded the quality of the evidence by one level for risk of bias and by two levels for imprecision, and rated it very low.

\section{4b. Hospital inpatient falls}

No trial reported on hospital inpatient falls.

\section{4c. Infections (e.g. wound infection or epidural abscess) within 30 days of surgery}

\section{4c.1. Wound infection}

Cassady 2000 reported one wound infection in the epidural group versus none in the systemic analgesia group. Klatt 2013 reported no wound infection in either group. Therefore, based on two trials with 93 participants, we did not find a difference for wound infection (RD $0.01,95 \% \mathrm{Cl}-0.05$ to $0.08 ; 1^{2}=0 \%$; Analysis 1.14) (Cassady 2000; Klatt 2013). The two trials were at unclear/high risk of bias for allocation concealment, blinding of participant and personnel taking care of the participant, blinding of outcome assessment, and other risks of bias. The two trials were at low risk of bias for all other domains. Trial sequential analysis calculated that the information size for a $50 \%$ relative risk reduction was 15,171 (alpha 0.05; power $80 \%$; two-sided test; $1.8 \%$ incidence in the intervention arm; RD; random-effects model; model variance based). We downgraded the quality of the evidence by one level for risk of bias and two levels for imprecision, and rated it very low.

\section{4c.2. Epidural abscess}

Two trials reported no complication/problem associated with the catheters (Blumenthal 2005; Blumenthal 2006). Ezhevskaya 2015 reported no complications in either group. Klatt 2013 reported that late -onset neurological events were absent in all participants. Random sequence generation was at low risk for three trials (Blumenthal 2005; Blumenthal 2006; Klatt 2013), and at unclear risk for Ezhevskaya 2015. Allocation concealment was at unclear risk of bias for the four trials. Blinding of participant and personnel taking care of the participant and blinding of outcome assessment were at low risk for Ezhevskaya 2015 and at unclear/high risk for the other three trials. Attrition bias and reporting bias were at low risk for the four trials. Other risks of bias were at unclear risk for Klatt 2013 and at low risk for the other three trials. The treatment group distribution was unknown for one trial (Ezhevskaya 2015). Therefore, based on three trials with 120 participants, we did not find a difference in epidural abscess (RD $0.00,95 \% \mathrm{Cl}-0.05$ to 0.05 ; $\mathrm{I}^{2}=0 \%$; Analysis 1.15) (Blumenthal 2005; Blumenthal 2006; Klatt 2013). Trial sequential analysis indicated that the information size for a $50 \%$ relative risk reduction was 2,147,483,647 (alpha 0.05; power $80 \%$; two-sided test; $0.01 \%$ incidence in the control arm (Sethna 2010); RD; random-effects model; heterogeneity correction model variance based). We downgraded the quality of the evidence by one level for risk of bias and two levels for imprecision, and rated it very low.

\section{4d. Neurological complications}

Blumenthal 2005 and Blumenthal 2006 reported no complications/ problems associated with the catheters. Ezhevskaya 2015 reported no complications in either group. Klatt 2013 reported that late-onset neurological events were absent in all participants. O'Hara 2004 reported three participants with lasting neurological problems in the epidural group. Two participants had persistent sensory deficits that resolved at three and six months. Their conclusions were that these problems were secondary to the spinal correction. One participant was excluded from the trial due to lower extremities paralysis on emergence from anaesthesia. According to the protocol, this participant had received a bolus of $3 \mathrm{~mL}$ of a solution containing bupivacaine $0.1 \%$ and fentanyl $5 \mu \mathrm{g} /$ $\mathrm{mL}$ followed by an infusion at $4 \mathrm{~mL} /$ hour started prior to wound closure. Paralysis resolved at eight months and was judged to be secondary to the spinal correction. Therefore, all neurological complications were secondary to the surgical procedure and there was no neurological complication attributed to epidural analgesia. The treatment group distribution was unknown for one trial (Ezhevskaya 2015).

Based on four trials with 151 participants, we did not find a difference in the risk of neurological complications (RD 0.01, 95\% $\mathrm{Cl}-0.04$ to $0.06 ; 12=0 \%$ ). Random sequence generation, attrition bias, and reporting bias were at low risk for the four trials. Allocation concealment was at low risk of bias for one trial (O'Hara 2004), and at unclear risk of bias for the other three trials. Blinding of participant and personnel taking care of the participants was at low risk for one trial (O'Hara 2004), and at unclear/high risk for three trials (Blumenthal 2005; Blumenthal 2006; Klatt 2013). Blinding of outcome assessment was at low risk for two trials 
(Blumenthal 2006; O'Hara 2004), and at unclear/high risk for two trials (Blumenthal 2005; Klatt 2013). Other risks of bias were at low risk for two trials (Blumenthal 2005; Blumenthal 2006), and at unclear risk for two trials (Klatt 2013; O'Hara 2004). Trial sequential analysis indicated that the information size for a $50 \%$ relative risk increase was 9971 (alpha 0.05; power 80\%; two-sided test; $0.033 \%$ incidence in the intervention arm; $0.022 \%$ incidence in the control arm; random-effects model; heterogeneity correction model variance based). We downgraded the quality of evidence for absence of difference by three levels: one for risk of bias and two for imprecision and rated it very low.

\section{DISCUSSION}

\section{Summary of main results}

This review demonstrates that epidural analgesia reduces postoperative pain, accelerates return of gastrointestinal function (local anaesthetic alone), and increases patient satisfaction.

An improvement in pain control after surgery with the use of epidural analgesia compared with systemic analgesia such as found in the present review was in accordance with results found in adults for various surgeries including abdominal surgery (Guay 2016). However, it was unclear if better analgesia at rest and on movement for at least 72 hours after surgery would have been significant if all included studies had adhered to aggressive systemic analgesia for all of the included participants.

Likewise, acceleration of return of gastrointestinal function with an epidural containing a local anaesthetic is also consistent with results found on other type of surgeries (Guay 2016). Epidural analgesia may promote a faster return of intestinal transit through various mechanisms including a reduction in opioid administration, a blockade of sympathetic gut innervation (creating a relative parasympathetic predominance), a direct effect of systemic local anaesthetics, or a combination of these (McCarthy 2010). However, as opposed to findings in abdominal surgery, for spine surgery there was a faster return of gastrointestinal function clearly demonstrated only in trials using local anaesthetic without the addition of opioids (Blumenthal 2005; Blumenthal 2006). Although one author reported that bowel sounds were present in a higher percentage of participants on the day of surgery ( $20 \%$ for epidural analgesia versus $0 \%$ for systemic analgesia) and at postoperative day one ( $80 \%$ versus $43.75 \%$ ) while using a mixture of local anaesthetic and an opioid, this did not result in faster resumption of liquid oral intake (Cassady 2000). Likewise, also infusing a mixture of a local anaesthetic and an opioid through one or two catheters, Klatt 2013 reported similar mean times for first bowel movement after surgery.

Thoraco-lumbar spine surgery is associated with risks of neurological damage. Therefore, being able to proceed to a neurological examination after the surgery is critical. Interestingly, our review seemed to suggest that epidural opioids alone would be an acceptable mode of pain control at rest during the first few hours after the surgery (Analysis 1.1). However, it is to note that only one trial used opioids alone (Malviya 1999), and this trial was not performed on children undergoing scoliosis surgery but on children with cerebral palsy undergoing selective dorsal rhizotomy. The latter is a surgery much less extensive than scoliosis surgery consisting in partial or complete laminectomies at six spinal levels only. Therefore, the use of opioids only would need to be studied before applying this solution to children undergoing scoliosis surgery. Also, delaying the introduction of epidural local anaesthetics to postoperative day one such as done in two trials (Blumenthal 2005; Blumenthal 2006), did not seem to impede the beneficial effect of epidural local anaesthetic to influence the accelerative return of gastrointestinal function (Analysis 1.9).

The use of epidural analgesia may be associated with some technical problems. One author noted a high rate of primary catheter failure (Gauger 2009). This was not corroborated by other authors. As the catheter is most often inserted by the surgeon at the end of surgery under direct vision, one would normally expect that most catheters would be placed in an optimal position. However, this might not be the case for surgeons unfamiliar with the technique. Blumenthal and colleagues confirmed all catheter positions with injection of a contrast material and intraoperative radiographies (Blumenthal 2005; Blumenthal 2006). Three trials mentioned that their catheter insertion technique was similar to the one reported by Shaw 1996 (Cassady 2000; Gauger 2009; Klatt 2013). Shaw and colleagues used a Teflon-styletted catheter passed through the paravertebral soft tissue. The exact type of catheter (open-ended versus multiport, soft tip versus firm tip, or wire-reinforced or not) used in the included trials was unclear. One author reported a dislodged catheter (Malviya 1999). None of the trials reported methods of catheter fixation. Finally, one author reported a high rate of catheter leakage causing premature cessation of epidural analgesia in two participants (Klatt 2013). None of the trials mentioned methods to prevent leakage (Auyong 2017).

There were no neurological complications attributed to epidural analgesia in any of the included trials. Our review was clearly underpowered to eliminate an increase in incidence of neurological complications with epidural analgesia in this population. There were three neurological complications attributed to the surgery and they all came from the same trial (O'Hara 2004). This trial included 31 participants. Ten participants received an infusion of bupivacaine $0.1 \%$ and fentanyl $5 \mu \mathrm{g} / \mathrm{mL}, 12$ participants received an infusion of bupivacaine $0.0625 \%$ and fentanyl $5 \mu \mathrm{g} / \mathrm{mL}$, and nine participants received an infusion of $0.9 \%$ sodium chloride. They reported three lasting complications (longer than one month). Of the three complications, two were sensory deficits only (no motor loss) and all three complications resolved within one year. The incidence of neurological complications reported by these authors (3/31 participants; $9.7 \%$ ( $95 \% \mathrm{Cl} 3.4 \%$ to $24.9 \%$ ) exceeded the incidence expected with actual techniques (less than $1 \%$; de Mendonca 2016).

Haematomas are possible even with epidural catheter placement under direct vision. Some patients may have congenital haemostasis abnormalities contributing or not to increased risk of bleeding. For instance, idiopathic scoliosis is associated with abnormal collagen and platelet function (Floman 1983; Uden 1980). Children with cerebral palsy or muscular dystrophies may have increased bleeding (Brenn 2004; Noordeen 1999). Finally and most of all, dilution of coagulation factors or platelets (or both) or fibrinolysis that may occur (especially with extensive surgeries) not only mandate adequate blood loss/transfusion-sparing strategies but also strict monitoring before considering epidural catheter insertion and withdrawal (Alajmi 2017; Guay 1994; Horlocker 2001; Nakai 2011). It is unclear if laminectomies performed during 
surgery would offer any degree of protection against neurological damage due to a compression from haematoma.

\section{Overall completeness and applicability of evidence}

We are confident that our review reflects the available literature on epidural analgesia for thoraco-lumbar spine surgery in children.

\section{Quality of the evidence}

The quality of evidence was moderate, low, or very low. Despite this imperfect quality of the body of evidence, we are quite confident that epidural analgesia reduces pain at rest and on movement up to 72 hours after surgery. This is supported by the fact that pain was lower in epidural groups at all time points where we measured it. Although the reduction may seem modest, most differences were higher than 1 point. Considering that this is just a mean (some children may have experienced more pain than others) and that this lasted at least 72 hours, we consider that this finding is clinically relevant. Likewise, although some measurements concerning a faster return of gastrointestinal transit were contradictory and present only when local anaesthetics alone were infused, we consider that being able to increase the number of children who tolerate solid food within $\mathbf{4 8}$ hours is also highly clinically relevant.

\section{Potential biases in the review process}

The quality of the trials, though not optimal, was comparable to other trials published on epidural analgesia (Guay 2016), and probably sufficient enough to allow us to draw valid conclusions. Strikingly, we discovered a low number of published trials on this important issue. Although a well-known unfortunate phenomenon, science on the management of children is often derived from trials published on adults. In this review, three of the trials included in the analysis contained some participants older than 18 years: Blumenthal 2005 (10 to 30 years; mean age 17 years), Klatt 2013 (10 to 21 years), and O'Hara 2004 (13 to 21 years). This causes us to agree with some authorities that specify children as 'therapeutic orphans' within research (Morales-Olivas 2006). Unfortunately, a paucity of evidence to aid clinical practice for children has continued despite efforts such as the Pediatric Research Equity Act (PREA) passed in 2003 (Hudgins 2018). For instance, many drugs commonly used in children are administered without formal paediatric data to support their benefit. A cross-sectional analysis of new drug applications submitted to the US Federal Drug Agency (FDA) from December 2003 to July 2012 revealed that the mean time between approval in adults and availability of paediatric data for drugs approved without paediatric assessments was 6.5 years (Hudgins 2018). Likewise, off-label medications would be prescribed 1.5 times more than FDA-approved medications for children with migraines (Lai 2017). We think that support to encourage more paediatric well-performed trials is still needed. Nevertheless, we do not think that the inclusions of trials that may have contained some participants older than 18 years of age was extensive enough to affect the validity of our findings.

We attempted to conduct a comprehensive search for studies, but the fact that one study has not yet been incorporated may be a source of potential bias.

Study authors used different pain scales. When this happens, analysis should be done as SMD instead of MDs (Borenstein 2009b). Because this is not a 'clinical' unit, we did two things. First, when all scales were scales from 0 to 10 , we gave results both as means and SDs and as SMDs (Analysis 1.1; Analysis 1.2; Analysis 1.4). Conclusions drawn were never affected by the type of analysis (MD or SMD). Second, when we could give results only as SMDs, then we gave a clinical equivalence.

\section{Agreements and disagreements with other studies or reviews}

Improved postoperative analgesia and acceleration of return of gastrointestinal function with epidural analgesia compared with systemic analgesia is in accordance with the findings reported for other types of surgeries in other populations (Guay 2016). Likewise, one meta-analysis comparing epidural analgesia with IV analgesia in people undergoing major spine surgery reported that epidural analgesia provided significantly superior analgesia, higher patient satisfaction, and decreased overall opioid consumption compared with IV patient-controlled analgesia following major spine surgery (Meng 2017). Review authors found no difference in the adverse effects associated with these two methods of analgesia and conclude that high-quality trials are needed to verify their findings (Meng 2017).

\section{AUTHORS' CONCLUSIONS}

\section{Implications for practice}

There is moderate- and low-quality evidence that there may be a small additional reduction in pain up to 72 hours after surgery with epidural analgesia compared with systemic analgesia. Two very small studies showed epidural analgesia with local anaesthetic alone may accelerate the return of gastrointestinal function. The safety of this technique in children undergoing thoraco-lumbar surgery is uncertain due to the very low quality of the evidence.

The study in 'Studies awaiting classification' table may alter the conclusions of the review once assessed.

\section{Implications for research}

Large randomized trials comparing epidural analgesia with systemic analgesia in the context of maximal co-analgesia and intravenous lidocaine might be useful.

Large prospective trials establishing the safety of epidural analgesia in this specific context might be useful.

\section{ACKNOWLEDGEMENTS}

\section{Review}

We would like to thank Ann Møller (content editor); Jing Xie (statistical editor); Anthony Bradley, Ewan D McNicol, and Vaughan L Thomas (peer reviewers); Brian Stafford (consumer referee); and Andrew Smith (Co-ordinating Editor) for their help and editorial advice during the preparation of this systematic review.

We extend our thanks to authors who provided additional information on their trial or informed us that their data were no longer available: Alain Borgeat and Stephan Blumenthal (Blumenthal 2005; Blumenthal 2006), Anna A Ezhevskaya (Ezhevskaya 2015), Joshua Klatt and Man Hung (Klatt 2013), and Jerome F O'Hara (O'Hara 2004). 


\section{Protocol}

We would like to thank Javier Eslava-Schmalbach's (Content Editor); and Vaughan L Thomas, Ewan D McNicol, and Nayan $\mathrm{K}$ Desai (Peer Reviewers) for help and editorial advice provided during preparation of the protocol for the systematic review (Guay 2017). We would also like to thank the following Cochrane Anaesthesia Critical and Emergency Care editors who screened the draft protocol: Bronagh Blackwood, Jane Cracknell, Harald Herkner, Nathan Pace, Janne Vendt, and Cathal Walsh. 


\section{RE F E R E N C E S}

\section{References to studies included in this review}

Blumenthal 2005 \{published data only\}

Blumenthal S. Information on our trial. Email to: J Guay 1 November 2017.

* Blumenthal S, Min K, Nadig M, Borgeat A. Double epidural catheter with ropivacaine versus intravenous morphine: a comparison for postoperative analgesia after scoliosis correction surgery. Anesthesiology 2005;102(1):175-80. [PUBMED: 15618801]

\section{Blumenthal 2006 \{published data only\}}

* Blumenthal S, Borgeat A, Nadig M, Min K. Postoperative analgesia after anterior correction of thoracic scoliosis: a prospective randomized study comparing continuous double epidural catheter technique with intravenous morphine. Spine 2006;31(15):1646-51. [PUBMED: 16816757]

Borgeat A. Information on our trial. Email to: J Guay 24 October 2017.

Marquardt M, Blumenthal S, Min K, Borgeat A. Ventral scoliosis correction followed by double epidural catheter technique with continuous ropivacaine for postoperative analgesia. Regional Anesthesia and Pain Medicine 2005;30 (5 Suppl 1):51.

\section{Cakar Turhan 2011 \{published data only\}}

Cakar Turhan KS, Ozgencil E, Ozturk Mamik F, Hasdogan M, Baykal Tutal Z, Bezirgan U, et al. Postoperative preemptive segmental epidural analgesia and wound infiltration following the posterior fusion surgery in adolescent patients with scoliosis. Regional Anesthesia and Pain Medicine 2011;36 (7 Suppl):E166. [EMBASE: 70735656]

\section{Cassady 2000 \{published data only\}}

Cassady JF Jr, Lederhaas G, Cancel DD, Cummings RJ, Loveless EA. A randomized comparison of the effects of continuous thoracic epidural analgesia and intravenous patient-controlled analgesia after posterior spinal fusion in adolescents. Regional Anesthesia and Pain Medicine 2000;25(3):246-53. [DOI: 10.1053/xr.2000.5661; PUBMED: $10834778]$

\section{Ezhevskaya 2012a \{published data only\}}

* Ezhevskaya A, Ovechkin A. Effects of two-level thoracic epidural anesthesia on hemodynamics and hemostasis during dorsalis correction of scoliosis. Regional Anesthesia and Pain Medicine. 2013; Vol. 38 Issue 4:A93.

Ezhevskaya A, Ovechkin A. Perioperative epidural analgesia before and after posterior correction of adolescents idiopathic scoliosis. Regional Anesthesia and Pain Medicine 2012;37 (5 Suppl 1):E222.

\section{Ezhevskaya 2015 \{published data only\}}

Ezhevskaya A. Information on our trial. Email to: J Guay 25 January 2018.
* Ezhevskaya A, Presyakova M, Prusakova Z. The double-blind study of isolated and combined use of tranexamic acid and epidural anesthesia in scoliosis surgery. Regional Anesthesia and Pain Medicine 2015;40 (5 Suppl 1):e98. [EMBASE: 72027161]

\section{Gauger 2009 \{published data only\}}

Gauger VT, Lewis TV, Burke C, Merkel S, Farley FA. Epidural versus intravenous patient-controlled analgesia in children after spinal fusion. Abstracts of the American Anesthesiologists Annual Meeting. Chicago, Illinois, USA: Available at www.asaabstracts.com, October 14 to 18, 2006:A1350.

* Gauger VT, Voepel-Lewis TD, Burke CN, Kostrzewa AJ, Caird MS, Wagner DS, et al. Epidural analgesia compared with intravenous analgesia after pediatric posterior spinal fusion. Journal of Pediatric Orthopedics 2009;29(6):588-93. [DOI: 10.1097/BPO.0b013e3181b2ba08; PUBMED: 19700988]

\section{Klatt 2013 \{published data only\}}

Hung M. Information on our trial. Email to: J Guay 13 January 2019.

Hung M. Information on our trial. Email to: J Guay 22 January 2018.

Hung M. Information on our trial. Email to: J Guay 23 February 2018.

Hung M. Information on our trial. Email to: J Guay 28 January 2018.

Hung M. Information on our trial. Email to: J Guay 5 September 2018.

* Klatt JW, Mickelson J, Hung M, Duncan S, Miller C, Smith JT. A randomized prospective evaluation of 3 techniques of postoperative pain management after posterior spinal instrumentation and fusion. Spine 2013;38(19):1626-31. [DOI: 10.1097/BRS.0b013e31829cab0b; PUBMED: 23715024 ]

\section{Malviya 1999 \{published data only\}}

Malviya S, Pandit U, Merkel S, Muraszko K, Zang L, Shayeritz J. A comparison of epidural and intravenous analgesia after selective dorsal rhizotomy. Anesthesia and Analgesia 1995;80:S293.

* Malviya S, Pandit UA, Merkel S, Voepel-Lewis T, Zang L, Siewert M, et al. A comparison of continuous epidural infusion and intermittent intravenous bolus doses of morphine in children undergoing selective dorsal rhizotomy. Regional Anesthesia and Pain Medicine 1999;24(5):438-43. [PUBMED: 10499756]

\section{O'Hara 2004 \{published data only\}}

O'Hara J. Information on our trial. Email to: J Guay 1 March 2018.

* O'Hara JF Jr, Cywinski JB, Tetzlaff JE, Xu M, Gurd AR, Andrish JT. The effect of epidural vs intravenous analgesia for posterior spinal fusion surgery. Paediatric Anaesthesia 
2004;14(12):1009-15. [DOI: 10.1111/j.1460-9592.2004.01387.x; PUBMED: 15601351]

\section{Ozturk Mamik 2011 \{published data only\}}

Ozturk Mamik F, Hasdogan M, Ozgencil E, Alanoglu Z, Aybar S, Kalem M, et al. Postoperative preemptive segmental epidural analgesia following the posterior fusion surgery in adolescent patients with scoliosis. Regional Anesthesia and Pain Medicine 2011;36 (7 Suppl):E166. [EMBASE: 707356955]

\section{References to studies excluded from this review}

Adu-Gyamfi 1995 \{published data only\}

Adu-Gyamfi Y. Epidural morphine plus bupivacaine for relief of post-operative pain following Harrington rod insertion for correction of idiopathic scoliosis. Journal of International Medical Research 1995;23(3):211-7. [DOI: 10.1177/030006059502300309; PUBMED: 7649346]

\section{Aizenberg 2011 \{published data only\}}

Aizenberg VL, Ul'rikh GE, Ukolov Klu, Zabolotskii DV, Ivanov MD, Malashenko NS. Methods of analgesia in children after surgical correction of the scoliotic spinal deformities. Anesteziologiia $i$ Reanimatologiia 2011;56(1):59-62. [PUBMED: 21510068]

\section{Akin Takmaz 2011 \{published data only\}}

Akin Takmaz S, Basar H, Ozgun C, Ozdemir HM, Sakaogulin A. Epidural analgesia following posterior scoliosis correction surgery in adolescent: double epidural catheter technique with patient controlled analgesia versus continue infusion. European Journal of Anaesthesiology 2011;28 (Suppl):208. [EMBASE: 70681639]

\section{Amaranath 1989 \{published data only\}}

Amaranath L, Andrish JT, Gurd AR, Weiker GG, Yoon H. Efficacy of intermittent epidural morphine following posterior spinal fusion in children and adolescents. Clinical Orthopaedics and Related Research 1989;249:223-6. [PUBMED: 2582672]

\section{Arms 1998 \{published data only\}}

Arms DM, Smith JT, Osteyee J, Gartrell A. Postoperative epidural analgesia for pediatric spine surgery. Orthopedics 1998;21(5):539-44. [PUBMED: 9606693]

\section{Bernard 1995a \{published data only\}}

* Bernard JM, Kick O, Bonnet F. Comparison of intravenous and epidural clonidine for postoperative patient-controlled analgesia. Anesthesia and Analgesia 1995;81(4):706-12. [PUBMED: 7573998 ]

Bernard JM, Kick O, Bonnet F. Intravenous versus epidural patient controlled analgesia with clonidine. Anesthesiology 1994;81 (3A):A947.

\section{Cohen 2017 \{published data only\}}

Cohen M, Aquilante C, Zuk J, Galinkin J. Intrathecal morphine versus epidural extended-release morphine for postoperative pain control in pediatric spinal fusion patients. Clinical Pharmacology and Therapeutics 2013:S48. [EMBASE: 70980554]
* Cohen M, Zuk J, McKay N, Erickson M, Pan Z, Galinkin J. Intrathecal morphine versus extended-release epidural morphine for postoperative pain control in pediatric patients undergoing posterior spinal fusion. Anesthesia and Analgesia 2017;124(6):2030-7. [PUBMED: 28448398]

\section{Ekatodramis 2002 \{published data only\}}

Ekatodramis G, Min K, Cathrein P, Borgeat A. Use of a double epidural catheter provides effective postoperative analgesia after spine deformity surgery. Journal Canadien d'Anesthesie [Canadian Journal of Anaesthesia] 2002;49(2):173-7. [PUBMED: 11823396]

\section{Erdogan 2017 \{published data only\}}

Erdogan MA, Ozgul U, Ucar M, Korkmaz MF, Aydogan MS, Ozkan AS, et al. Patient-controlled intermittent epidural bolus versus epidural infusion for posterior spinal fusion after adolescent idiopathic scoliosis: prospective, randomized, double-blinded study. Spine 2017;42(12):882-6. [PUBMED: 27792112]

\section{Eshevskaya 2013 \{published data only\}}

Eshevskaya A. Effects of single-shot and continuous two-level epidural anesthesia on pain management and stress response in patients undergoing scoliosis correction. Regional Anesthesia and Pain Medicine 2013:E151. [EMBASE: 71366553]

\section{Ezhevskaya 2012b \{published data only\}}

Ezhevskaya AA, Prusakova ZH. Epidural analgesia in surgical treatment of scoliosis. Anesteziologiia i Reanimatologiia 2012;57(2):27-30. [PUBMED: 22834284]

\section{Ezhevskaya 2012c \{published data only\}}

Ezhevskaya A, Ovechkin A. Surgical stress response during continuous epidural analgesia in patients undergoing high intensity spine fusion. Regional Anesthesia and Pain Medicine 2012;37 (5 Suppl 1):E222. [EMBASE: 70880928]

\section{Ezhevskaya 2014a \{published data only\}}

Ezhevskaya A, Ovechkin A. Beneficial effects of regional anesthesia on outcome after major spinal fusion. Regional Anesthesia and Pain Medicine 2014;39 (5 Suppl 1):e175. [EMBASE: 71687680]

* Ezhevskaya AA, Prusakova ZhB, Maksimova LP, Sholkina MN, Balmusova EA, Ovechkin AM. Effects of epidural anesthesia on stress-induced immune suppression during major corrective spine surgery. Anesteziologiia i Reanimatologiia 2014;59(6):4-9. [PUBMED: 25831694]

Ezhevskaya AA, Prusakva ZhB, Zagrekov VI, Prokhorova YN, Ovechkin AM. The advantages of continuous epidural anesthesia in spinal deformity surgery. Sovremennye Tehnologii $v$ Medicine 2014;6(3):72-6. [EMBASE: 600247387]

\section{Ezhevskaya 2014b \{published data only\}}

Ezhevskaya A, Ovechkin A. The analgesic effect of ultrasoundguided subcostal tap-block compared with thoracic epidural and general anesthesia in patients undergoing extreme-lateral inter body fusion. Regional Anesthesia and Pain Medicine 2014;39 (5 Suppl 1):E177. 


\section{Goodarzi 1993 \{published data only\}}

Goodarzi M, Shier NH, Ogden JA. Epidural versus patientcontrolled analgesia with morphine for postoperative pain after orthopaedic procedures in children. Journal of Pediatric Orthopedics 1993;13(5):663-7. [PUBMED: 8376571]

Goodarzi 1999 \{published data only\}

Goodarzi M. Comparison of epidural morphine, hydromorphone and fentanyl for postoperative pain control in children undergoing orthopaedic surgery. Paediatric Anaesthesia 1999;9(5):419-22. [PUBMED: 10447905]

Khinkover 2006 \{published data only\} Khinkover VV, Nazarov IP. Continuous epidural anesthesia in patients after surgical treatment for scoliosis. Anesteziologiia i Reanimatologiia 2006;51(4):68-9. [DOI: 616-089.5-032:611.819.59:616.711-007.55-089; PUBMED: $17061592]$

\section{Lawhorn 1994 \{published data only\}}

Lawhorn CD, Boop F, Brown R, Andelman P. Epidural pain management in the postrhizotomy patient. Pediatric Neurosurgery 1994;20(3):198-202. [PUBMED: 8204495]

\section{Loughnan 1990 \{published data only\}}

Loughnan BA, Murdoch LJ, Hetreed MA, Howard LA, Hall GM. Effects of $2 \%$ lignocaine on somatosensory evoked potentials recorded in the extradural space. British Journal of Anaesthesia 1990;65(5):643-7. [PUBMED: 2248842]

Lowry 2001 \{published data only\}

Lowry KJ, Tobias J, Kittle D, Burd T, Gaines RW. Postoperative pain control using epidural catheters after anterior spinal fusion for adolescent scoliosis. Spine 2001;26(11):1290-3. [PUBMED: $11389401]$

\section{Milbrandt 2009 \{published data only\}}

Milbrandt TA, Singhal M, Minter C, McClung A, Talwalkar VR, Iwinski HJ, et al. A comparison of three methods of pain control for posterior spinal fusions in adolescent idiopathic scoliosis. Spine 2009;34(14):1499-503. [DOI: 10.1097/ BRS.0b013e3181a90ceb; PUBMED: 19525843]

\section{Nóbrega 2017 \{published data only\}}

Nóbrega S, Ferreira A, Ramos S. Epidural analgesia in paediatric scoliosis surgery: an effective approach. Regional Anesthesia and Pain Medicine 2017;42 (5 Suppl 1):e64. [EMBASE: 619674841

\section{Pham 2008 \{published data only\}}

Pham Dang C, Delecrin J, Pereon Y, Falconi I, Passuti N, Malinge $\mathrm{M}$, et al. Epidural analgesia after scoliosis surgery: electrophysiologic and clinical assessment of the effects of bupivacaine $0.125 \%$ plus morphine versus ropivacaine $0.2 \%$ plus morphine. Journal of Clinical Anesthesia 2008;20(1):17-24. [PUBMED: 18346604]

\section{Ravish 2012 \{published data only\}}

Ravish M, Muldowney B, Becker A, Hetzel S, McCarthy JJ, Nemeth BA, et al. Pain management in patients with adolescent idiopathic scoliosis undergoing posterior spinal fusion: combined intrathecal morphine and continuous epidural versus PCA. Journal of Pediatric Orthopedics 2012;32(8):799-804. [PUBMED: 23147623]

\section{Saudan 2008 \{published data only\}}

* Saudan S, Habre W, Ceroni D, Meyer PA, Greenberg RS, Kaelin A, et al. Safety and efficacy of patient controlled epidural analgesia following paediatric spinal surgery. Paediatric Anaesthesia 2008;18(2):132-9. [PUBMED: 18184244]

Saudan S, von Ungern-Sternberg BS, Ceroni D, Meyer PA, Greenberg RS, Kaelin A, et al. Safety and efficacy of patient controlled epidural analgesia following paediatric spine surgery. Paediatric Anaesthesia 2007;17:610-11. [DOI: 10.1111/ j.1460-9592.2007.02255_10.x]

Sekar 2004 \{published data only\}

Sekar C, Rajasekaran S, Kannan R, Reddy S, Shetty TA, Pithwa YK. Preemptive analgesia for postoperative pain relief in lumbosacral spine surgeries: a randomized controlled trial. Spine Journal 2004;4(3):261-4. [PUBMED: 15125846]

Shaw 1996 \{published data only\}

Shaw BA, Watson TC, Merzel DI, Gerardi JA, Birek A. The safety of continuous epidural infusion for postoperative analgesia in pediatric spine surgery. Journal of Pediatric Orthopedics 1996;16(3):374-7. [PUBMED: 8728641]

Sparkes 1989 \{published data only\}

Sparkes ML, Klein AS, Duhaime AC, Mickle JP. Use of epidural morphine for control of postoperative pain in selective dorsal rhizotomy for spasticity. Pediatric Neuroscience 1989;15(5):229-32. [PUBMED: 2488950]

Sucato 2005 \{published data only\}

Sucato DJ, Duey-Holtz A, Elerson E, Safavi F. Postoperative analgesia following surgical correction for adolescent idiopathic scoliosis: a comparison of continuous epidural analgesia and patient-controlled analgesia. Spine 2005;30(2):211-7. [PUBMED: 15644759]

Sundarathiti 2010 \{published data only\}

Sundarathiti P, Pasutharnchat K, Jommaroeng P. Thoracic epidural-general analgesia in scoliosis surgery. Journal of Clinical Anesthesia 2010;22(6):410-4. [PUBMED: 20868960]

Tobias 2001 \{published data only\}

Tobias JD, Gaines RW, Lowry KJ, Kittle D, Bildner C. A dual epidural catheter technique to provide analgesia following posterior spinal fusion for scoliosis in children and adolescents. Paediatric Anaesthesia 2001;11(2):199-203. [PUBMED: 11240879]

\section{Turner 2000 \{published data only\}}

Turner A, Lee J, Mitchell R, Berman J, Edge G, Fennelly M. The efficacy of surgically placed epidural catheters for analgesia after posterior spinal surgery. Anaesthesia 2000;55(4):370-3. [PUBMED: 10781125] 
Van Boerum 2000 \{published data only\}

Van Boerum DH, Smith JT, Curtin MJ. A comparison of the effects of patient-controlled analgesia with intravenous opioids versus Epidural analgesia on recovery after surgery for idiopathic scoliosis. Spine 2000;25(18):2355-7. [PUBMED: 10984788]

\section{References to studies awaiting assessment}

Kick 1995 \{published data only\}

Kick O, Pereon Y, Bernard JM. [Peridurale morphingabe uber den kaudalkanal bei der operativen korrektur von scoliosen]. Anaesthesist 1995;44 (Suppl 1):S91.

\section{References to ongoing studies}

EUCTR2008-001642-19-SE \{published and unpublished data\}

EUCTR2008-001642-19-SE. Perioperative pain management in children and adolescents undergoing scoliosis surgery. Intravenous analgesia with S-ketamine and morphine versus epidural analgesia with fentanyl-bupivacaineepinephrine. Pain, nausea and psychological impact. www.clinicaltrialsregister.eu/ctr-search/trial/2008-001642-19/ SE (first received 27 June 2008).

\section{Additional references}

\section{Agabegi 2015}

Agabegi SS, Kazemi N, Sturm PF, Mehlman CT. Natural history of adolescent idiopathic scoliosis in skeletally mature patients: a critical review. Journal of the American Academy of Orthopaedic Surgeons 2015;23(12):714-23. [PUBMED: 26510624]

\section{Alajmi 2017}

Alajmi T, Saeed H, Alfaryan K, Alakeel A, Alfaryan T. Efficacy of tranexamic acid in reducing blood loss and blood transfusion in idiopathic scoliosis: a systematic review and meta-analysis. Journal of Spine Surgery 2017;3(4):531-40. [PUBMED: 29354728]

\section{Auyong 2017}

Auyong DB, Cantor DA, Green C, Hanson NA. The effect of fixation technique on continuous interscalene nerve block catheter success: a randomized, double-blind trial. Anesthesia and Analgesia 2017;124(3):959-65. [PUBMED: 28151818]

\section{Bernard 1995b}

Bernard JM, Surbled M, Lagarde D, Trennec A. Postoperative analgesia for spine surgery in adults and adolescents [Analgésie après chirurgie du rachis chez l'adulte et l'adolescent]. Cahiers d'Anesthésiologie 1995;43(6):557-64.

\section{Borenstein 2009a}

Borenstein M, Hedges LV, Higgins JP, Rothstein HR. Publication bias. Introduction to Meta-Analysis. 1st Edition. Chichester, UK: Wiley, 2009:277-92.

\section{Borenstein 2009b}

Borenstein M, Hedges LV, Higgins JP, Rothstein HR. Effects size based on means. Introduction to Meta-Analysis. 1st Edition. Chichester, UK: Wiley, 2009:21-32.

\section{Borgeat 2008}

Borgeat A, Blumenthal S. Postoperative pain management following scoliosis surgery. Current Opinion in Anaesthesiology 2008;21(3):313-6. [PUBMED: 18458547]

\section{Brant R}

Brant R. Sample size calculator. www.stat.ubc.ca/ ${ }^{\text {rollin }}$ (accessed 4 April 2017).

\section{Brenn 2004}

Brenn BR, Theroux MC, Dabney KW, Miller F. Clotting parameters and thromboelastography in children with neuromuscular and idiopathic scoliosis undergoing posterior spinal fusion. Spine 2004;29(15):E310-4. [PUBMED: 15284525]

\section{Cates 2016}

Cates C. Visual Rx. www.nntonline.net/visualrx (accessed 4 April 2017).

\section{Center for Disease Control and Prevention 2015}

United States Department of Health and Human Services, Centers for Disease Control and Prevention. Health, United States, 2015. www.cdc.gov (accessed 26 November 2016).

\section{Chua 2016}

Chua K, Tan CY, Chen Z, Wong HK, Lee EH, Tay SK, et al. Longterm follow-up of pulmonary function and scoliosis in patients with Duchenne's muscular dystrophy and spinal muscular atrophy. Journal of Pediatric Orthopedics 2016;36(1):63-9. [PUBMED: 26642076]

\section{Comprehensive Meta-Analysis 2007 [Computer program]}

Meta-Analysis.com. Comprehensive Meta-Analysis. Version 2.2.044 for Windows. Meta-Analysis.com, 2007.

\section{de Mendonca 2016}

de Mendonca RG, Sawyer JR, Kelly DM. Complications after surgical treatment of adolescent idiopathic scoliosis. Orthopedic Clinics of North America 2016;47(2):395-403. [DOI: 10.1016/j.ocl.2015.09.012; PUBMED: 26772948]

\section{De Rojas 2014}

De Rojas JO, Syre P, Welch WC. Regional anesthesia versus general anesthesia for surgery on the lumbar spine: a review of the modern literature. Clinical Neurology and Neurosurgery 2014;119:39-43. [PUBMED: 24635923]

\section{Deeks 2002}

Deeks JJ. Issues in the selection of a summary statistic for metaanalysis of clinical trials with binary outcomes. Statistics in Medicine 2002;21(11):1575-600. [PUBMED: 12111921]

\section{Deeks 2011}

Deeks JJ, Higgins JPT, Altman DG editors. Analysing data and undertaking meta-analyses. Cochrane Handbook for Systematic Reviews of Interventions Version 5.1.0 (updated 
March 2011). The Cochrane Collaboration, 2011:Available from handbook.cochrane.org.

\section{Duval 2000a}

Duval S, Tweedie R. Trim and fill: a simple funnel-plot-based method of testing and adjusting for publication bias in metaanalysis. Biometrics 2000;56(2):455-63. [PUBMED: 10877304]

\section{Duval 2000b}

Duval S, Tweedie R. A nonparametric 'trim and fill' method accounting for publication bias in meta-analysis. Journal of the American Statistical Association 2000;95:89-98.

\section{Floman 1983}

Floman Y, Liebergall M, Robin GC, Eldor A. Abnormalities of aggregation, thromboxane $\mathrm{A} 2$ synthesis, and $14 \mathrm{C}$ serotonin release in platelets of patients with idiopathic scoliosis. Spine 1983;8(3):236-41. [PUBMED: 6623192]

\section{GRADEpro GDT [Computer program]}

McMaster University (developed by Evidence Prime). GRADEpro GDT. Version accessed 6 August 2016. Hamilton (ON): McMaster University (developed by Evidence Prime), 2015.

\section{Gramke 2007}

Gramke HF, de Rijke JM, van Kleef M, Raps F, Kessels AG, Peters ML, et al. The prevalence of postoperative pain in a crosssectional group of patients after day-case surgery in a university hospital. Clinical Journal of Pain 2007;23(6):543-8. [PUBMED: 17575496]

\section{Guay 1994}

Guay J, Haig M, Lortie L, Guertin MC, Poitras B. Predicting blood loss in surgery for idiopathic scoliosis. Journal Canadien d'Anesthesie [Canadian Journal of Anaesthesia] 1994;41(9):775-81. [PUBMED: 7954993]

\section{Guay 2016}

Guay J, Nishimori M, Kopp S. Epidural local anaesthetics versus opioid-based analgesic regimens for postoperative gastrointestinal paralysis, vomiting and pain after abdominal surgery. Cochrane Database of Systematic Reviews 2016, Issue 7. [DOI: 10.1002/14651858.CD001893.pub2; PUBMED: 27419911]

\section{Higgins 2003}

Higgins JP, Thompson SG, Deeks JJ, Altman DG. Measuring inconsistency in meta-analyses. BMJ (Clinical Research Ed.) 2003;327(7414):557-60. [PUBMED: 12958120]

\section{Higgins 2011}

Higgins JP, Green S, editor(s). Cochrane Handbook for Systematic Reviews of Interventions Version 5.1.0 (updated March 2011). The Cochrane Collaboration, 2011. Available from handbook.cochrane.org.

\section{Horlocker 2001}

Horlocker TT, Nuttall GA, Dekutoski MB, Bryant SC. The accuracy of coagulation tests during spinal fusion and instrumentation. Anesthesia and Analgesia 2001;93(1):33-8. [PUBMED: 11429335]

\section{Hudgins 2018}

Hudgins JD, Bacho MA, Olsen KL, Bourgeois FT. Pediatric drug information available at the time of new drug approvals: a cross-sectional analysis. Pharmacoepidemiology and Drug Safety 2018;27(2):161-7. [PUBMED: 29148107]

\section{Jazayeri 2015}

Jazayeri SB, Beygi S, Shokraneh F, Hagen EM, RahimiMovaghar V. Incidence of traumatic spinal cord injury worldwide: a systematic review. European Spine Journal 2015;24(5):905-18. [PUBMED: 24952008]

\section{Lai 2017}

Lai LL, Koh L, Ho JA, Ting A, Obi A. Off-label prescribing for children with migraines in U.S. ambulatory care settings. Journal of Managed Care and Specialty Pharmacy 2017;23(3):382-7. [PUBMED: 28230456]

\section{Loughman 1995}

Loughman BA, Fennelly ME, Henley M, Hall GM. The effects of differing concentrations of bupivacaine on the epidural somatosensory evoked potential after posterior tibial nerve stimulation. Anesthesia and Analgesia 1995;81(1):147-51. [PUBMED: 7598245]

\section{McCarthy 2010}

McCarthy GC, Megalla SA, Habib AS. Impact of intravenous lidocaine infusion on postoperative analgesia and recovery from surgery: a systematic review of randomized controlled trials. Drugs 2010;70(9):1149-63. [PUBMED: 20518581]

\section{McColl 1998}

McColl A, Smith H, White P, Field J. General practitioner's perceptions of the route to evidence based medicine: a questionnaire survey. BMJ 1998;316(7128):361-5. [PUBMED: 9487174]

\section{McNicol 2016}

McNicol ED, Tzortzopoulou A, Schumann R, Carr DB, Kalra A. Antifibrinolytic agents for reducing blood loss in scoliosis surgery in children. Cochrane Database of Systematic Reviews 2016, Issue 9. [DOI: 10.1002/14651858.CD006883.pub3; PUBMED: 27643712]

\section{Meng 2017}

Meng Y, Jiang H, Zhang C, Zhao J, Wang C, Gao R, et al. A comparison of the postoperative analgesic efficacy between epidural and intravenous analgesia in major spine surgery: a meta-analysis. Journal of Pain Research 2017;10:405-15. [PUBMED: 28243145]

\section{Moher 2009}

Moher D, Liberati A, Tetzlaff J, Altman DG, PRISMA Group. Preferred reporting items for systematic reviews and metaanalyses: the PRISMA statement. BMJ 2009;339:b2535. [PUBMED: 19622551]

\section{Morales-Olivas 2006}

Morales-Olivas FJ, Morales-Carpi C. Clinical trials in children. Reviews on Recent Clinical Trials 2006;1(3):251-8. [PUBMED: 18473977] 


\section{Nakai 2011}

Nakai K, Yamamoto K, Tobetto Y, Mita N, Wakamatsu N, Kato $\mathrm{M}$, et al. Transient paraplegia due to epidural hematoma after catheter withdrawal. Masui. The Japanese Journal of Anesthesiology 2011;60(9):1094-6. [PUBMED: 21950045]

\section{Negrini 2015}

Negrini S, Minozzi S, Bettany-Saltikov J, Chockalingam N, Grivas TB, Kotwicki T, et al. Braces for idiopathic scoliosis in adolescents. Cochrane Database of Systematic Reviews 2015, Issue 6. [DOI: 10.1002/14651858.CD006850.pub3; PUBMED: 26086959]

\section{Noordeen 1999}

Noordeen MH, Haddad FS, Muntoni F, Gobbi P, Hollyer JS, Bentley G. Blood loss in Duchenne muscular dystrophy: vascular smooth muscle dysfunction?. Journal of Pediatric Orthopedics. Part B 1999;8(3):212-5. [PUBMED: 10399127]

\section{Pace 2011}

Pace NL. Research methods for meta-analyses. Best Practice and Research. Clinical Anaesthesiology 2011;25(4):523-33. [PUBMED: 22099918]

\section{Pogue 1998}

Pogue J, Yusuf S. Overcoming the limitations of current meta-analysis of randomised controlled trials. Lancet 1998;351(9095):47-52. [PUBMED: 9433436]

\section{Prism 2007 [Computer program]}

GraphPad Software, Inc. Prism. Version 5 for Windows. GraphPad Software, Inc, 2007.

\section{Ran 2016}

Ran B, Fan Y, Yuan F, Guo K, Zhu X. Pulmonary function change and its influencing factors after preoperative brace treatment in patients with adolescent idiopathic scoliosis: a retrospective case-control study. Medicine 2016;95(43):e5088. [PUBMED: 27787360]

\section{Review Manager 2014 [Computer program]}

Nordic Cochrane Centre, The Cochrane Collaboration. Review Manager 5 (RevMan 5). Version 5.3. Copenhagen: Nordic Cochrane Centre, The Cochrane Collaboration, 2014.

\section{Rucker 2011}

Rucker G, Schwarzer G, Carpenter JR, Binder H, Schumacher M. Treatment-effect estimates adjusted for small-study effects via a limit meta-analysis. Biostatistics 2011;12(1):122-42. [DOI: 10.1093/biostatistics/kxq046; PUBMED: 20656692]

\section{Schünemann 2011}

Schünemann HJ, Oxman AD, Vist GE, Higgins JP, Deeks JJ, Glasziou P, et al. Chapter 12 . Interpreting results and drawing conclusions . In: Higgins JP, Green S, editor(s). Cochrane Handbook for Systematic Reviews of Interventions Version
5.1.0 (updated March 2011). The Cochrane Collaboration, 2011. Available from handbook.cochrane.org.

\section{Schünemann 2013}

Schünemann H, Brożek J, Guyatt G, Oxman A, ed(s). Handbook for Grading the Quality of Evidence and the Strength of Recommendations Using the GRADE Approach. Grading of Recommendations, Assessment, Development and Evaluation (GRADE) Working Group, 2013.

\section{Sethna 2010}

Sethna NF, Clendenin D, Athiraman U, Solodiuk J, Rodriguez DP, Zurakowski D. Incidence of epidural catheter-associated infections after continuous epidural analgesia in children. Anesthesiology 2010;113(1):224-32. [DOI: 10.1097/ ALN.0b013e3181de6cc5; PUBMED: 20526185]

\section{Sharma 2012}

Sharma S, Balireddy RK, Vorenkamp KE, Durieux ME. Beyond opioid patient-controlled analgesia: a systematic review of analgesia after major spine surgery. Regional Anesthesia and Pain Medicine 2012;37(1):79-98. [PUBMED: 22030723]

\section{Sud 2013}

Sud A, Tsirikos Al. Current concepts and controversies on adolescent idiopathic scoliosis: part I. Indian Journal of Orthopaedics 2013;47(2):117-28. [PUBMED: 23682172]

\section{Thorlund 2018 [Computer program]}

Thorlund K, Engstrøm J, Wetterslev J, Brok J, Imberger GI, Gluud G. Trial Sequential Analysis. Copenhagen, Denmark: Copenhagen Trial Unit, (accessed 25 August 2018).

\section{Uden 1980}

Uden A, Nilsson IM, Willner S. Collagen changes in congenital and idiopathic scoliosis. Acta Orthopaedica Scandinavica 1980;51(2):271-4. [PUBMED: 7435186]

\section{White 2007}

White PF, Kehlet $\mathrm{H}$. Improving pain management: are we jumping from the frying pan into the fire?. Anesthesia and Analgesia 2007; Vol. 105, issue 1:10-2. [PUBMED: 17578944]

\section{World Health Organization 2013}

World Health Organization. Spinal cord injury. www.who.int (accessed 16 February 2017).

\section{References to other published versions of this review Guay 2017}

Guay J, Suresh S, Kopp S, Johnson RL. Postoperative epidural analgesia versus systemic analgesia for thoraco-lumbar spine surgery in children. Cochrane Database of Systematic Reviews 2017, Issue 10. [DOI: 10.1002/14651858.CD012819]

* Indicates the major publication for the study 
CHARACTERISTICS OF STUDIES

Characteristics of included studies [ordered by study ID]

Blumenthal 2005

Parallel RCT
Ethics committee: approval obtained
Informed consent: written consents obtained
Site: Orthopaedic University Hospital Balgrist, Zurich, Switzerland
Setting: university hospital
Dates of data collection: over 18-month period
Funding: institutional or departmental sources, or both

Participants

30 participants

\section{Inclusion criteria}

ASA 1-3, aged 10-30 years (mean age 17 years), body weight 30-90 kg, body height $130-180 \mathrm{~cm}$, elective idiopathic scoliosis correction with a dorsal approach over at least 7 vertebral levels, no participant had iliac crest bone harvest

\section{Exclusion criteria}

Any contraindication for epidural catheter placement, known allergy to drugs used in the study, drug abuse, pregnancy, cardiac arrhythmia or myocardial infarction within the previous 6 months, preoperative neurological deficit, inability to use a visual analogue scale with a scaled ruler for assessing adequately postoperative pain, incorrect epidural catheter placement, accidental perforation of the dura while placing the epidural catheter, or occurrence of postoperative neurological deficit

No participant had iliac crest bone harvest

Interventions

Intervention: continuous double epidural catheter technique $(n=15)$

Comparator: continuous IV morphine $(n=15)$

\section{Outcomes}

\section{Relevant to this review}

1. Pain at rest and on movement (coughing)

2. Vomiting (number of participants who experienced vomiting from 0 to 48 hours)

3. Bowel function (time to first flatus)

4. Patient satisfaction

\section{Others}

1. Rescue analgesic

2. Pruritus

3. Pulmonary complications defined as respiratory rate $<8$ breaths/minute, oxygen saturation $<92 \%$, or apparent lobar atelectasis on chest radiograph

Rotes
Conflict of interest: none reported
DOI: not available


Blumenthal 2005 (Continued)

Correspondence: email sent 7 October 2017. Authors replied that their data were no longer available.

Additional information requested on 23 February 2018. Authors did not reply.

\section{Risk of bias}

\begin{tabular}{|c|c|c|}
\hline Bias & Authors' judgement & Support for judgement \\
\hline $\begin{array}{l}\text { Random sequence genera- } \\
\text { tion (selection bias) }\end{array}$ & Low risk & $\begin{array}{l}\text { Quote: "prospectively randomized according to a computer randomization } \\
\text { list." }\end{array}$ \\
\hline $\begin{array}{l}\text { Allocation concealment } \\
\text { (selection bias) }\end{array}$ & Unclear risk & Not reported \\
\hline $\begin{array}{l}\text { Blinding of participants } \\
\text { and personnel (perfor- } \\
\text { mance bias) } \\
\text { All outcomes }\end{array}$ & High risk & Quote: "unblinded" \\
\hline $\begin{array}{l}\text { Blinding of outcome as- } \\
\text { sessment (detection bias) } \\
\text { All outcomes }\end{array}$ & High risk & Quote: "unblinded" \\
\hline $\begin{array}{l}\text { Incomplete outcome data } \\
\text { (attrition bias) } \\
\text { All outcomes }\end{array}$ & Low risk & No participants were excluded during the study. \\
\hline $\begin{array}{l}\text { Selective reporting (re- } \\
\text { porting bias) }\end{array}$ & Low risk & All measurement reported \\
\hline Other bias & Low risk & Groups well balanced \\
\hline
\end{tabular}

Blumenthal 2006

\begin{tabular}{ll}
\hline Methods & Parallel RCT \\
Ethics committee: approval obtained \\
Informed consents: written consents obtained \\
Site: Departments of Anesthesiology and Orthopedic Surgery, Balgrist Clinic, and Department of Ortho- \\
pedics, University of Zurich, Zurich, Switzerland \\
Setting: university hospital \\
Dates of data collection: unspecified \\
Funding: no funds received \\
\hline
\end{tabular}

Participants

30 adolescents

\section{Inclusion criteria}

ASA 1-3, aged 11-17 years (mean age 14 years), body weight $30-90 \mathrm{~kg}$, body height $130-180 \mathrm{~cm}$, thoracic idiopathic scoliosis scheduled for anterior correction through thoracotomy approach with the instrumentation of $\geq 6$ vertebral levels

\section{Exclusion criteria}


Blumenthal 2006 (Continued)

Any contraindications for epidural catheter placement, known allergy to the study drugs, drug abuse, preoperative neurological deficit, inability to use a visual analogue scale, incorrect epidural catheter placement including accidental perforation of the dura, and postoperative neurological deficit

Interventions

Intervention: continuous double epidural catheter technique $(\mathrm{n}=15)$

Comparator: continuous IV morphine $(n=15)$

\begin{tabular}{|c|c|}
\hline Outcomes & $\begin{array}{l}\text { Relevant to this review } \\
\text { 1. Pain at rest and on movement (coughing) } \\
\text { 2. Vomiting (number of participants who experienced vomiting from } 0 \text { to } 48 \text { hours) } \\
\text { 3. Bowel function (time to first flatus) } \\
\text { 4. Patient satisfaction } \\
\text { Others } \\
\text { 1. Rescue analgesic } \\
\text { 2. Pruritus } \\
\text { 3. Pulmonary complications defined as oxygen saturation }<92 \% \text { or lobar atelectasis on chest radiograph }\end{array}$ \\
\hline Notes & $\begin{array}{l}\text { Registration: not reported } \\
\text { Conflict of interest: no benefits in any form have been or will be received from a commercial party relat- } \\
\text { ed directly or indirectly to the subject of this manuscript. } \\
\text { DOI: N/A } \\
\text { Correspondence: Email sent } 8 \text { October } 2017 \text {, reply received } 24 \text { October } 2017 \text {. Additional information re- } \\
\text { quested on } 23 \text { February } 2018 \text {. Authors did not reply. }\end{array}$ \\
\hline
\end{tabular}

\section{Risk of bias}

\begin{tabular}{|c|c|c|}
\hline Bias & Authors' judgement & Support for judgement \\
\hline $\begin{array}{l}\text { Random sequence genera- } \\
\text { tion (selection bias) }\end{array}$ & Low risk & $\begin{array}{l}\text { Randomized to either the IV morphine group or the epidural catheter group us- } \\
\text { ing computer randomization program. }\end{array}$ \\
\hline $\begin{array}{l}\text { Allocation concealment } \\
\text { (selection bias) }\end{array}$ & Unclear risk & Not reported \\
\hline $\begin{array}{l}\text { Blinding of participants } \\
\text { and personnel (perfor- } \\
\text { mance bias) } \\
\text { All outcomes }\end{array}$ & Unclear risk & Not reported \\
\hline $\begin{array}{l}\text { Blinding of outcome as- } \\
\text { sessment (detection bias) } \\
\text { All outcomes }\end{array}$ & Low risk & $\begin{array}{l}\text { Data collection was done by a research nurse not involved in and not aware of } \\
\text { the aim of the study. }\end{array}$ \\
\hline $\begin{array}{l}\text { Incomplete outcome data } \\
\text { (attrition bias) } \\
\text { All outcomes }\end{array}$ & Low risk & No loss to follow-up \\
\hline $\begin{array}{l}\text { Selective reporting (re- } \\
\text { porting bias) }\end{array}$ & Low risk & All results reported \\
\hline Other bias & Low risk & Groups well balanced \\
\hline
\end{tabular}




Methods
Ethics committee: not reported
Informed consent: not reported
Site: Department of Anesthesiology and Intensive Care Unit, Ankara University, Faculty of Medicine,
Ankara, Turkey
Setting: university hospital
Dates of data collection: unspecified
Funding: unspecified

\begin{tabular}{ll}
\hline Participants & 30 participants \\
Inclusion criteria \\
Adolescents with idiopathic scoliosis \\
Exclusion criteria \\
Not reported
\end{tabular}

Interventions Intervention: preoperative segmental epidural analgesia (single injection) plus wound infiltration plus
IV PCA with morphine $(\mathrm{n}=15)$

Comparator: IV PCA with morphine $(\mathrm{n}=15)$

Outcomes

\section{Relevant to this review}

1. Pain scores at rest and on movement

2. Patient satisfaction

\section{Others}

1. Rescue analgesia

2. Sleep quality

Rotes
Conflict of interest: not reported
DOI: N/A
Conference abstract only
Correspondence: email sent 9 October 2017, no reply received. Additional information requested on 23
February 2018. Authors did not reply.

\section{Risk of bias}

\begin{tabular}{lll}
\hline Bias & Authors' judgement & Support for judgement \\
\hline $\begin{array}{l}\text { Random sequence genera- } \\
\text { tion (selection bias) }\end{array}$ & Unclear risk & Quote: "randomized;" no details \\
\hline $\begin{array}{l}\text { Allocation concealment } \\
\text { (selection bias) }\end{array}$ & Unclear risk & Not reported \\
\hline
\end{tabular}


Cakar Turhan 2011 (Continued)
Blinding of participants
Low risk
Quote: "double blind study" and personnel (perfor- mance bias)
All outcomes

\begin{tabular}{lll}
\hline $\begin{array}{l}\text { Blinding of outcome as- } \\
\text { sessment (detection bias) } \\
\text { All outcomes }\end{array}$ & Low risk & Quote: "double blind study" \\
\hline $\begin{array}{l}\text { Incomplete outcome data } \\
\text { (attrition bias) } \\
\text { All outcomes }\end{array}$ & Low risk & No loss to follow-up reported \\
\hline $\begin{array}{l}\text { Selective reporting (re- } \\
\text { porting bias) }\end{array}$ & Low risk & Results reported in the method section were reported in the results section \\
\hline $\begin{array}{l}\text { Other bias } \\
\end{array}$ & Unclear risk & $\begin{array}{l}\text { Few details available, conference abstract. Wound infiltration at the end of } \\
\text { surgery for the epidural group only. }\end{array}$ \\
\hline
\end{tabular}

Cassady 2000

Parallel RCT
Ethics committee: approved by the Nemours Children's Clinic Clinical Research Review Committee and
the Baptist Medical Center Institutional Review Board.
Informed consent: each participant gave written assent for participation in the investigation. Written
informed
consent was obtained from each patient's parent or legal guardian.
Site: Wolfson Children's Hospital, Jacksonville, FL
Setting: university hospital
Dates of data collection: unspecified
Funding: supported by the Nemours Foundation. One study author was working for Ancile Pharmaceu-
ticals (DDC), San Diego, CA, USA

\section{Participants}

33 participants

\section{Inclusion criteria}

ASA 1 or 2, aged 11-18 years with idiopathic scoliosis scheduled for elective posterior spinal fusion

\section{Exclusion criteria}

Coexisting haematological, cardiac, gastrointestinal, neurological, psychiatric, or pulmonary diseases; or a history of allergy to any of the study medications

Interventions

Intervention: epidural analgesia $(n=17)$
Comparator: IV PCA with morphine $(n=16)$

Premedication: midazolam, either $0.5 \mathrm{mg} / \mathrm{kg}$ orally or $0.1-0.2 \mathrm{mg} / \mathrm{kg} \mathrm{IV}$, before entering the operating room

Induction: sodium thiopental $4-5 \mathrm{mg} / \mathrm{kg}$ or propofol $2-3 \mathrm{mg} / \mathrm{kg}$ and a non-depolarizing muscle relaxant, i.e. either vecuronium $0.1 \mathrm{mg} / \mathrm{kg}$ or pancuronium $0.1 \mathrm{mg} / \mathrm{kg}$ 


Relevant to this review
Outcomes
$\begin{aligned} & \text { 1. Pain scores (a } 0 \text { score was attributed when the participant was asleep; values taken at rest) } \\ & \text { 3. Return of gastrointestinal function } \\ & \text { 4. Respiratory depression (airway obstruction or respiratory rate }<10 \text { breaths/minute or pulse oximetry } \\ & \leq 94 \% \text { despite oxygen administration at } 2 \mathrm{~L} / \text { minute) }\end{aligned}$

\section{Others}

1. Analgesic requirement

2. Transfusion requirement

Notes
Conflict of interest: not reported
DOI: $10.1053 / x r .2000 .5661$
Correspondence: Joseph R Cassady Jr, MD, Department of Anesthesiology and Critical Care Medicine,
Nemours Children's Clinic, 807 Nra St, Jacksonville, FL 32207. E-mail: jcassady@nemours.org. Addition-
al information requested on 23 February 2018. Invalid email address. Letter sent on 23 February 2018.
Authors did not reply.

\section{Risk of bias}

\begin{tabular}{lll}
\hline Bias & Authors' judgement & Support for judgement \\
\hline $\begin{array}{l}\text { Random sequence genera- } \\
\text { tion (selection bias) }\end{array}$ & Low risk & Quote: "randomized by use of random numbers table" \\
\hline $\begin{array}{l}\text { Allocation concealment } \\
\text { (selection bias) }\end{array}$ & Unclear risk & Not reported \\
\hline $\begin{array}{l}\text { Blinding of participants } \\
\begin{array}{l}\text { and personnel (perfor- } \\
\text { mance bias) } \\
\text { All outcomes }\end{array}\end{array}$ & High risk & Quote: "nonblinded" \\
\hline
\end{tabular}

$\begin{array}{lll}\text { Blinding of outcome as- } & \text { High risk } & \text { Quote: "nonblinded" } \\ \text { sessment (detection bias) } & & \\ \text { All outcomes } & \end{array}$

Incomplete outcome data Low risk

(attrition bias)

All outcomes

\begin{abstract}
3 participants assigned to receive epidural analgesia and 1 participant receiving IV PCA were withdrawn from the study.

Among the epidural group, 1 participant was judged by a member of the medical staff as too somnolent for safe initiation of the epidural bupivacaine-fentanyl infusion until approximately 2 hours after the required time, thus prohibiting initial data collection and introducing a major protocol violation. The second participant refused to comply with data collection postoperatively by rejecting the pain scale. The third participant had the epidural catheter removed in the postanaesthesia care unit at the request of her surgeon for a transient unilateral upper extremity neurological deficit that subsequently proved unrelated to analgesic therapy.
\end{abstract}

The participant in the IV PCA group withdrew because of postoperative noncompliance with patient-controlled instructions. 
Cassady 2000 (Continued)
Selective reporting (re-
All results reported porting bias)

Other bias

Unclear risk

Not by intention-to-treat

Number of fused vertebrae was 12.1 for epidural group and 10.4 for systemic analgesia

Ezhevskaya 2012a

$\begin{array}{ll}\text { Methods } & \text { Parallel RCT } \\ & \text { Ethics committee: not reported } \\ \text { Informed consent: not reported } \\ \text { Site: not reported } \\ \text { Setting: university hospital } \\ \text { Dates of data collection: not reported } \\ \text { Funding: unspecified }\end{array}$

Participants 135 participants aged $12-25$ years with idiopathic scoliosis undergoing posterior spinal fusion and in-
strumentation

\section{Inclusion criteria}

Deformities Grade III or IV

\section{Exclusion criteria}

Not reported

\begin{tabular}{ll}
\hline Interventions & Intervention: epidural analgesia $(\mathrm{n}=70)$ \\
Comparator: IV PCA with opioids $(\mathrm{n}=65)$ \\
Maintenance: sevoflurane and fentanyl
\end{tabular}

Outcomes

\section{Relevant to this review}

1. Pain scores

2. Return of gastrointestinal function

3. Satisfaction

\section{Others}

1. Blood loss

2. Haemodynamic parameters

$\begin{array}{ll}\text { Notes } & \text { Registration: unspecified } \\ \text { Conflict of interest: not reported } & \\ \text { DOI: not reported } \\ \text { Correspondence: Anna A Ezhevskaya, MD, Department of Anesthesiology and Reanimation, Nizhny } \\ \text { Novgorod Research Institute of Traumatology and Orthopedics, 18 Verhne-Voljskaya naberejnaya, } \\ \text { Nizhny Novgorod, Russia, 603155; E-mail: annaezhe@yandex.ru }\end{array}$


Ezhevskaya 2012a (Continued)

Email sent 22 January 2018, no reply received. Additional information requested on 23 February 2018. Authors did not reply

\section{Risk of bias}

\begin{tabular}{lll}
\hline Bias & Authors' judgement & Support for judgement \\
\hline $\begin{array}{l}\text { Random sequence genera- } \\
\text { tion (selection bias) }\end{array}$ & Unclear risk & Quote: "prospectively randomized", no details \\
\hline $\begin{array}{l}\text { Allocation concealment } \\
\text { (selection bias) }\end{array}$ & Unclear risk & Not reported \\
\hline $\begin{array}{l}\text { Blinding of participants } \\
\text { and personnel (perfor- } \\
\text { mance bias) } \\
\text { All outcomes }\end{array}$ & Unclear risk & Not reported \\
\hline $\begin{array}{l}\text { Blinding of outcome as- } \\
\text { sessment (detection bias) }\end{array}$ & Unclear risk & Not reported \\
All outcomes & \\
\hline $\begin{array}{l}\text { Incomplete outcome data } \\
\text { (attrition bias) } \\
\text { All outcomes }\end{array}$ & Unclear risk & Unclear; groups unequal (45 vs 35), no explanation provided \\
\hline $\begin{array}{l}\text { Selective reporting (re- } \\
\text { porting bias) }\end{array}$ & Unclear risk & Conference abstract; no numbers provided \\
\hline \begin{tabular}{l} 
Other bias \\
\hline
\end{tabular} & Unclear risk & No details on group characteristics \\
\hline
\end{tabular}

\section{Ezhevskaya 2015}

\begin{tabular}{ll}
\hline Methods & Parallel RCT \\
Ethics committee: not reported \\
Informed consent: not reported \\
Site: not reported \\
Setting: university hospital \\
Dates of data collection \\
Funding: unspecified \\
\hline
\end{tabular}

\section{Participants}

115 participants, aged 15-18 years undergoing scoliosis surgery

\section{Inclusion criteria}

Not reported

\section{Exclusion criteria}

Not reported 
Comparator: systemic analgesia with ( $\mathrm{n}=$ unspecified) or without tranexamic acid $(\mathrm{n}=$ unspecified $)$

General anaesthesia with sevoflurane

Outcomes Relevant to this review

1. Complications

\section{Others}

1. Blood loss

Rogistration: unspecified
Conflict of interest: not reported
DOI: N/A
Correspondence: Anna A Ezhevskaya, MD, Department of Anesthesiology and Reanimation, Nizhny
Novgorod Research Institute of Traumatology and Orthopedics, 18 Verhne-Voljskaya naberejnaya,
Nizhny Novgorod, Russia, 603155; E-mail: annaezhe@yandex.ru
Email sent to authors 22 January 2018. Text of abstract received from authors. Additional information
requested 23 February 2018. Authors did not reply

\section{Risk of bias}

\begin{tabular}{|c|c|c|}
\hline Bias & Authors' judgement & Support for judgement \\
\hline $\begin{array}{l}\text { Random sequence genera- } \\
\text { tion (selection bias) }\end{array}$ & Unclear risk & Quote: "randomized," no details \\
\hline $\begin{array}{l}\text { Allocation concealment } \\
\text { (selection bias) }\end{array}$ & Unclear risk & Not reported \\
\hline $\begin{array}{l}\text { Blinding of participants } \\
\text { and personnel (perfor- } \\
\text { mance bias) } \\
\text { All outcomes }\end{array}$ & Low risk & Quote: "double-blind study" \\
\hline $\begin{array}{l}\text { Blinding of outcome as- } \\
\text { sessment (detection bias) } \\
\text { All outcomes }\end{array}$ & Low risk & Quote: "double-blind study" \\
\hline $\begin{array}{l}\text { Incomplete outcome data } \\
\text { (attrition bias) } \\
\text { All outcomes }\end{array}$ & Low risk & No loss to follow-up reported \\
\hline $\begin{array}{l}\text { Selective reporting (re- } \\
\text { porting bias) }\end{array}$ & Low risk & Conference abstract reporting on blood loss \\
\hline Other bias & Low risk & $\begin{array}{l}\text { No failed epidural reported } \\
\text { No details on demographic data provided }\end{array}$ \\
\hline
\end{tabular}

\section{Gauger 2009}

Methods Parallel RCT


Ethics committee: approved by Institutional Review Board

Informed consent: written informed consent obtained from parents or guardians, and oral assent obtained from participant

Site: University of Michigan Health Systems, Ann Arbor, MI, USA

Setting: university hospital

Dates of data collection: between August 2003 and June 2006

Funding: unspecified

\begin{tabular}{ll}
\hline Participants & 38 participants \\
Inclusion criteria \\
ASA 1 or 2, aged 8-18 years undergoing posterior spinal fusion for idiopathic scoliosis \\
Exclusion criteria \\
Unspecified \\
Intervention: epidural analgesia ( $=19)$ \\
Comparator: IV PCA ( $=19)$ \\
Premedication: oral acetaminophen (paracetamol; $15 \mathrm{mg} / \mathrm{kg} ;$ maximum $650 \mathrm{mg}$ ) plus midazolam at the \\
discretion of the attending physician \\
Induction: sevoflurane \\
Maintenance: nitrous oxide, isoflurane, propofol, and sufentanil \\
Aprotinin
\end{tabular}

Outcomes

\section{Relevant to this review}

1. Pain scores

2. Vomiting

3. Satisfaction (number of participants satisfied with the technique)

\section{Others}

1. Analgesic requirements

2. Muscle spasms ( $8 \%$ of participants who received epidural analgesia experienced moderate-to-severe spasms through postoperative day 3 compared with $35 \%$ of participants in the IV group $(P>0.05) .7$ (58\%) participants in the epidural analgesia group and $17(100 \%)$ participants in the systemic analgesia group required diazepam $(P=0.007)$.

Notes

Registration: not reported
Conflict of interest: not reported

DOI: 10.1097/BPO.0b013e3181b2ba08

Correspondence: Michelle S Caird, MD, Department of Orthopaedic Surgery, Pediatric Orthopaedics Service, 1500 E. Medical Center Dr Ann Arbor, MI 48109; E-mail: sugiyama@med.umich.edu.

Email sent 13 January 2018, no reply received. Additional information requested 23 February 2018. Authors did not reply

\section{Risk of bias}


Gauger 2009 (Continued)

\begin{tabular}{lll} 
Bias & Authors' judgement & Support for judgement \\
\hline $\begin{array}{l}\text { Random sequence genera- } \\
\text { tion (selection bias) }\end{array}$ & Low risk & Quote: "using a random numbers table" \\
\hline $\begin{array}{l}\text { Allocation concealment } \\
\text { (selection bias) }\end{array}$ & Unclear risk & Not reported
\end{tabular}

\begin{tabular}{|c|c|c|}
\hline $\begin{array}{l}\text { Blinding of participants } \\
\text { and personnel (perfor- }\end{array}$ & High risk & $\begin{array}{l}\text { Quote: "findings from this study may have been limited by our inability to } \\
\text { blind patients or care providers to the study group assignment." }\end{array}$ \\
\hline
\end{tabular}

All outcomes

\begin{tabular}{ll}
\hline Blinding of outcome as- & High risk
\end{tabular}

All outcomes

$\begin{array}{lll}\begin{array}{l}\text { Incomplete outcome data } \\ \text { (attrition bias) } \\ \text { All outcomes }\end{array} & \text { Low risk } & \begin{array}{l}43 \text { participants enrolled in this study. However, } 2 \text { participants with neuromus- } \\ \text { cular scoliosis were inadvertently recruited and } 3 \text { in the epidural group never } \\ \text { had an epidural catheter placed (1 due to intraoperative bleeding, } 1 \text { due to in- } \\ \text { traoperative hypotension, and } 1 \text { where the catheter could not be advanced). } \\ \text { These participants were excluded from the study, leaving } 19 \text { participants each } \\ \text { in the epidural and IV groups. }\end{array} \\ & \begin{array}{l}7 \text { participants in the epidural analgesia group (37\%) experienced early epidur- } \\ \text { al failure, and } 2 \text { in the IV PCA group remained intubated, sedated, and ventilat- } \\ \text { ed for several hours postoperatively; these participants were included in the } \\ \text { intention-to-treat analysis. }\end{array} \\ & \text { All results reported } \\ \begin{array}{l}\text { Selective reporting (re- } \\ \text { porting bias) }\end{array} & \text { Low risk }\end{array}$

\begin{tabular}{ll}
\hline Other bias & Unclear risk \\
& Quote: "all data are presented as "per protocol" unless otherwise specified."
\end{tabular}

\section{Klatt 2013}

Parallel RCT
Ethics committee: approval obtained
Informed consent: informed consents obtained
Site: Primary Children's Medical Center, Salt Lake City, University of Utah School of Medicine, Salt Lake
City, UT, USA
Setting: university hospital
Dates of data collection: 2009-2011
Funding: departmental "no funds were received in support of this work."

Participants

60 participants

\section{Inclusion criteria}

Aged 10-21 years; body weight 30-90 kg 
Klatt 2013 (Continued)

\title{
Exclusion criteria
}

Contraindications to epidural catheter placement, known allergy to study drugs, history of drug abuse, pregnancy, cardiac arrhythmia, or neurological deficit

Interventions

Intervention: single catheter epidural analgesia $(n=21)$ or double catheter technique $(n=18)$

Comparator: IV analgesia $(\mathrm{n}=21)$

Premedication: participants who required preoperative anxiolysis received midazolam $0.5 \mathrm{mg} / \mathrm{kg}$ (up to a maximum of $15 \mathrm{mg}$ ) orally or $2 \mathrm{mg}$ IV

Induction: propofol, lidocaine, fentanyl, and rocuronium

Maintenance: desflurane or propofol and fentanyl

Nausea and vomiting prophylaxis with dexamethasone $4 \mathrm{mg}$ and ondansetron $4 \mathrm{mg}$

\section{Outcomes}

\section{Relevant to this review}

\author{
1. Pain scores \\ 2. Vomiting \\ 3. Return of gastrointestinal function \\ 4. Time to first mobilization \\ 5. Hospital length of stay
}

\section{Others}

1. Analgesic requirements

Rogistration: not registered
Conflict of interest: "relevant financial activities outside the submitted work: board membership, con-
sultancy, royalties"
DOI: $10.1097 /$ BRS.0b013e31829cab0b
Correspondence: Joshua WB Klatt, MD, Department of Orthopaedic Surgery, University of Utah School
of Medicine, Primary Children's Medical Center, 100 N Mario Capecchi Dr, Ste 4550, Salt Lake City, UT
84113; E-mail: joshua.klatt@hsc.utah.edu
Email sent 20 January 2018, additional information received 22 and 28 January 2018. Additional infor-
mation requested 23 February 2018, response received 23 February 2018

\section{Risk of bias}

\begin{tabular}{lll}
\hline Bias & Authors' judgement & Support for judgement \\
\hline $\begin{array}{l}\text { Random sequence genera- } \\
\text { tion (selection bias) }\end{array}$ & Low risk & Quote: "randomized using a random number generator" \\
\hline $\begin{array}{l}\text { Allocation concealment } \\
\text { (selection bias) }\end{array}$ & Unclear risk & Quote: "randomized using a random number generator" \\
\hline $\begin{array}{l}\text { Blinding of participants } \\
\text { and personnel (perfor- } \\
\text { mance bias) }\end{array}$ & High risk & Quote: "unblinded" \\
$\begin{array}{l}\text { All outcomes } \\
\begin{array}{l}\text { Blinding of outcome as- } \\
\text { sessment (detection bias) }\end{array}\end{array}$ & High risk & Quote: "unblinded" \\
\end{tabular}


Klatt 2013 (Continued)

All outcomes

$\begin{array}{ll}\begin{array}{l}\text { Incomplete outcome data } \\ \text { (attrition bias) }\end{array} & \begin{array}{l}6 \text { participants were withdrawn due to the inability to maintain the pain man- } \\ \text { agement protocol }(n=4) \text { or epidural leak }(n=2)\end{array}\end{array}$

All outcomes

agement protocol $(n=4)$ or epidural leak $(n=2)$

\begin{tabular}{|c|c|c|}
\hline $\begin{array}{l}\text { Selective reporting (re- } \\
\text { porting bias) }\end{array}$ & Low risk & All results reported \\
\hline Other bias & Unclear risk & $\begin{array}{l}\text { Not in intention-to-treat: } 3 \text { of the withdrawn participants mistakenly received } \\
\text { alternate modes of pain management, whereas } 1 \text { (withdrawn due to a proto- } \\
\text { col deviation) continued on the same mode; however, the protocol regimen } \\
\text { was modified. }\end{array}$ \\
\hline
\end{tabular}

\section{Malviya 1999}

Parallel RCT
Ethics committee: approved by the University of Michigan Institutional Review Board
Informed consent: written informed consents obtained from parents
Site: CS Mott Children's Hospital, Ann Harbor, MI, USA
Setting: university hospital
Dates of data collection
Funding: departmental

Participants 27 participants

\section{Inclusion criteria}

Aged 2-14 years with spastic cerebral palsy scheduled for posterior selective rhizotomy

\section{Exclusion criteria}

Scheduled for multiple procedures

Intervention: epidural analgesia $(\mathrm{n}=13)$
Comparator: IV analgesia $(\mathrm{n}=14)$
Induction and maintenance: halothane
Maintenance: nitrous oxide and isoflurane
Rectal acetaminophen (paracetamol)

\section{Outcomes}

\section{Relevant to this review}

1. Pain scores

2. Vomiting

3. Return of gastrointestinal function measured as: time to first liquid ingestion (hours) and time to first solid food ingestion (hours)

4. Parent satisfaction

\section{Others}


Malviya 1999 (Continued)

1. Respiratory depression

2. Muscles spasms

3. Activity tolerance

Rotes
Conflict of interest: unspecified
DOI: N/A
Correspondence: Shobha Malviya, MD, Department of Anesthesiology, CS Mott Children's Hospital,
F3900/Box 0211, 1500 E Medical Center Drive, Ann Arbor, MI 48109-0211, USA. Email: smalviya@u-
mich.edu. Additional information requested 23 February 2018. Authors did not reply

\section{Risk of bias}

\begin{tabular}{|c|c|c|}
\hline Bias & Authors' judgement & Support for judgement \\
\hline $\begin{array}{l}\text { Random sequence genera- } \\
\text { tion (selection bias) }\end{array}$ & Unclear risk & Quote: "randomly assigned," no details \\
\hline $\begin{array}{l}\text { Allocation concealment } \\
\text { (selection bias) }\end{array}$ & Unclear risk & Not reported \\
\hline $\begin{array}{l}\text { Blinding of participants } \\
\text { and personnel (perfor- } \\
\text { mance bias) } \\
\text { All outcomes }\end{array}$ & Unclear risk & Not reported \\
\hline $\begin{array}{l}\text { Blinding of outcome as- } \\
\text { sessment (detection bias) } \\
\text { All outcomes }\end{array}$ & Unclear risk & $\begin{array}{l}\text { These nurses, blinded to the method of analgesia and to the bedside nurses' } \\
\text { assessments, scored the child's pain during each segment using the FLACC be- } \\
\text { havioural tool. scores were later correlated with the bedside nurse's FLACC } \\
\text { scores to determine the reliability of the bedside assessment of pain. }\end{array}$ \\
\hline $\begin{array}{l}\text { Incomplete outcome data } \\
\text { (attrition bias) } \\
\text { All outcomes }\end{array}$ & Low risk & $\begin{array}{l}2 \text { participants in the epidural group excluded because } 1 \text { had received intraop- } \\
\text { erative IV opioids and in } 1 \text {, the epidural catheter became dislodged on the first } \\
\text { postoperative day }\end{array}$ \\
\hline $\begin{array}{l}\text { Selective reporting (re- } \\
\text { porting bias) }\end{array}$ & Low risk & All results reported \\
\hline Other bias & Low risk & $\begin{array}{l}\text { No failed epidural reported } \\
\text { Groups well balanced }\end{array}$ \\
\hline
\end{tabular}

\section{O'Hara 2004}

$\begin{array}{ll}\text { Methods } & \text { Parallel RCT } \\ & \text { Ethics committee: institutional research board approval obtained } \\ \text { Informed consent: written informed consents obtained } \\ \text { Site: The Cleveland Clinic Foundation, Cleveland, OH, USA } \\ \text { Setting: university hospital } \\ \text { Dates of data collection: approximately 1998-2002 }\end{array}$


O'Hara 2004 (Continued)

Funding: departmental resources

Participants

31 ASA 1 or 2 adolescents/young adults aged 13-21 years scheduled for elective posterior spinal fusion for idiopathic scoliosis

\section{Inclusion criteria}

Able to participate in visual analogue scale evaluations

\section{Exclusion criteria}

Anaesthetic or opioid allergy; history of chemical dependency; non-ambulatory status; participants with coexisting haematological, cardiac, gastrointestinal, neurological, psychiatric, or pulmonary disease

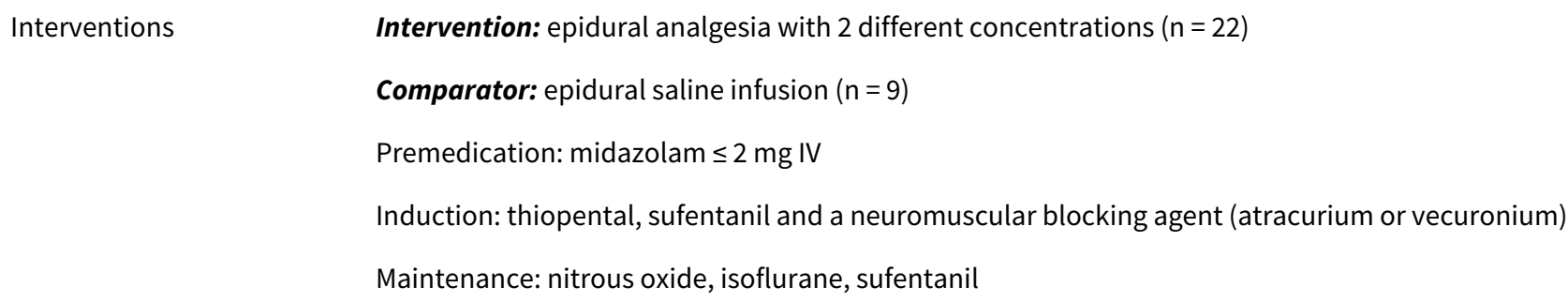

\section{Outcomes}

\section{Relevant to this review}

1. Pain scores

2. Return of gastrointestinal function measured as: time to first liquid ingestion (hours) and time to first solid food ingestion (hours)

3. Time to first mobilization

4. Hospital length of stay (days)

\section{Others}

1. Time ambulate

Notes $\begin{aligned} & \text { Registration: not registered outside the institution } \\ & \text { Conflict of interest: none } \\ & \text { DOI: } 10.1111 / \text { j.1460-9592.2004.01387.x } \\ & \text { Correspondence: Jerome F O'Hara, Department of General Anesthesiology/E31, Cleveland Clinic Foun- } \\ & \text { dation, } 9500 \text { Euclid Avenue, Cleveland, OH 44195, USA (email: oharaj@ccf.org). Additional information } \\ & \text { requested on } 23 \text { February 2018. Response received } 1 \text { March } 2018\end{aligned}$

\section{Risk of bias}

\begin{tabular}{lll}
\hline Bias & Authors' judgement & Support for judgement \\
\hline $\begin{array}{l}\text { Random sequence genera- } \\
\text { tion (selection bias) }\end{array}$ & Low risk & $\begin{array}{l}\text { Quote: "using a random numbers table, patients were assigned to one of the } \\
\text { three groups." }\end{array}$ \\
\hline $\begin{array}{l}\text { Allocation concealment } \\
\text { (selection bias) }\end{array}$ & Low risk & Quote: "was blinded" \\
\hline $\begin{array}{l}\text { Blinding of participants } \\
\begin{array}{l}\text { and personnel (perfor- } \\
\text { mance bias) }\end{array}\end{array}$ & Low risk \\
\begin{tabular}{l} 
All outcomes \\
\hline
\end{tabular}
\end{tabular}


O'Hara 2004 (Continued)
Blinding of outcome as-
Low risk
Quote: "double-blinded" sessment (detection bias)

All outcomes

$\begin{array}{ll}\begin{array}{l}\text { Incomplete outcome data } \\ \text { (attrition bias) }\end{array} & \text { Low risk } \\ \text { All outcomes } & \begin{array}{l}36 \text { participants enrolled: epidural catheter could not be inserted for } 2 \text { partici- } \\ \text { pants; } 1 \text { participant had severe respiratory depression postoperatively; } 1 \text { par- } \\ \text { ticipant emerged from anaesthesia with lower extremity paralysis, and } 1 \text { par- } \\ \text { ticipant had incomplete data collection. }\end{array}\end{array}$

Selective reporting (re- Low risk All results reported

porting bias)

\begin{tabular}{ll}
\hline Other bias & Not in intention-to-treat \\
& Groups comparable for demographic characteristics \\
\hline
\end{tabular}

\section{Ozturk Mamik 2011}

\begin{tabular}{ll}
\hline Methods & Parallel RCT \\
Ethics committee: not reported \\
Informed consent: not reported \\
Site: not reported \\
Setting: unspecified \\
Dates of data collection: unspecified \\
Funding: unspecified \\
\hline
\end{tabular}

\section{Participants}

30 participants

\section{Inclusion criteria}

Adolescents with idiopathic scoliosis undergoing posterior spinal fusion

\section{Exclusion criteria}

Not reported

\begin{tabular}{ll}
\hline Interventions & Intervention: epidural analgesia $(n=15)$ \\
Comparator: IV PCA $(n=15)$
\end{tabular}

\section{Outcomes Relevant to this review}

1. Pain scores

\section{Others}

1. Analgesic requirements

2. Haemodynamic parameters

Rogistration: unspecified
Conflict of interest: not reported
DOI: not reported


Ozturk Mamik 2011 (Continued)

Correspondence: contact information not provided in the conference abstract

\section{Risk of bias}

\begin{tabular}{|c|c|c|}
\hline Bias & Authors' judgement & Support for judgement \\
\hline $\begin{array}{l}\text { Random sequence genera- } \\
\text { tion (selection bias) }\end{array}$ & Unclear risk & Quote: "randomized: no details" \\
\hline $\begin{array}{l}\text { Allocation concealment } \\
\text { (selection bias) }\end{array}$ & Unclear risk & Not reported \\
\hline $\begin{array}{l}\text { Blinding of participants } \\
\text { and personnel (perfor- } \\
\text { mance bias) } \\
\text { All outcomes }\end{array}$ & Low risk & Quote: "double blind study" \\
\hline $\begin{array}{l}\text { Blinding of outcome as- } \\
\text { sessment (detection bias) } \\
\text { All outcomes }\end{array}$ & Low risk & Quote: "double blind study" \\
\hline $\begin{array}{l}\text { Incomplete outcome data } \\
\text { (attrition bias) } \\
\text { All outcomes }\end{array}$ & Low risk & No loss to follow-up \\
\hline $\begin{array}{l}\text { Selective reporting (re- } \\
\text { porting bias) }\end{array}$ & Low risk & All results reported \\
\hline Other bias & Low risk & $\begin{array}{l}\text { No failed epidural reported } \\
\text { Groups were comparable for demographic data. }\end{array}$ \\
\hline
\end{tabular}

ASA: American Society of Anesthesiologists, DOI: Digital Object Identifier, FLACC: Faces, Legs, Activity, Cry, Consolability pain scores, IV: intravenous, n: number of participants; N/A: not available, PCA: patient-controlled analgesia; RCT: randomized controlled trial.

Characteristics of excluded studies [ordered by study ID]

\begin{tabular}{ll}
\hline Study & Reason for exclusion \\
\hline Adu-Gyamfi 1995 & Different study design: not randomized \\
\hline Aizenberg 2011 & Different study design: not randomized \\
\hline Akin Takmaz 2011 & $\begin{array}{l}\text { Different intervention. Compared continuous infusion vs patient-controlled analgesia in people } \\
\text { with epidural analgesia with 2 catheters }\end{array}$ \\
\hline Amaranath 1989 & Different study design: not randomized \\
\hline Arms 1998 & Different study design. All participants had epidural analgesia \\
\hline Bernard $1995 a$ & Different population. Study on "young adults" \\
\hline Cohen 2017 & Different intervention. Comparison of intrathecal morphine vs epidural morphine \\
\hline Ekatodramis 2002 & Different study design. All participants had epidural analgesia \\
\hline
\end{tabular}




\begin{tabular}{ll}
\hline Study & Reason for exclusion \\
\hline Erdogan 2017 & $\begin{array}{l}\text { Different intervention. Compared patient-controlled intermittent bolus epidural analgesia and pa- } \\
\text { tient-controlled continuous epidural analgesia for postoperative pain control in adolescent idio- } \\
\text { pathic scoliosis }\end{array}$ \\
\hline
\end{tabular}

\begin{tabular}{ll} 
Eshevskaya 2013 & Different intervention. All participants had epidural analgesia after surgery \\
\hline Ezhevskaya 2012b & Different study design. Possibly a retrospective study \\
\hline Ezhevskaya 2012c & $\begin{array}{l}\text { Different study design. Not randomized. Quote: "all patients were divided into two groups. Group E } \\
(\mathrm{N}=105) \text { had epidural analgesia (ropivacaine, fentanyl, and epinephrine) and endotracheal anaes- } \\
\text { thesia with sevoflurane during surgery and continuous epidural analgesia with ropivacaine, fen- } \\
\text { tanyl and epinephrine after surgery; Group } \mathrm{G}(\mathrm{N}=60) \text { had general anaesthesia with sevoflurane and } \\
\text { fentanyl and systemic administration of opioids after surgery." }\end{array}$
\end{tabular}

Ezhevskaya 2014a Different study population: 350 participants aged 15-65 years

\begin{tabular}{ll}
\hline Ezhevskaya 2014b & Different intervention: comparison of analgesic and opioid-sparing effects of a single-injection ul- \\
& trasound-guided subcostal transversus abdominal plane block with continuous thoracic epidural \\
& analgesia
\end{tabular}

\begin{tabular}{ll}
\hline Goodarzi 1993 & Different study population: no back surgery \\
\hline Goodarzi 1999 & $\begin{array}{l}\text { Different intervention: comparison of epidural morphine, hydromorphone, and fentanyl for post- } \\
\text { operative pain control in children undergoing various types of orthopaedic surgery }\end{array}$ \\
\hline
\end{tabular}

\begin{tabular}{ll}
\hline Khinkover 2006 & Different study design. Not an RCT \\
\hline Lawhorn 1994 & $\begin{array}{l}\text { Different intervention. Authors reported a randomized double-blind prospective study comparing } \\
\text { epidural morphine } 80 \mu \mathrm{g} / \mathrm{kg} \text { to epidural morphine } 80 \mu \mathrm{g} / \mathrm{kg} \text { plus butorphanol } 40 \mu \mathrm{gg} / \mathrm{kg} \text { in children } \\
\text { undergoing rhizotomy. }\end{array}$
\end{tabular}

\begin{tabular}{ll}
\hline Loughnan 1990 & No outcome of interest measured \\
\hline Lowry 2001 & Different study design. Not an RCT, did not contain a control group without epidural analgesia \\
\hline Milbrandt 2009 & Different study design. Retrospective cohort study \\
\hline Nóbrega 2017 & Different study design. Retrospective study \\
\hline Pham 2008 & $\begin{array}{l}\text { Different study design. No control group. All participants received epidural analgesia with either } \\
\text { ropivacaine or bupivacaine }\end{array}$ \\
\hline Saudan 2008 & Different study design. Retrospective study \\
\hline Sekar 2004 & Different study design. Observational study. All participants received epidural analgesia \\
\hline Shaw 1996 & Different population. Only 1 of the 2 groups contained participants under 18 years of age \\
\hline Sparkes 1989 & Different study design. Descriptive clinical study \\
\hline Sucato 2005 & Different study design. Not an RCT \\
\hline Sundarathiti 2010 & Different study design. Retrospective study \\
\hline
\end{tabular}




\begin{tabular}{ll}
\hline Study & Reason for exclusion \\
\hline Tobias 2001 & Different study design. Not an RCT, did not contain a control group without epidural analgesia \\
\hline Turner 2000 & Different study design. Not an RCT \\
\hline Van Boerum 2000 & Different study design. Retrospective study \\
\hline
\end{tabular}

$\mathrm{RCT}$ : randomized controlled trial.

Characteristics of studies awaiting assessment [ordered by study ID]

\begin{tabular}{ll}
\hline Kick 1995 & N/A \\
\hline Methods & N/A \\
\hline Participants & N/A \\
\hline Interventions & N/A \\
\hline Outcomes & $\begin{array}{l}\text { This reference came from the list of reference of a review article (Bernard JM et al. Analgésie après } \\
\text { chirurgie du rachis chez l'adulte et l'adolescent. Cahiers d'Anesthésiologie 1995; 43:6: 557-64) and } \\
\text { no details were available. }\end{array}$ \\
\hline Notes & We have not been able to obtain a copy of this article despite requests to 2 university libraries
\end{tabular}

N/A: not available.

Characteristics of ongoing studies [ordered by study ID]

\section{EUCTR2008-001642-19-SE}

Trial name or title

Perioperative pain management in children and adolescents undergoing scoliosis surgery. Intravenous analgesia with s-ketamine and morphine versus epidural analgesia with fentanyl-bupivacaine-epinephrine. Pain, nausea and psychological impact

\begin{tabular}{ll}
\hline Methods & Parallel single-blind RCT \\
\hline Participants & Consecutive children/adolescents scheduled for correctional surgery for idiopathic scoliosis. Aged \\
& $12-18$ years \\
\hline
\end{tabular}

Interventions Intervention group: epidural analgesia with fentanyl-bupivacaine-epinephrine

Comparator group: intravenous analgesia with s-ketamine and morphine

\begin{tabular}{|c|c|}
\hline \multirow[t]{2}{*}{ Outcomes } & $\begin{array}{l}\text { Primary end points: pain at hospital and at home, intensity and duration, measured by VAS ( } 0-100 \\
\mathrm{~mm} \text { ) }\end{array}$ \\
\hline & $\begin{array}{l}\text { Secondary objectives: nausea, gastrointestinal function, amount of and time to first rescue analge- } \\
\text { sia, global rating of patient satisfaction, pruritus, postoperative psychological impact }\end{array}$ \\
\hline
\end{tabular}

\begin{tabular}{ll}
\hline Starting date & Registered 27 June 2008 \\
\hline Contact information & No contact author listed, no contact address \\
\hline
\end{tabular}


EUCTR2008-001642-19-SE (Continued)

RCT: randomized controlled trial; VAS: visual/verbal analogue scale.

\section{DATA AND ANALYSES}

\section{Comparison 1. Epidural analgesia versus systemic analgesia for postoperative pain after back surgery in children}

\begin{tabular}{|c|c|c|c|c|}
\hline Outcome or subgroup title & No. of studies & $\begin{array}{l}\text { No. of partici- } \\
\text { pants }\end{array}$ & Statistical method & Effect size \\
\hline 1 Pain at rest at $6-8$ hours & 4 & 116 & $\begin{array}{l}\text { Mean Difference (IV, Random, 95\% } \\
\mathrm{Cl} \text { ) }\end{array}$ & $-1.32[-1.83,-0.82]$ \\
\hline 1.1 Local anaesthetic only & 2 & 60 & $\begin{array}{l}\text { Mean Difference (IV, Random, 95\% } \\
\mathrm{CI})\end{array}$ & $-1.31[-1.84,-0.79]$ \\
\hline 1.2 Opioid only & 1 & 27 & $\begin{array}{l}\text { Mean Difference (IV, Random, 95\% } \\
\mathrm{CI})\end{array}$ & $-2.29[-4.51,-0.06]$ \\
\hline $\begin{array}{l}1.3 \text { Local anaesthetic plus } \\
\text { opioid }\end{array}$ & 1 & 29 & $\begin{array}{l}\text { Mean Difference (IV, Random, 95\% } \\
\mathrm{CI})\end{array}$ & $-0.38[-2.77,2.01]$ \\
\hline 2 Pain at rest at $20-32$ hours & 6 & 208 & $\begin{array}{l}\text { Mean Difference (IV, Random, 95\% } \\
\mathrm{Cl} \text { ) }\end{array}$ & $-1.06[-1.56,-0.57]$ \\
\hline 2.1 Local anaesthetic only & 2 & 60 & $\begin{array}{l}\text { Mean Difference (IV, Random, 95\% } \\
\mathrm{CI})\end{array}$ & $-1.47[-1.97,-0.98]$ \\
\hline 2.2 Opioid only & 1 & 27 & $\begin{array}{l}\text { Mean Difference (IV, Random, 95\% } \\
\mathrm{Cl} \text { ) }\end{array}$ & $-2.0[-3.87,-0.13]$ \\
\hline $\begin{array}{l}2.3 \text { Local anaesthetic plus } \\
\text { opioid }\end{array}$ & 3 & 121 & $\begin{array}{l}\text { Mean Difference (IV, Random, 95\% } \\
\mathrm{Cl} \text { ) }\end{array}$ & $-0.27[-1.03,0.50]$ \\
\hline $\begin{array}{l}3 \text { Pain on movement at } 24 \\
\text { hours }\end{array}$ & 3 & 87 & $\begin{array}{l}\text { Std. Mean Difference (Random, } \\
95 \% \mathrm{Cl} \text { ) }\end{array}$ & $-1.51[-2.27,-0.76]$ \\
\hline 3.1 Local anaesthetic only & 2 & 60 & $\begin{array}{l}\text { Std. Mean Difference (Random, } \\
95 \% \mathrm{Cl} \text { ) }\end{array}$ & $-1.81[-2.74,-0.89]$ \\
\hline 3.2 Opioid only & 1 & 27 & $\begin{array}{l}\text { Std. Mean Difference (Random, } \\
95 \% \mathrm{Cl} \text { ) }\end{array}$ & $-0.95[-1.76,-0.15]$ \\
\hline 4 Pain at rest at 48 hours & 5 & 148 & $\begin{array}{l}\text { Mean Difference (IV, Random, 95\% } \\
\mathrm{CI})\end{array}$ & $-1.10[-1.62,-0.58]$ \\
\hline 4.1 Local anaesthetic only & 2 & 60 & $\begin{array}{l}\text { Mean Difference (IV, Random, 95\% } \\
\mathrm{CI})\end{array}$ & $-1.48[-1.97,-0.99]$ \\
\hline 4.2 Opioid only & 1 & 27 & $\begin{array}{l}\text { Mean Difference (IV, Random, 95\% } \\
\mathrm{Cl} \text { ) }\end{array}$ & $0.0[-1.22,1.22]$ \\
\hline
\end{tabular}




\begin{tabular}{|c|c|c|c|c|}
\hline Outcome or subgroup title & No. of studies & $\begin{array}{l}\text { No. of partici- } \\
\text { pants }\end{array}$ & Statistical method & Effect size \\
\hline $\begin{array}{l}4.3 \text { Local anaesthetic plus } \\
\text { opioid }\end{array}$ & 2 & 61 & $\begin{array}{l}\text { Mean Difference (IV, Random, 95\% } \\
\mathrm{CI})\end{array}$ & $-0.74[-1.80,0.31]$ \\
\hline $\begin{array}{l}5 \text { Pain on movement at } 48 \\
\text { hours }\end{array}$ & 2 & 60 & $\begin{array}{l}\text { Mean Difference (IV, Random, 95\% } \\
\mathrm{CI})\end{array}$ & $-1.35[-1.77,-0.92]$ \\
\hline 6 Pain at rest at 72 hours & 5 & 157 & $\begin{array}{l}\text { Std. Mean Difference (Random, } \\
95 \% \mathrm{Cl} \text { ) }\end{array}$ & $-0.65[-1.19,-0.10]$ \\
\hline 6.1 Local anaesthetic only & 2 & 60 & $\begin{array}{l}\text { Std. Mean Difference (Random, } \\
95 \% \mathrm{Cl} \text { ) }\end{array}$ & $-1.36[-2.40,-0.33]$ \\
\hline 6.2 Opioid only & 1 & 27 & $\begin{array}{l}\text { Std. Mean Difference (Random, } \\
95 \% \mathrm{Cl} \text { ) }\end{array}$ & $-0.27[-1.03,0.49]$ \\
\hline $\begin{array}{l}6.3 \text { Local anaesthetic plus } \\
\text { opioid }\end{array}$ & 2 & 70 & $\begin{array}{l}\text { Std. Mean Difference (Random, } \\
95 \% \mathrm{Cl} \text { ) }\end{array}$ & $-0.37[-0.87,0.12]$ \\
\hline $\begin{array}{l}7 \text { Pain on movement at } 72 \\
\text { hours }\end{array}$ & 2 & 60 & $\begin{array}{l}\text { Mean Difference (IV, Random, 95\% } \\
\mathrm{CI})\end{array}$ & $-1.07[-1.38,-0.76]$ \\
\hline $\begin{array}{l}8 \text { Vomiting up to } 48 \text { hours af- } \\
\text { ter surgery }\end{array}$ & 6 & 215 & Risk Ratio (M-H, Random, 95\% Cl) & $0.87[0.58,1.30]$ \\
\hline 8.1 Local anaesthetic only & 2 & 60 & Risk Ratio (M-H, Random, 95\% Cl) & $0.52[0.14,1.90]$ \\
\hline 8.2 Opioids only & 1 & 27 & Risk Ratio (M-H, Random, 95\% Cl) & $1.20[0.73,1.96]$ \\
\hline $\begin{array}{l}8.3 \text { Local anaesthetic and } \\
\text { opioid }\end{array}$ & 3 & 128 & Risk Ratio (M-H, Random, 95\% Cl) & $0.84[0.46,1.53]$ \\
\hline $\begin{array}{l}9 \text { Return of gastrointestinal } \\
\text { function: number of partici- } \\
\text { pants with bowel movement } \\
\text { at } 48 \text { hours }\end{array}$ & 2 & 60 & Risk Ratio (M-H, Random, 95\% Cl) & $11.52[2.36,56.26]$ \\
\hline $\begin{array}{l}10 \text { Return of gastrointestinal } \\
\text { function: time to first liquid } \\
\text { ingestion }\end{array}$ & 2 & 56 & $\begin{array}{l}\text { Mean Difference (IV, Random, 95\% } \\
\mathrm{CI})\end{array}$ & $-5.02[-13.15,3.10]$ \\
\hline 10.1 Opioid only & 1 & 27 & $\begin{array}{l}\text { Mean Difference (IV, Random, 95\% } \\
\mathrm{CI})\end{array}$ & $-6.70[-17.10,3.70]$ \\
\hline $\begin{array}{l}10.2 \text { Local anaesthetic and } \\
\text { opioid }\end{array}$ & 1 & 29 & $\begin{array}{l}\text { Mean Difference (IV, Random, 95\% } \\
\mathrm{CI})\end{array}$ & $-2.40[-15.42,10.62]$ \\
\hline 11 Hospital length of stay & 2 & 89 & $\begin{array}{l}\text { Mean Difference (IV, Random, 95\% } \\
\mathrm{CI})\end{array}$ & $-0.29[-0.69,0.10]$ \\
\hline 12 Participant satisfaction & 2 & 60 & $\begin{array}{l}\text { Mean Difference (IV, Random, 95\% } \\
\mathrm{CI})\end{array}$ & $1.62[1.26,1.97]$ \\
\hline 13 Respiratory depression & 4 & 126 & $\begin{array}{l}\text { Risk Difference (M-H, Random, } \\
95 \% \mathrm{Cl})\end{array}$ & $-0.05[-0.16,0.05]$ \\
\hline
\end{tabular}




\begin{tabular}{lllll}
\hline Outcome or subgroup title & No. of studies & $\begin{array}{l}\text { No. of partici- } \\
\text { pants }\end{array}$ & Statistical method & Effect size \\
\hline 14 Wound infection & 2 & 93 & $\begin{array}{l}\text { Risk Difference (M-H, Random, } \\
95 \% \mathrm{Cl})\end{array}$ & $0.01[-0.05,0.08]$ \\
\hline 15 Epidural abscess & 3 & 120 & $\begin{array}{l}\text { Risk Difference (M-H, Random, } \\
95 \% \text { Cl) }\end{array}$ & $0.0[-0.05,0.05]$ \\
\hline $\begin{array}{l}16 \text { Neurological complica- } \\
\text { tions }\end{array}$ & 4 & 151 & $\begin{array}{l}\text { Risk Difference (M-H, Random, } \\
95 \% \mathrm{Cl})\end{array}$ & $0.01[-0.04,0.06]$ \\
\hline
\end{tabular}

Analysis 1.1. Comparison 1 Epidural analgesia versus systemic analgesia for postoperative pain after back surgery in children, Outcome 1 Pain at rest at 6-8 hours.

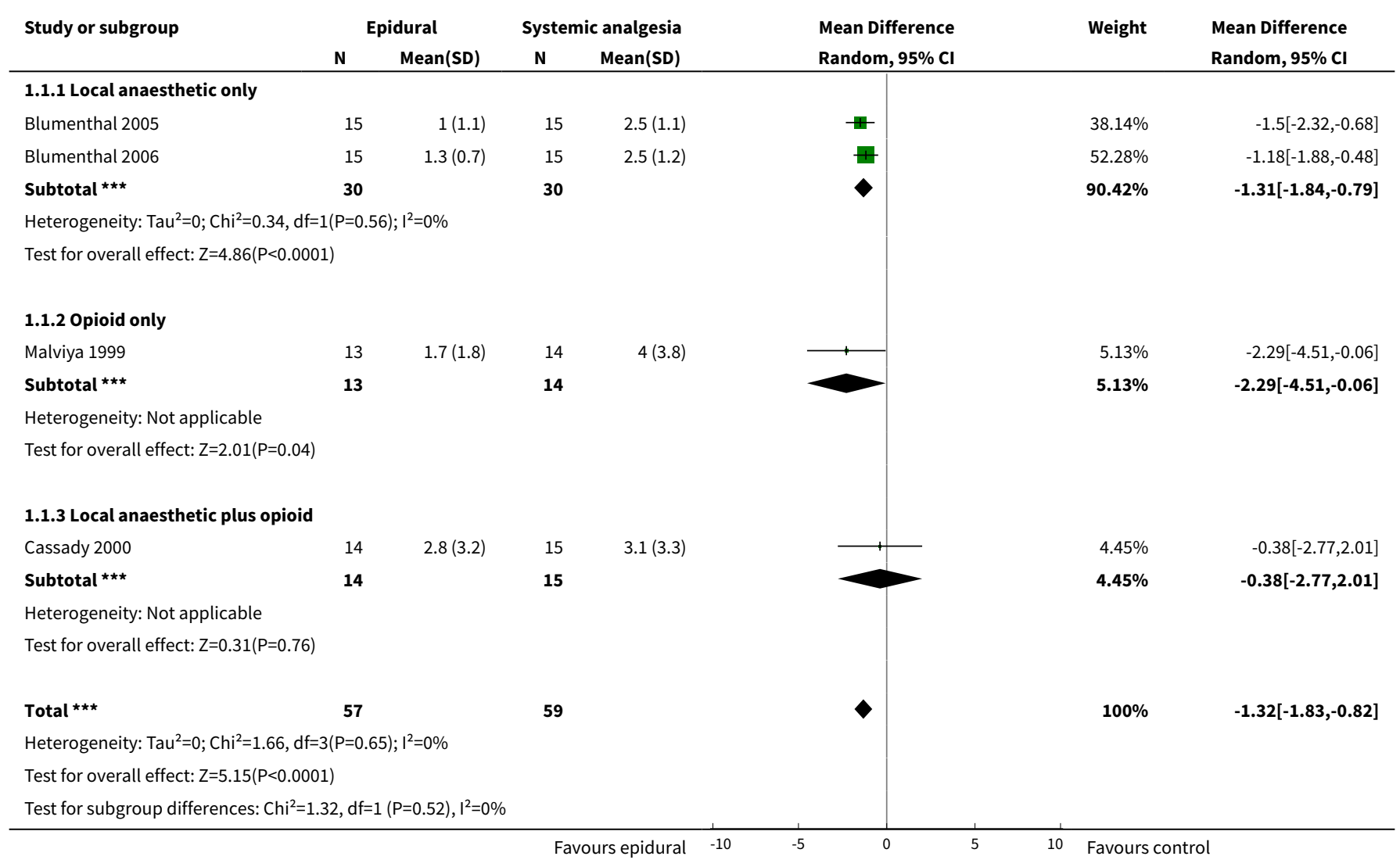

Analysis 1.2. Comparison 1 Epidural analgesia versus systemic analgesia for postoperative pain after back surgery in children, Outcome 2 Pain at rest at 20-32 hours.

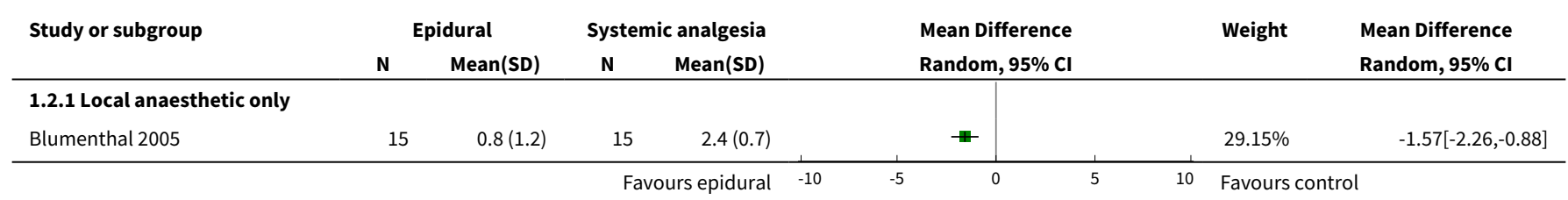




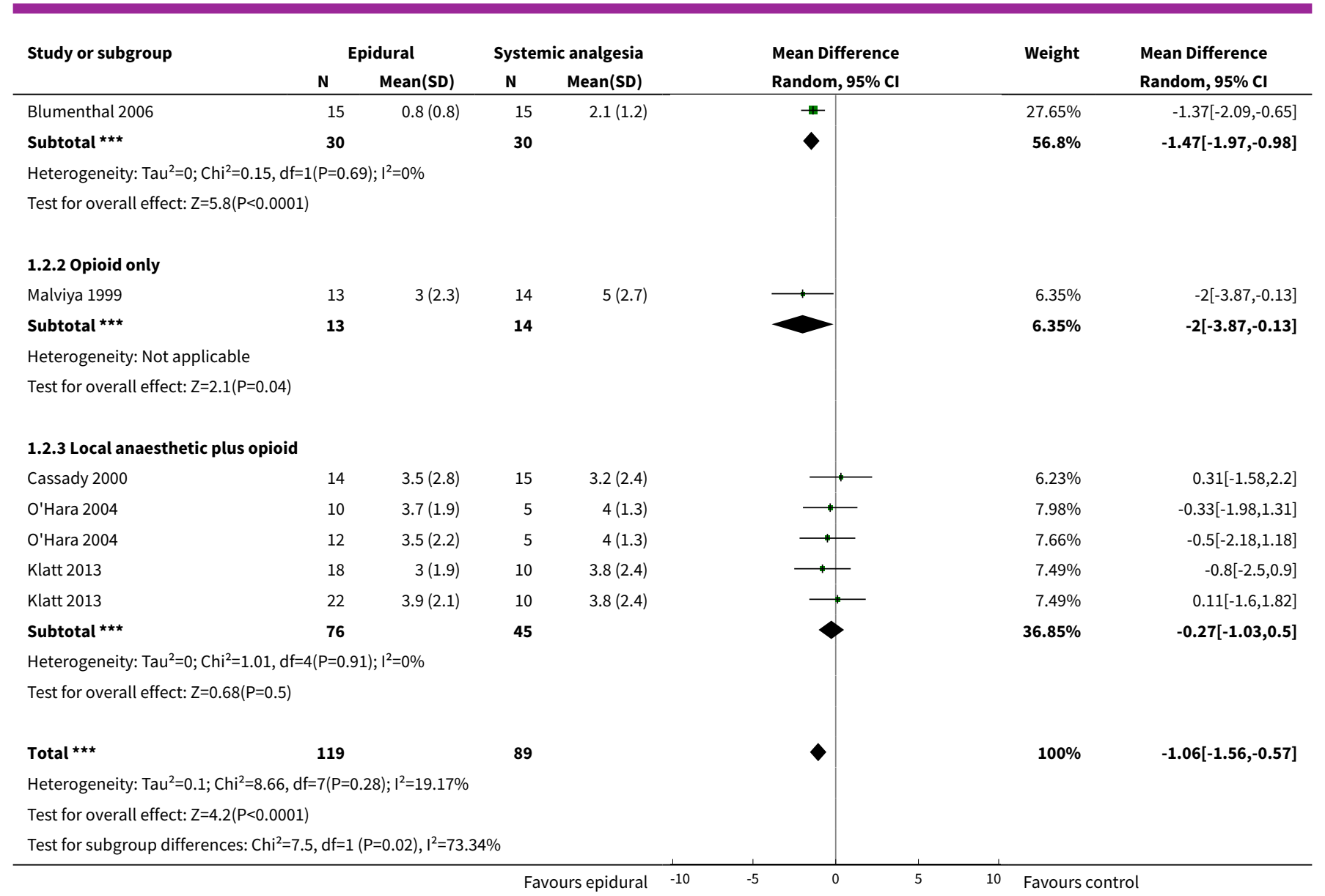

\section{Analysis 1.3. Comparison 1 Epidural analgesia versus systemic analgesia for postoperative pain after back surgery in children, Outcome 3 Pain on movement at 24 hours.}

\begin{tabular}{|c|c|c|c|c|c|c|}
\hline Study or subgroup & $\begin{array}{c}\text { Epidural } \\
\mathrm{N} \\
\end{array}$ & $\begin{array}{l}\text { Systemic } \\
\text { analgesia }\end{array}$ & $\begin{array}{l}\text { Std. Mean } \\
\text { Difference } \\
\text { (SE) }\end{array}$ & $\begin{array}{l}\text { Std. Mean Difference } \\
\text { IV, Random, } 95 \% \text { CI }\end{array}$ & Weight & $\begin{array}{l}\text { Std. Mean Difference } \\
\text { IV, Random, } 95 \% \mathrm{CI}\end{array}$ \\
\hline \multicolumn{7}{|c|}{ 1.3.1 Local anaesthetic only } \\
\hline Blumenthal 2005 & 15 & 15 & $-1.4(0.412)$ & 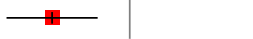 & $34.88 \%$ & $-1.38[-2.18,-0.57]$ \\
\hline Blumenthal 2006 & 15 & 15 & $-2.3(0.487)$ & . & $30.12 \%$ & $-2.32[-3.28,-1.37]$ \\
\hline Subtotal $(95 \% \mathrm{Cl})$ & & & & & $64.99 \%$ & $-1.81[-2.74,-0.89]$ \\
\hline \multicolumn{7}{|c|}{ Test for overall effect: $Z=3.85(P=0)$} \\
\hline \multicolumn{7}{|l|}{ 1.3.2 Opioid only } \\
\hline Malviya 1999 & 13 & 14 & $-1(0.41)$ & 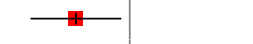 & $35.01 \%$ & $-0.95[-1.76,-0.15]$ \\
\hline Subtotal $(95 \% \mathrm{Cl})$ & & & & & $35.01 \%$ & $-0.95[-1.76,-0.15]$ \\
\hline \multicolumn{7}{|c|}{ Heterogeneity: $\operatorname{Tau}^{2}=0 ; \mathrm{Chi}^{2}=0, \mathrm{df}=0(\mathrm{P}<0.0001) ; \mathrm{I}^{2}=100 \%$} \\
\hline Total $(95 \% \mathrm{Cl})$ & & & & & $100 \%$ & $-1.51[-2.27,-0.76]$ \\
\hline \multicolumn{7}{|c|}{ Heterogeneity: $\mathrm{Tau}^{2}=0.25 ; \mathrm{Chi}^{2}=4.7, \mathrm{df}=2(\mathrm{P}=0.1) ; \mathrm{I}^{2}=57.45 \%$} \\
\hline Test for overall effec & & & & & & \\
\hline
\end{tabular}




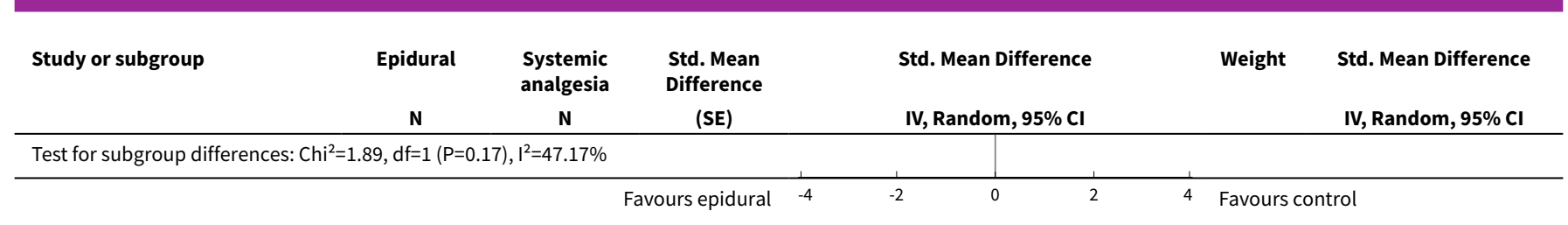

Analysis 1.4. Comparison 1 Epidural analgesia versus systemic analgesia for postoperative pain after back surgery in children, Outcome 4 Pain at rest at 48 hours.

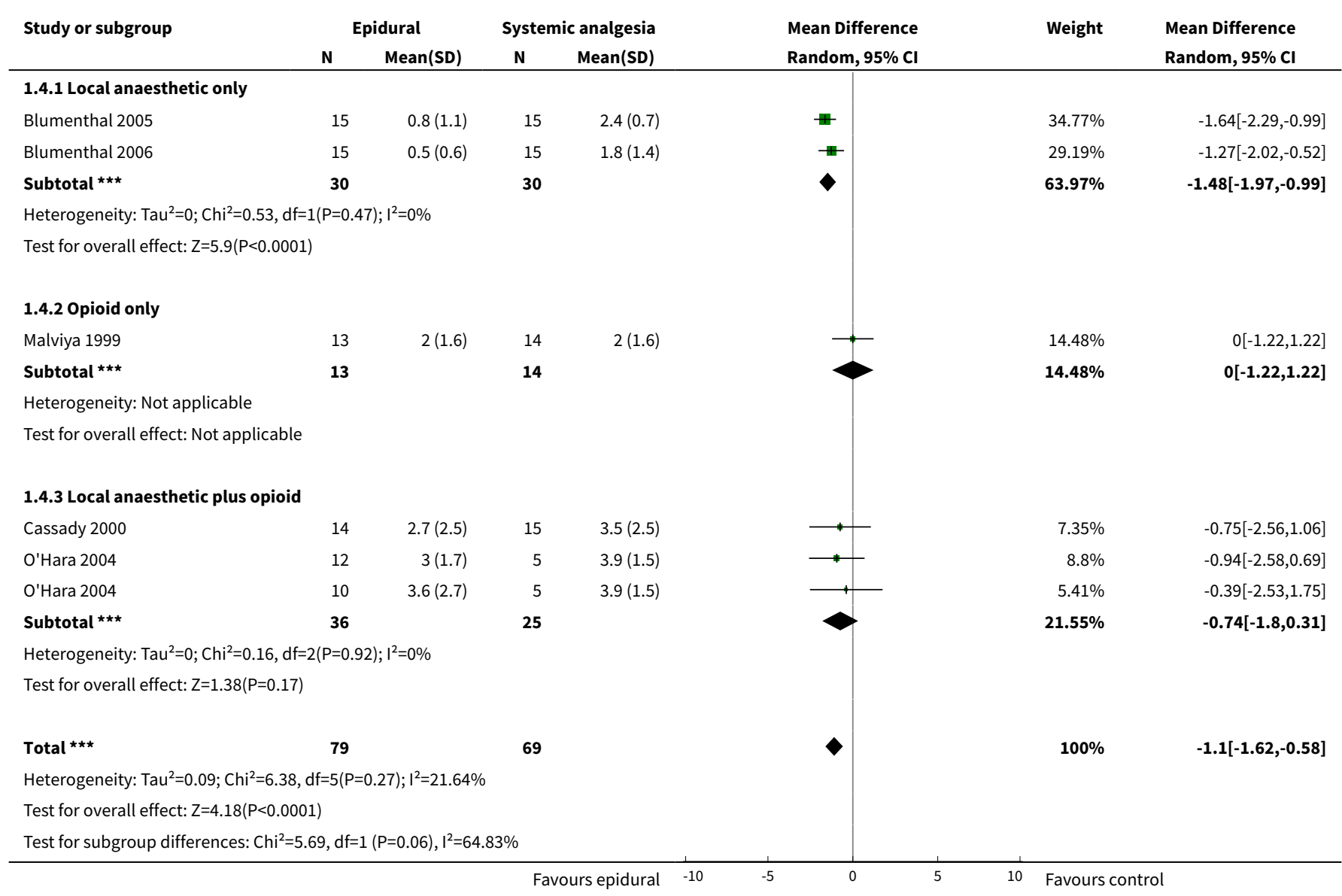

Analysis 1.5. Comparison 1 Epidural analgesia versus systemic analgesia for postoperative pain after back surgery in children, Outcome 5 Pain on movement at 48 hours.

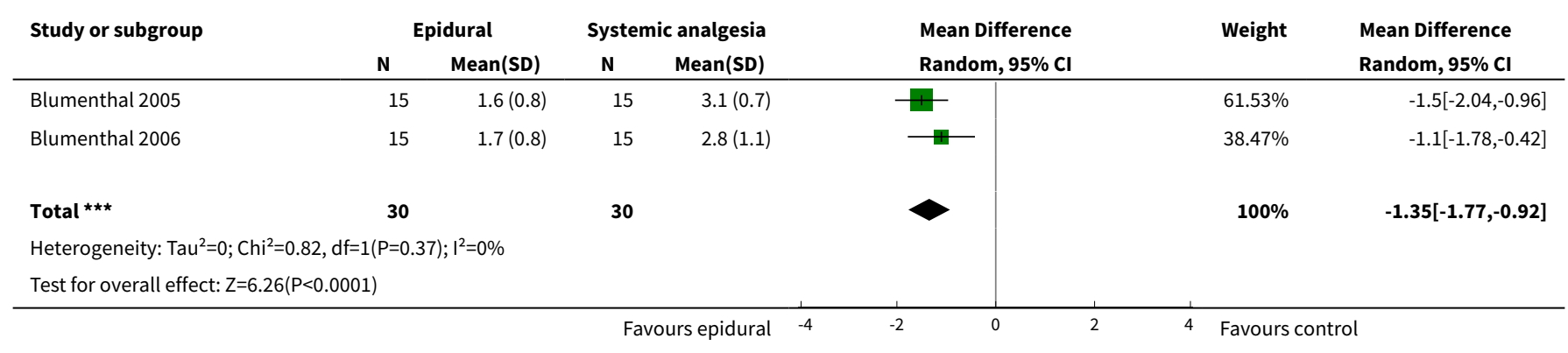


Analysis 1.6. Comparison 1 Epidural analgesia versus systemic analgesia for postoperative pain after back surgery in children, Outcome 6 Pain at rest at 72 hours.

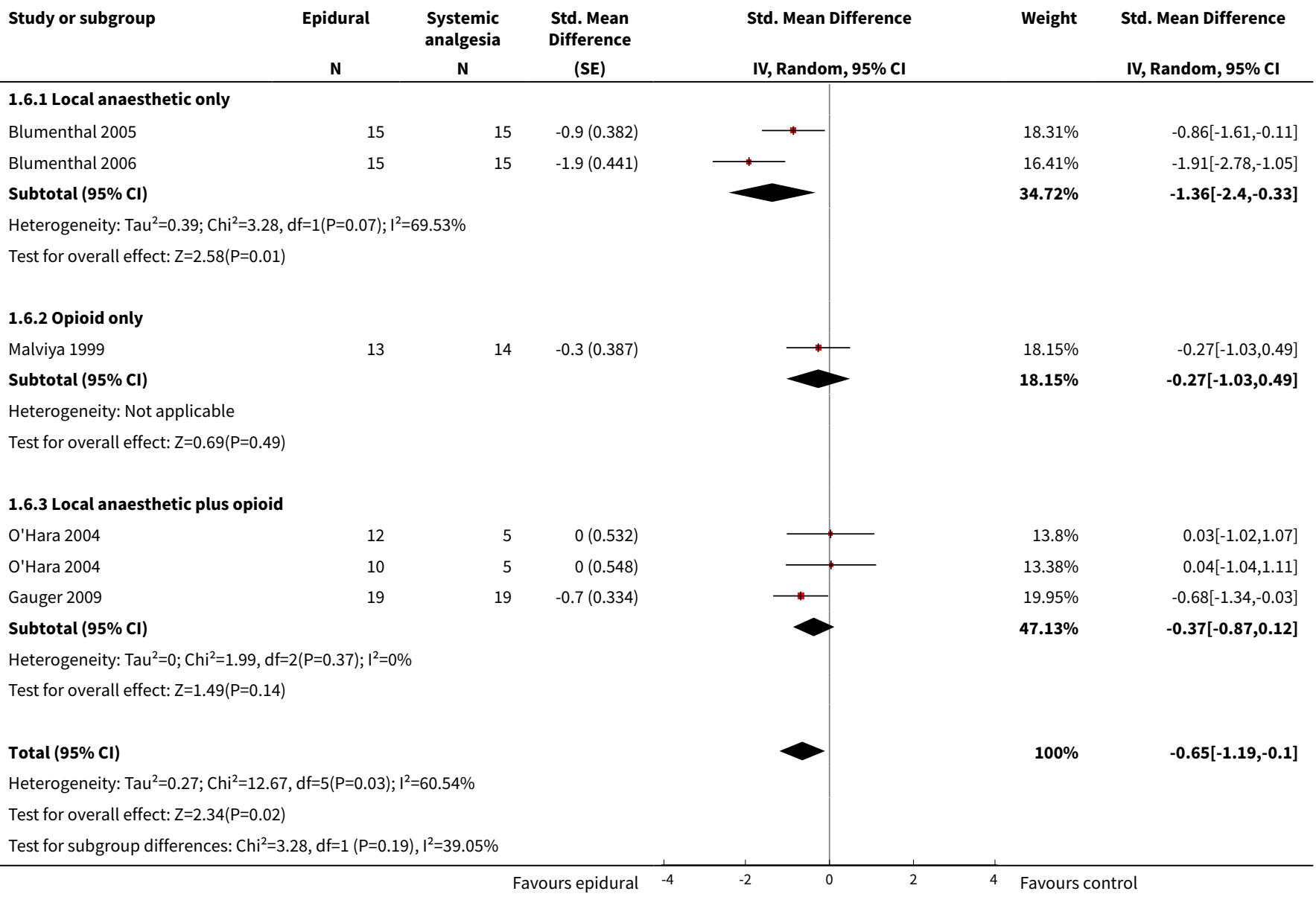

\section{Analysis 1.7. Comparison 1 Epidural analgesia versus systemic analgesia for postoperative pain after back surgery in children, Outcome 7 Pain on movement at 72 hours.}

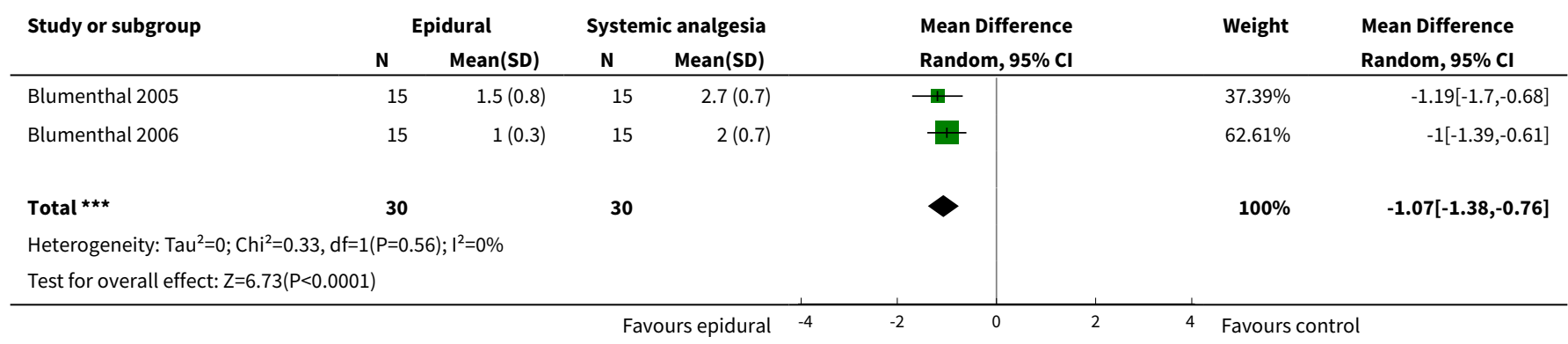


Analysis 1.8. Comparison 1 Epidural analgesia versus systemic analgesia for postoperative pain after back surgery in children, Outcome 8 Vomiting up to $\mathbf{4 8}$ hours after surgery.

\begin{tabular}{|c|c|c|c|c|c|}
\hline \multirow[t]{2}{*}{ Study or subgroup } & Epidural & $\begin{array}{l}\text { Systemic } \\
\text { analgesia }\end{array}$ & Risk Ratio & \multirow[t]{2}{*}{ Weight } & \multirow{2}{*}{$\begin{array}{c}\text { Risk Ratio } \\
\text { M-H, Random, } 95 \% \mathrm{Cl}\end{array}$} \\
\hline & $\mathrm{n} / \mathrm{N}$ & $n / N$ & M-H, Random, 95\% Cl & & \\
\hline \multicolumn{6}{|c|}{ 1.8.1 Local anaesthetic only } \\
\hline Blumenthal 2005 & $4 / 15$ & $5 / 15$ & $\longrightarrow$ & $9.78 \%$ & $0.8[0.27,2.41]$ \\
\hline Blumenthal 2006 & $1 / 15$ & $5 / 15$ & & $3.59 \%$ & $0.2[0.03,1.51]$ \\
\hline Subtotal $(95 \% \mathrm{Cl})$ & 30 & 30 & & $13.37 \%$ & $0.52[0.14,1.9]$ \\
\hline \multicolumn{6}{|c|}{ Heterogeneity: $\mathrm{Tau}^{2}=0.34 ; \mathrm{Chi}^{2}=1.48, \mathrm{df}=1(\mathrm{P}=0.22) ; \mathrm{I}^{2}=32.65 \%$} \\
\hline \multicolumn{6}{|c|}{ Test for overall effect: $Z=0.99(P=0.32)$} \\
\hline \multicolumn{6}{|l|}{ 1.8.2 Opioids only } \\
\hline Malviya 1999 & $10 / 13$ & $9 / 14$ & - & $23.42 \%$ & $1.2[0.73,1.96]$ \\
\hline Subtotal $(95 \% \mathrm{Cl})$ & 13 & 14 & & $23.42 \%$ & $1.2[0.73,1.96]$ \\
\hline \multicolumn{6}{|c|}{ Heterogeneity: Not applicable } \\
\hline \multicolumn{6}{|c|}{ Test for overall effect: $Z=0.72(P=0.47)$} \\
\hline \multicolumn{6}{|c|}{ 1.8.3 Local anaesthetic and opioid } \\
\hline Cassady 2000 & $12 / 14$ & $12 / 15$ & & $28.84 \%$ & $1.07[0.77,1.49]$ \\
\hline Gauger 2009 & $6 / 19$ & $14 / 19$ & $\longrightarrow$ & $16.91 \%$ & $0.43[0.21,0.88]$ \\
\hline Klatt 2013 & $8 / 18$ & $3 / 11$ & - & $9.89 \%$ & $1.63[0.55,4.87]$ \\
\hline Klatt 2013 & $4 / 21$ & $3 / 11$ & ${ }^{2}$ & $7.56 \%$ & $0.7[0.19,2.58]$ \\
\hline Subtotal $(95 \% \mathrm{Cl})$ & 72 & 56 & & $63.2 \%$ & $0.84[0.46,1.53]$ \\
\hline \multicolumn{6}{|c|}{ Total events: 30 (Epidural), 32 (Systemic analgesia) } \\
\hline \multicolumn{6}{|c|}{ Heterogeneity: $\mathrm{Tau}^{2}=0.2 ; \mathrm{Chi}^{2}=7.26, \mathrm{df}=3(\mathrm{P}=0.06) ; \mathrm{I}^{2}=58.66 \%$} \\
\hline \multicolumn{6}{|c|}{ Test for overall effect: $Z=0.56(P=0.58)$} \\
\hline \multicolumn{6}{|c|}{ Heterogeneity: $\mathrm{Tau}^{2}=0.12 ; \mathrm{Chi}^{2}=11.37, \mathrm{df}=6(\mathrm{P}=0.08) ; \mathrm{I}^{2}=47.23 \%$} \\
\hline \multicolumn{6}{|c|}{ Test for overall effect: $Z=0.68(P=0.5)$} \\
\hline Test for subgroup dif & $\mathrm{df}=1(\mathrm{P}=0.41), \mathrm{I}^{2}$ & & & & \\
\hline
\end{tabular}

Analysis 1.9. Comparison 1 Epidural analgesia versus systemic analgesia

for postoperative pain after back surgery in children, Outcome 9 Return of gastrointestinal function: number of participants with bowel movement at 48 hours.

\begin{tabular}{|c|c|c|c|c|c|}
\hline Study or subgroup & $\begin{array}{c}\text { Experimental } \\
n / N\end{array}$ & $\begin{array}{c}\text { Control } \\
\mathrm{n} / \mathrm{N}\end{array}$ & $\begin{array}{c}\text { Risk Ratio } \\
\text { M-H, Random, } 95 \% \mathrm{Cl} \\
\end{array}$ & Weight & $\begin{array}{c}\text { Risk Ratio } \\
\text { M-H, Random, } 95 \% \mathrm{Cl}\end{array}$ \\
\hline Blumenthal 2005 & $9 / 15$ & $1 / 15$ & - & $66.95 \%$ & $9[1.3,62.51]$ \\
\hline Blumenthal 2006 & $9 / 15$ & $0 / 15$ & & $33.05 \%$ & $19[1.2,299.63]$ \\
\hline Total $(95 \% \mathrm{Cl})$ & 30 & 30 & & $100 \%$ & $11.52[2.36,56.26]$ \\
\hline \multicolumn{6}{|c|}{ Total events: 18 (Experimental), 1 (Control) } \\
\hline Test for overall effec & & & & & \\
\hline
\end{tabular}


Analysis 1.10. Comparison 1 Epidural analgesia versus systemic analgesia for postoperative pain after back surgery in children, Outcome 10 Return of gastrointestinal function: time to first liquid ingestion.

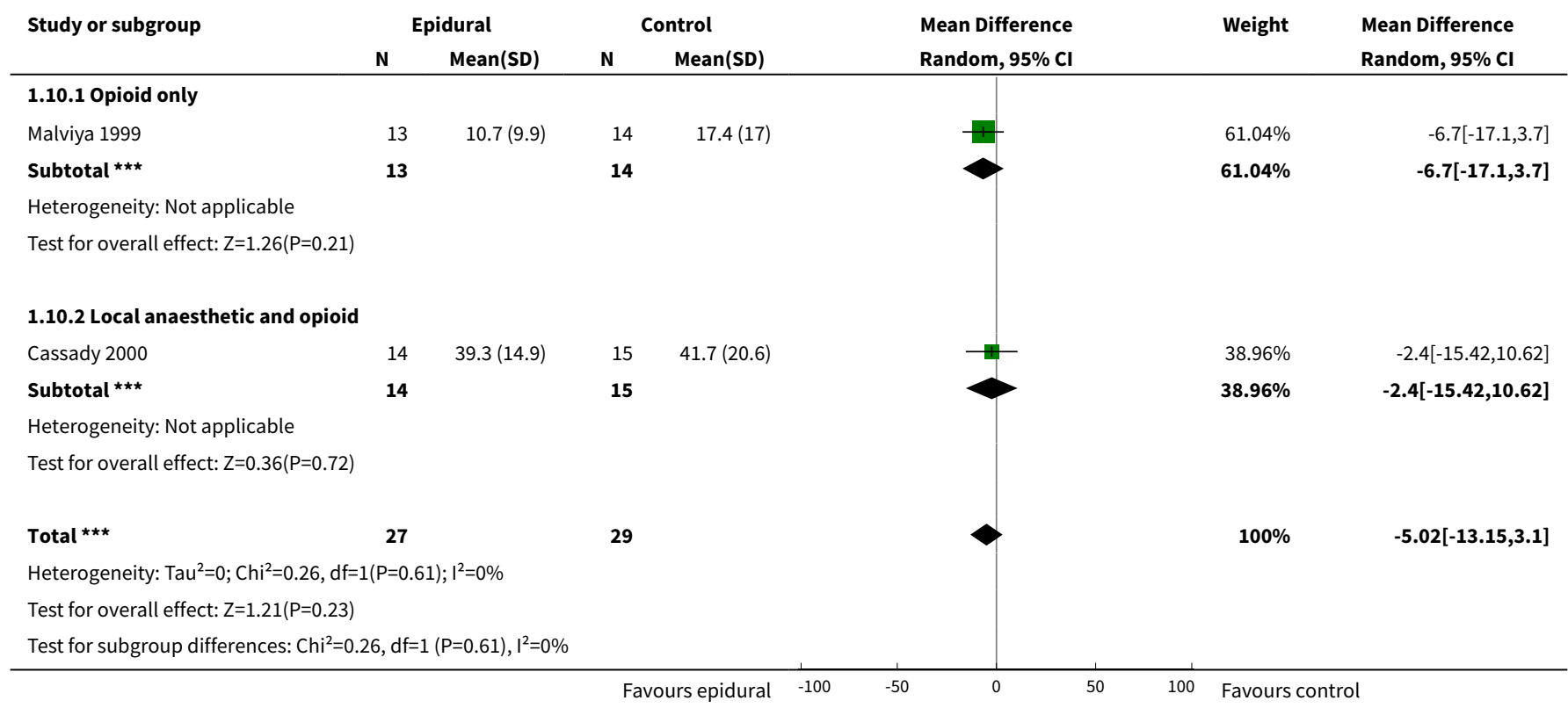

Analysis 1.11. Comparison 1 Epidural analgesia versus systemic analgesia for postoperative pain after back surgery in children, Outcome 11 Hospital length of stay.

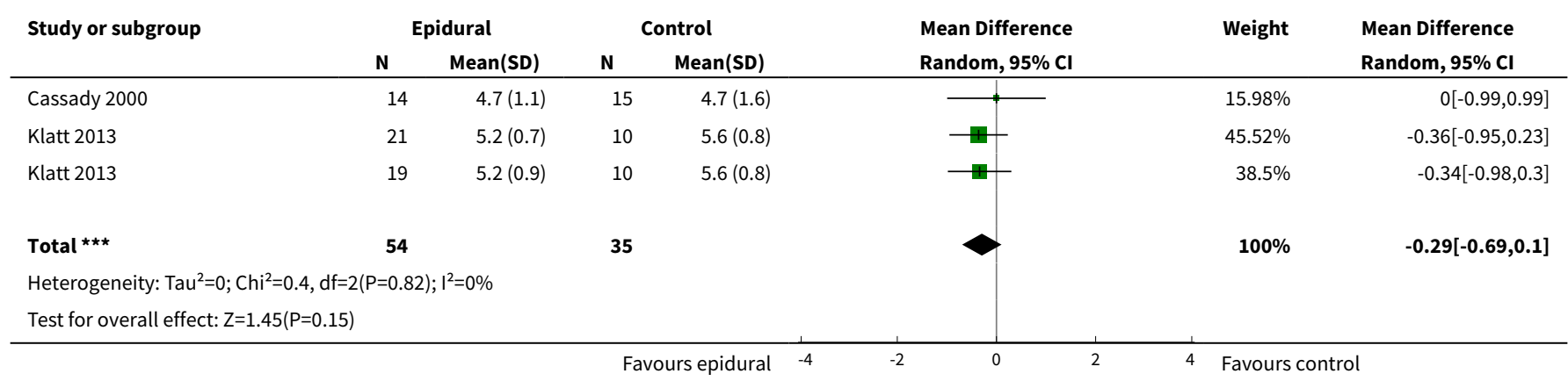

Analysis 1.12. Comparison 1 Epidural analgesia versus systemic analgesia for postoperative pain after back surgery in children, Outcome 12 Participant satisfaction.

\begin{tabular}{|c|c|c|c|c|c|c|c|}
\hline \multirow[t]{2}{*}{ Study or subgroup } & \multicolumn{2}{|c|}{ Epidural } & \multicolumn{2}{|c|}{ Control } & \multirow{2}{*}{$\begin{array}{l}\text { Mean Difference } \\
\text { Random, } 95 \% \mathrm{Cl}\end{array}$} & \multirow[t]{2}{*}{ Weight } & \multirow{2}{*}{$\begin{array}{l}\text { Mean Difference } \\
\text { Random, } 95 \% \mathrm{Cl}\end{array}$} \\
\hline & $\mathbf{N}$ & Mean(SD) & $\mathbf{N}$ & Mean(SD) & & & \\
\hline Blumenthal 2005 & 15 & $8.3(0.9)$ & 15 & $6.8(0.6)$ & —- & $42.08 \%$ & $1.5[0.95,2.05]$ \\
\hline Blumenthal 2006 & 15 & $9.1(0.6)$ & 15 & $7.4(0.7)$ & - & $57.92 \%$ & $1.7[1.23,2.17]$ \\
\hline Total $* \star \star$ & 30 & & 30 & & & $100 \%$ & $1.62[1.26,1.97]$ \\
\hline \multicolumn{8}{|c|}{ Heterogeneity: Tau $^{2}=0 ; \mathrm{Chi}^{2}=0.3, \mathrm{df}=1(\mathrm{P}=0.59) ; \mathrm{I}^{2}=0 \%$} \\
\hline
\end{tabular}




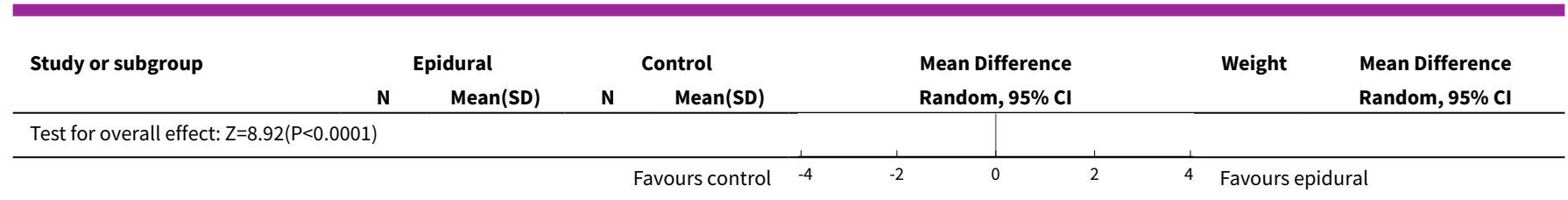

Analysis 1.13. Comparison 1 Epidural analgesia versus systemic analgesia for postoperative pain after back surgery in children, Outcome 13 Respiratory depression.

\begin{tabular}{|c|c|c|c|c|c|}
\hline Study or subgroup & $\begin{array}{l}\text { Epidural } \\
n / N\end{array}$ & $\begin{array}{c}\text { Control } \\
n / N\end{array}$ & $\begin{array}{c}\text { Risk Difference } \\
\text { M-H, Random, 95\% Cl }\end{array}$ & Weight & $\begin{array}{c}\text { Risk Difference } \\
\text { M-H, Random, } 95 \% \mathrm{CI}\end{array}$ \\
\hline Malviya 1999 & $0 / 13$ & $0 / 14$ & 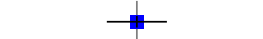 & $31.84 \%$ & $0[-0.13,0.13]$ \\
\hline Cassady 2000 & $0 / 14$ & $0 / 15$ & $\rightarrow$ & $34.04 \%$ & $0[-0.12,0.12]$ \\
\hline O'Hara 2004 & $0 / 22$ & $1 / 10$ & $\longrightarrow$ & $17.69 \%$ & $-0.1[-0.31,0.11]$ \\
\hline Gauger 2009 & $1 / 19$ & $5 / 19$ & $\longrightarrow$ & $16.44 \%$ & $-0.21[-0.43,0.01]$ \\
\hline Total $(95 \% \mathrm{Cl})$ & 68 & 58 & & $100 \%$ & $-0.05[-0.16,0.05]$ \\
\hline \multicolumn{6}{|c|}{ Total events: 1 (Epidural), 6 (Control) } \\
\hline \multicolumn{6}{|c|}{ Heterogeneity: $\mathrm{Tau}^{2}=0 ; \mathrm{Chi}^{2}=4.81, \mathrm{df}=3(\mathrm{P}=0.19) ; \mathrm{I}^{2}=37.66 \%$} \\
\hline \multicolumn{6}{|c|}{ Test for overall effect: $Z=0.99(P=0.32)$} \\
\hline
\end{tabular}

Analysis 1.14. Comparison 1 Epidural analgesia versus systemic analgesia for postoperative pain after back surgery in children, Outcome 14 Wound infection.

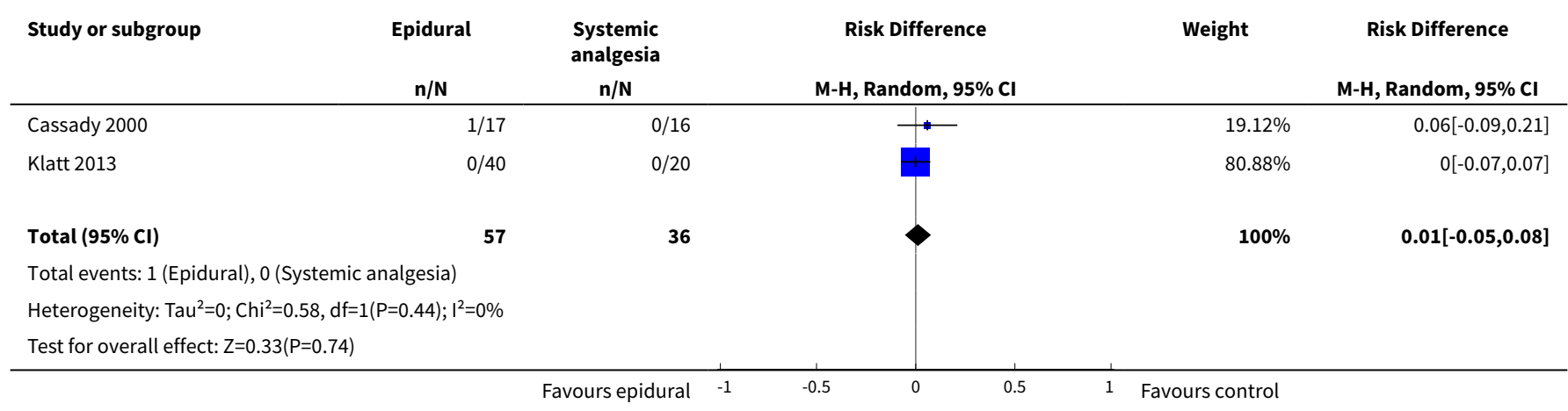

Analysis 1.15. Comparison 1 Epidural analgesia versus systemic analgesia for postoperative pain after back surgery in children, Outcome 15 Epidural abscess.

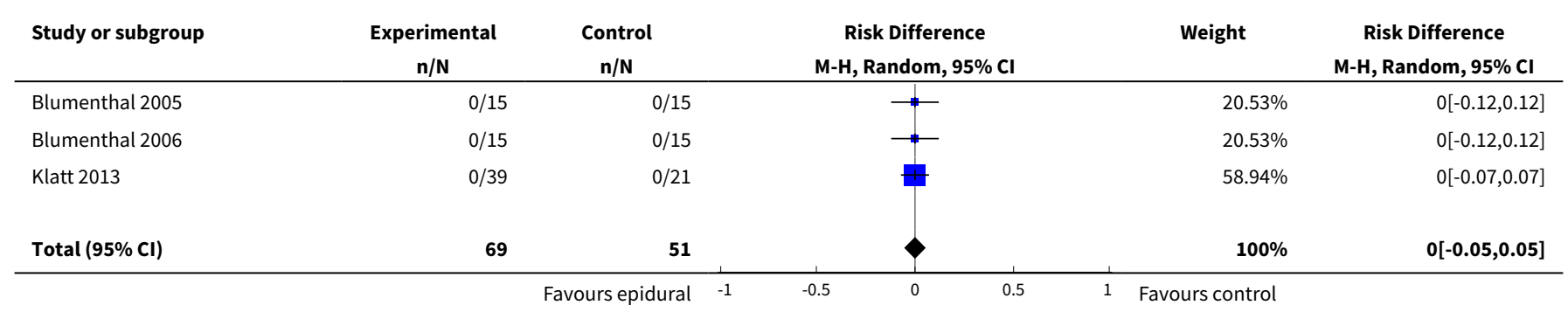




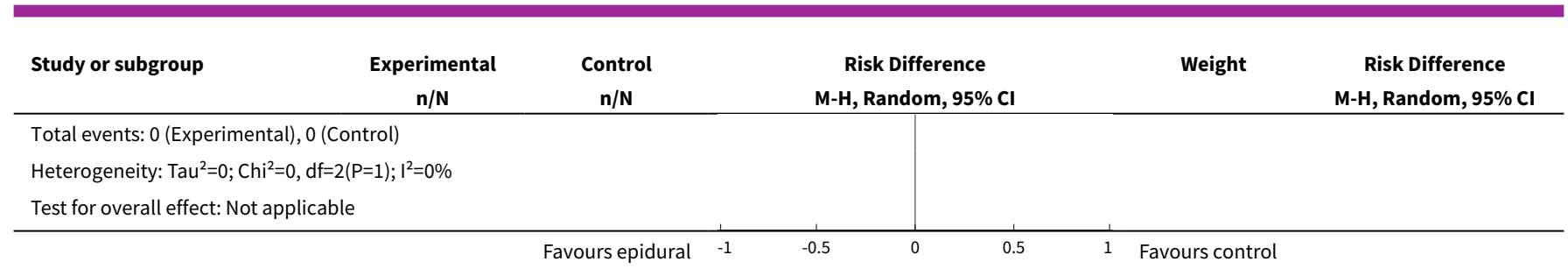

Analysis 1.16. Comparison 1 Epidural analgesia versus systemic analgesia for postoperative pain after back surgery in children, Outcome 16 Neurological complications.

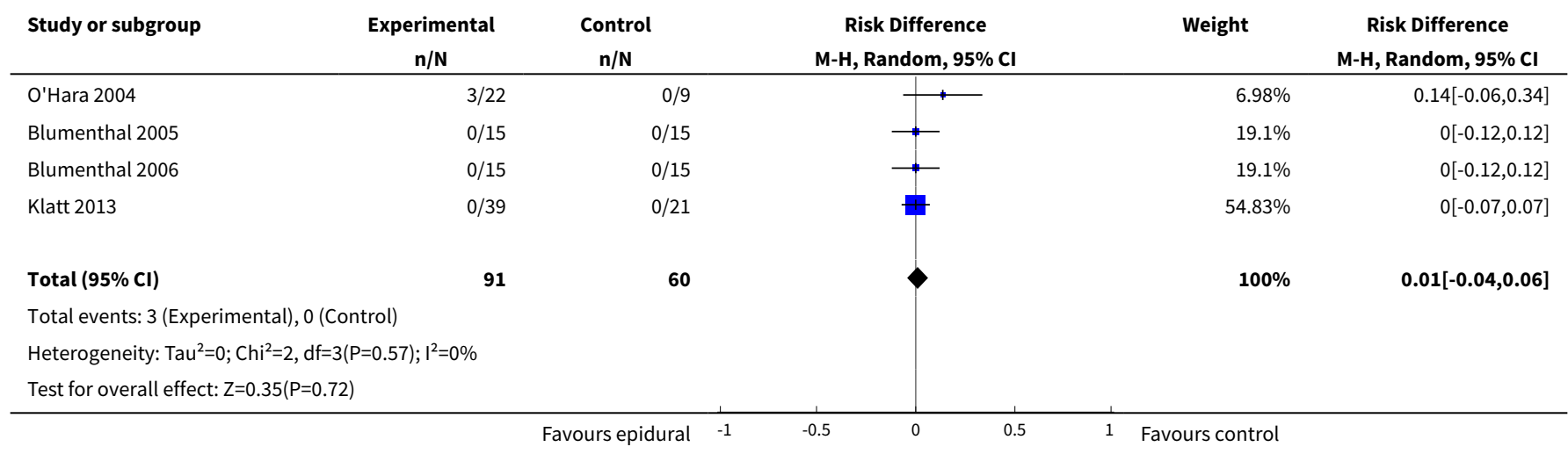

\section{ADDITIONAL TABLES}

Table 1. Surgical technique

Trial Surgical technique

Blumenthal 2005

The posterior instrumentation of the spine was done with pedicle screws in the thoracic and lumbar spine using universal spine system (USS, Stratec, Oberdorf, Lucerne, Switzerland).

The procedures were performed over 7 to 11 vertebral levels.

No surgical complications occurred.

\section{Blumenthal 2006}

The thoracotomy was done on the convex side through a single skin incision with subperiosteal resection of 1 rib.

The anterior instrumentation of the spine was done with vertebral screws and single 6-mm rod titanium implants.

The resected rib was used as autologous bone graft.

The length of the instrumentation was 6 or 7 vertebrae

No surgical complication occurred

\section{Cakar Turhan 2011}

Cassady 2000
Posterior instrumentation or fusion

Posterior thoraco-lumbar spinal fusion using 1 of 3 standard types of surgical instrumentation, i.e. Cotrel-Doubosett (CD; $n=10)$, Texas Scottish Rite Children's Hospital (TSRH; $n=5)$, or Synthes $(n=$ 20). 
Table 1. Surgical technique (Continued)

No excessive intraoperative blood loss was observed during this investigation.

1 participant had the epidural catheter removed in the postanaesthesia care unit at the request of her surgeon for a transient unilateral upper extremity neurological deficit that subsequently proved unrelated to analgesic therapy.

\begin{tabular}{|c|c|}
\hline Ezhevskaya 2012a & Posterior spinal fusion and segmental spinal instrumentation \\
\hline Ezhevskaya 2015 & Scoliosis surgery \\
\hline \multirow[t]{3}{*}{ Gauger 2009} & $\begin{array}{l}\text { Posterior spinal fusion procedures involved segmental instrumentation with hybrid constructs in- } \\
\text { cluding pedicle screws, sublaminar wires, and hooks. }\end{array}$ \\
\hline & $\begin{array}{l}8 \% \text { of participants who received patient-controlled epidural analgesia experienced moderate-to- } \\
\text { severe spasms through postoperative day } 3 \text { compared with } 35 \% \text { of participants in the IV pa- } \\
\text { tient-controlled analgesia group ( } P=\text { not significant). }\end{array}$ \\
\hline & $\begin{array}{l}7(58 \%) \text { participants in the patient-controlled epidural analgesia group and } 17(100 \%) \text { in the intra- } \\
\text { venous patient-controlled analgesia group required diazepam }(P=0.007) .\end{array}$ \\
\hline
\end{tabular}

Klatt 2013 Posterior spinal fusion was performed using segmental instrumentation with pedicle screws and bilateral transverse process hooks at the most cranial level of the construct.

There were no instances of spinal cord monitoring changes during surgery.

Late-onset neurological events were absent in all participants.

The incidence of muscle spasms was lower in the epidural group compared with the nurse-controlled analgesia group through postoperative day 3 and statistical significance for the difference was reached on the evening of surgery $(P=0.005)$, the morning of postoperative day $1(P=0.01)$, and evening of postoperative day $2(P=0.04)$.

Although fewer children in the epidural group required diazepam for muscle spasms through postoperative day 3 , this was not statistically significant.

O'Hara 2004 Posterior thoraco-lumbar segmental instrumentation.

2/9 (22\%) participants had paraesthesia likely secondary to spinal correction.

1 participant had a persistent partial sensory block which resolved after 3 months and the other participant after 6 months.

1 participant in the high-dose epidural group was also excluded after emerging from anaesthesia with lower extremity paralysis secondary to surgical correction. Paralysis resolved by 8 months.

n: number of participants; NR: not reported.

Table 2. Analgesic techniques

\begin{tabular}{lll}
\hline Trial & Epidural analgesia & Systemic analgesia \\
\hline Blumenthal 2005 & Double catheter technique inserted by the surgeon (T1-T4 & Remifentanil target-controlled infu- \\
& $\begin{array}{l}\text { and L1-L4) (placement confirmed radiologically) with ropiva- } \\
\text { caine 0.3\% started the morning after surgery for 1 group: 4-8 } \\
\text { mL boluses through each catheter according to the height of }\end{array}$ & night after surgery.
\end{tabular}


Table 2. Analgesic techniques (Continued)

the participants, followed by infusions of $4-10 \mathrm{~mL} /$ hour in each catheter to obtain a sensory blockade from $\mathrm{T} 2$ to T12.
Continuous intravenous analgesia with morphine at $0.05 \mathrm{mg} / \mathrm{kg} /$ hour thereafter for 1 group.

All participants received oral rofecoxib once a day $(25 \mathrm{mg}$ when $<50 \mathrm{~kg}$ body weight or $50 \mathrm{mg}$ when $>50 \mathrm{~kg}$ body weight) and intravenous acetaminophen (paracetamol) 1 g every 6 hours was provided for participants weighing $>40 \mathrm{~kg}$ and $25 \mathrm{mg} / \mathrm{kg}$ every 6 hours for participants weighing $<40$ $\mathrm{kg}$.

As a rescue analgesic, intravenous morphine $0.025 \mathrm{mg} / \mathrm{kg}$ was administered if VAS was greater than 30 and titrated to keep a respiratory rate $>8$ breaths/minute.
Blumenthal 2006
Double catheter technique inserted by the surgeon (T1-T4 and L1-L4) (placement confirmed radiologically) with ropivacaine $0.3 \%$ started the morning after surgery for 1 group: 4-8 $\mathrm{mL}$ boluses through each catheter according to the height of the participants, followed by infusions of $4-10 \mathrm{~mL} /$ hour in each catheter to obtain a sensory blockade from $\mathrm{T} 2$ to $\mathrm{T} 12$.
Remifentanil target-controlled infusion for all participants for the first night after surgery.

Continuous intravenous analgesia with morphine at $0.05 \mathrm{mg} / \mathrm{kg} /$ hour thereafter for 1 group.

All participants received oral rofecoxib once a day $(25 \mathrm{mg}$ when $<50 \mathrm{~kg}$ or 50 $\mathrm{mg}$ when $>50 \mathrm{~kg}$ ) and intravenous acetaminophen ( $1 \mathrm{~g}$ for participants $>40$ $\mathrm{kg}$ body weight and $25 \mathrm{mg} / \mathrm{kg}$ for participants $<40 \mathrm{~kg}$ ) every 6 hours.

Intravenous morphine $0.025 \mathrm{mg} / \mathrm{kg}$ was administered as a rescue analgesic if VAS exceeded 30.

IV PCA with morphine for all participants. caine plus $15 \mathrm{~mL}$ of sodium chloride $0.9 \%$ was prepared.

IV PCA with morphine (up to $0.03 \mathrm{mg} /$ $\mathrm{kg} /$ dose or $0.3 \mathrm{mg} / \mathrm{kg} / 4$ hours).

Rescue analgesia with ketorolac 0.5 $\mathrm{mg} / \mathrm{kg}$

(maximum single dose $30 \mathrm{mg}$ ) every 6 hours as required for the first 72 hours.

$10 \mathrm{~mL}$ bolus of $\mathrm{bup}$
line) $1: 200,000$.

Bupivacaine $0.125 \%$ and fentanyl $0.0025 \mathrm{mg} / \mathrm{mL}$ was begun at a rate of $0.35 \mathrm{mg} / \mathrm{kg} /$ hour (up to $0.4 \mathrm{mg} / \mathrm{kg} /$ hour) of bupivacaine $(0.28-0.32 \mathrm{~mL} / \mathrm{kg} /$ hour) started within 30 minutes of arrival in postanaesthesia care unit continued an adequate oral fluid intake. 
Table 2. Analgesic techniques (Continued)

Ezhevskaya 2012a
Preoperative epidural puncture at 2 levels (T4-T5 and T10-T11) with injection of $0.75 \%$ ropivacaine $(15-25 \mathrm{~mL}$ ) plus fentanyl $200 \mu \mathrm{g}$.

Postoperative infusion of ropivacaine $0.2 \%$ plus fentanyl and epinephrine (adrenaline),
Ezhevskaya 2015
Thoracic epidural anaesthesia with $0.75 \%$ ropivacaine and fentanyl

IV PCA with opioids.

Epidural catheter was inserted by the surgeon under direct visualization at the midpoint of the incision (T9-T12) and advanced 3-5 cm cephalad as described by Shaw 1996.

Loaded with fentanyl $1 \mu \mathrm{g} / \mathrm{kg}$ (maximum $50 \mu \mathrm{g}$ ) and $5 \mu \mathrm{g} / \mathrm{kg}$ hydromorphone (maximum $0.2 \mathrm{mg}$ ) diluted in $0.3 \mathrm{~mL} / \mathrm{kg}$ preservative-free saline (maximum $10 \mathrm{~mL}$ ).

Patient-controlled epidural analgesia.

Bupivacaine $0.1 \%$ plus hydromorphone $10 \mu \mathrm{g} / \mathrm{mL}$ at $8 \mathrm{~mL} /$ hour plus bolus dosing of $2 \mathrm{~mL}$ every 30 minutes

Adjusted for pain score $<4$ without oversedation.
Not reported.

IV PCA.

Hydromorphone $2 \mu \mathrm{g} / \mathrm{kg} /$ hour continuous infusion; $2 \mu \mathrm{g} / \mathrm{kg}$ bolus dose.

All participants received oral acetaminophen

(paracetamol; $15 \mathrm{mg} / \mathrm{kg}$; maximum $650 \mathrm{mg}$ ) every 4-6 hours for adjuvant analgesia, diazepam $(0.05-0.1 \mathrm{mg} / \mathrm{kg}$ IV; maximum $5 \mathrm{mg}$ ) every 6 hours as needed for muscle spasms, diphenhydramine $(0.5 \mathrm{mg} / \mathrm{kg} \mathrm{IV}$; maximum 25 $\mathrm{mg}$ ) and dolasetron $(0.35 \mathrm{mg} / \mathrm{kg}$, maximum $12.5 \mathrm{mg}$ ) for pruritus and postoperative nausea and vomiting as required.

Adjusted for pain score $<4$ without oversedation.

IV PCA with hydromorphone.
1 (T10-T11 advanced $5 \mathrm{~cm}$ cephalad; Shaw 1996) or 2 (T7T8 and T12-L1) epidural catheters placed under direct visualization after instrumentation of the spine was complete. A rongeur was used to make a hole in the ligamentum flavum large enough for placement of the catheter. The distal end of the catheter was tunnelled through the paraspinal muscles at separate entry-site in the skin.

Bupivacaine $0.1 \%$ plus fentanyl $2 \mu \mathrm{g} / \mathrm{mL} 0.2 \mathrm{~mL} / \mathrm{kg}$ (divided in 2 for participants with 2 catheters) (maximum $12 \mathrm{~mL}$ ).

Bupivacaine $01 \%$ plus fentanyl $2 \mu \mathrm{g} / \mathrm{mL}$ at $12 \mathrm{~mL} /$ hour plus 0.1 $\mathrm{mL} / \mathrm{kg}$ (lockout period 1 hour).

Rate, bolus dose, and fentanyl concentrations adjusted on pain scores.

Malviya $1999 \quad \begin{aligned} & 1 \text { catheter placed by the surgeon at the cephalad end of the in- } \\ & \text { cision }\end{aligned}$
cision.

Preservative-free morphine (Duramorph) $30 \mu \mathrm{g} / \mathrm{kg}$ (saline added for a volume of $0.15 \mathrm{~mL} / \mathrm{kg}$ ) followed by $3 \mu \mathrm{g} / \mathrm{kg} / \mathrm{hour}$ (adjusted on FLACC pain scores $\leq 3$; maximal dose $5 \mu \mathrm{g} / \mathrm{kg}$ / hour) for 3 days.
IV morphine $0.05-0.1 \mathrm{mg} / \mathrm{kg}$ followed by $0.02 \mathrm{mg} / \mathrm{kg}$ dose via a nurse-controlled analgesia device.

Diazepam for muscle spasms.
Directly placed midthoracic epidural catheter advanced $3-5 \mathrm{~cm}$ cephaladly.
IV PCA with morphine adjusted on pain scores. 
Table 2. Analgesic techniques (Continued)

$3 \mathrm{~mL}$ bolus followed by $4 \mathrm{~mL} /$ hour of $0.1 \%$ bupivacaine plus

fentanyl $5 \mu \mathrm{g} / \mathrm{mL}(\mathrm{n}=10)$ or $0.065 \%$ bupivacaine plus fentanyl 5

$\mu \mathrm{g} / \mathrm{mL}(\mathrm{n}=12)$.

Bolus allowed.

Ozturk Mamik 2011

Catheter inserted before surgery.

IV PCA with morphine.

$15 \mathrm{~mL}$ levobupivacaine $0.5 \%$ plus morphine $20 \mu \mathrm{g} / \mathrm{kg}$ and saline $15 \mathrm{~mL}$ : $2 \mathrm{~mL}$ of solution per segment operated on administered before surgery.

Catheter removed after injection.

FLACC: Faces, Legs, Activity, Cry, Consolability pain scores; IV: intravenous; L: lumbar vertebrae; PCA: patient-controlled analgesia; T: thoracic vertebrae; VAS: verbal/visual analogue scale for pain.

Table 3. Complications possibly related to the analgesic technique

\begin{tabular}{ll}
\hline Trial & Epidural analgesia \\
\hline Blumenthal 2005 & No complications related to the epidural catheter occurred. \\
& Postoperative clinical neurological assessment was uneventful. \\
& After the initial epidural ropivacaine bolus, 4 participants \\
& showed a transient motor blockade of $>1$ (1 participant had Bro- \\
& mage 2,3 participants had Bromage 3) on the modified Bromage \\
& scale, which spontaneously resolved within 180 minutes and did \\
& not recur during the continuous epidural infusion until the end of \\
& the study. \\
& The occurrence of postoperative pruritus was significantly de- \\
creased in the epidural group.
\end{tabular}

\section{Systemic analgesia}

The occurrence of postoperative pruritus was significantly decreased in the epidural group

Blumenthal 2006

No technical problem occurred with the epidural catheters.

Postoperative pruritus occurred significantly lower in

No neurological complications observed. the epidural group

2 participants had a transient motor blockade. (Bromage 1 and

2) after epidural bolus injections, which normalized within 120 minutes.

Postoperative pruritus occurred significantly lower in the epidural group.

$\begin{array}{ll}\text { Cakar Turhan } 2011 & \begin{array}{l}\text { No adverse effects related to morphine and local anaesthetic } \\ \text { consumption seen }\end{array}\end{array}$

No adverse effects related to morconsumption seen phine seen.

\section{Cassady 2000}

\section{1/14 participants receiving epidural analgesia developed a wound infection.}

There were no incidents of clinically significant hypotension noted in either group.

There were no incidents of clinically significant respiratory depression noted in either group.

6/14 (42.9\%) participants receiving epidural analgesia experienced pruritus, with a mean of $1.3 \pm 1.9$ episodes.
No participants receiving PCA experienced an infection.

There were no incidents of clinically significant respiratory depression noted in either group.

There were no incidents of clinically significant hypotension noted in either group. 
There were no incidents of clinically significant respiratory depression noted in either group.

$7 / 15$ (46.7\%) participants receiving patient-controlled analgesia experienced pruritus, with a mean of $0.7 \pm$ 1.7 episodes

\begin{tabular}{|c|c|}
\hline Ezhevskaya 2012a & $\begin{array}{l}\text { Non-invasive haemodynamic monitoring showed that epidur- } \\
\text { al does not lead to life-threatening disorders in myocardial con- } \\
\text { tractility, cardiac output, systemic vascular resistance, and criti- } \\
\text { cal increase of the content of extravascular lung water. }\end{array}$ \\
\hline
\end{tabular}

\begin{tabular}{ll}
\hline Ezhevskaya 2015 & There were no complications. \\
\hline Gauger 2009 & $7(37 \%)$ participants experienced early epidural failure. \\
& $\begin{array}{l}1 \text { participant experienced respiratory depression (i.e. decreased } \\
\text { respiratory rate and oxygen desaturation }<90 \%) \text { treated with } \\
\text { supplemental oxygen and lowering or discontinuation of the opi- } \\
\text { oid infusion. }\end{array}$
\end{tabular}

1 participant had hypotension requiring discontinuation of the epidural.

1 participant complained of paraesthesia.

1 participant required readmission for an ileus.

1 participant developed a pneumothorax requiring chest tube placement.

Platt $2013 \quad$ Paraesthesia: 4 participants with 1 catheter and 1 participant
with 2 catheters.

10 participants had epidural leakage causing discontinuation for 2 participants.

No respiratory distress.

No cases of clinically significant hypotension that were thought to be directly related to the epidural infusions to the extent that the infusions were changed.

No alterations to the epidurals were necessary so that a better neurological examination could be obtained.

No episodes of wound infection.

No readmission.

Late-onset neurological events were absent in all participants.

All adverse effects were minor in nature and required routine nursing and medical care.
The incidence of adverse effects was significantly higher in the group without epidural (no details provided).
There were no complications.

2 participants in the IV group remained intubated, sedated, and ventilated for several hours postoperatively.

3 participants experienced respiratory depression (i.e. decreased respiratory rate and oxygen desaturation < $90 \%$ ) treated with supplemental oxygen and lowering or discontinuation of the opioid infusion.

1 participant developed a pneumothorax.

1 participant developed a fever.

Paraesthesia: 2 participants.

No episodes of wound infection.

No readmission.

Late-onset neurological events were absent in all participants.

All adverse effects were minor in nature and required routine nursing and medical care.

\section{1 dislodged catheter.}

No respiratory depression.

The incidence of pruritus that required treatment was similar between groups during the postoperative period.
No respiratory depression.

The incidence of pruritus that required treatment was similar between groups during the postoperative period. 
Table 3. Complications possibly related to the analgesic technique (Continued)

1 participant required catheterization for urinary retention after initial removal of the bladder catheter.

\section{9/22 (41\%) participants with the active epidural infusions vs 0/9 participants with placebo had a lower extremity paraesthesia.}

Within 24 hours after epidural catheter was discontinued, sensory examination returned to normal in $7 / 9(78 \%)$ of these participants who had a paraesthesia postoperatively.

In 2/9 (22\%) participants, the paraesthesia was likely secondary to spinal correction.

1 participant had a persistent partial sensory block which resolved after 3 months and the other participant after 6 months.

1 participant in the high-dose epidural group was also excluded after emerging from anaesthesia with lower extremity paralysis secondary to surgical correction. Paralysis resolved by 8 months.
1 participant in the placebo group was excluded secondary to severe respiratory depression demonstrated by increased $\mathrm{PaCO}_{2}$ (6.5-7.8 $\mathrm{kPa}$; 50$60 \mathrm{mmHg}$ ) and a decreased respiratory rate ( $6-8$ breaths/minute). This was felt to be secondary to IV patient-controlled analgesia morphine dosing.

No significant difference detected among the groups regarding the incidence of sedation $(P=0.10)$ or pruritus $(P=0.32)$.

No significant difference detected among the groups regarding the incidence of sedation $(P=0.10)$ or pruritus $(P=0.32)$.

Ozturk Mamik $2011 \quad$ Not reported Not reported

IV: intravenous; $\mathrm{PaCO}_{2}$ : partial pressure of carbon dioxide.

\section{AP P E N D I C E S}

\section{Appendix 1. Search terms for CENTRAL}

\section{September 2017}

Cochrane Central Register of Controlled Trials : Issue 8 of 12, August 2017

\#1 MeSH descriptor: [Spinal Diseases] explode all trees and with qualifier(s): [Surgery - SU] 1169

\#2 MeSH descriptor: [Spinal Fusion] explode all trees 1078

\#3 MeSH descriptor: [Scoliosis] explode all trees 293

\#4 ((Spine* or spinal or lumbar) near/3 surg*) or scolios ${ }^{\star}$ or thoracolumbar or (thoraco* near/3 lumbar) or (thoracic near/3 (lumbar or spine)) 6192

\#5 \#1 or \#2 or \#3 or \#4 6638

\#6 MeSH descriptor: [Analgesia, Epidural] explode all trees 1960

\#7 MeSH descriptor: [Anesthetics, Local] explode all trees 7115

\#8 MeSH descriptor: [Analgesics, Opioid] explode all trees 6247

\#9 ((local or systemic) near/4 an?esth*) or opioid* or epidural* or analg* 54236

\#10 \#6 or \#7 or \#8 or \#9 56615

\#11 MeSH descriptor: [Postoperative Period] explode all trees 5354

\#12 MeSH descriptor: [Pain, Postoperative] explode all trees 11672

\#13 MeSH descriptor: [Postoperative Care] explode all trees 4406

\#14 postoperative or post operative 82797

\#15 \#11 or \#10 or \#12 or \#14 118395

$\# 16$ \#5 and \#10 and \#15 1954

\#17 \#16 in Trials 1697

14 November 2018 (September 2017 to December 2018)

(spine surgery OR spinal surgery) AND (epidural analgesia OR epidural anesthesia) AND (postoperative pain OR postoperative care) 74

\section{Total CENTRAL 1771}




\section{Appendix 2. Search terms for MEDLINE}

September 2017

Database: Ovid MEDLINE(R) Epub Ahead of Print, In-Process \& Other Non-Indexed Citations, Ovid MEDLINE(R) Daily and Ovid MEDLINE(R) $<1946$ to Present>

1 ((Spine* or spinal or lumbar) adj3 surg*).mp. or exp Spinal Diseases/su or Spinal Fusion/ or scoliosis/ or scolios ${ }^{\star}$.mp. or thoracolumbar.mp. or (thoraco* adj3 lumbar).mp. or (thoracic adj3 (lumbar or spine)).mp. (83497)

2 Analgesia, Epidural/or Anesthetics, Local/or Analgesics, Opioid/ or ((local or systemic) adj4 an?esth*).mp. or opioid*.mp. or epidural*.mp. or analg*.mp. (306319)

3 exp Postoperative Period/ or exp Pain, Postoperative/ or Postoperative Care/ or post?operative.mp. or post operative.mp. (751418)

4 ((randomized controlled trial or controlled clinical trial).pt. or randomi?ed.ab. or placebo.ab. or drug therapy.fs. or randomly.ab. or trial.ab. or groups.ab.) not (exp animals/ not humans.sh.) (3698955)

51 and 2 and 3 and 4 (1116)

\section{November 2018 (2017 to 2018)}

1 (spine and (epidural anesthesia or epidural analgesia) and (postoperative pain or postoperative period)).af. (41)

2 limit 1 to $y r=" 2017-2018 "(7)$

Total MEDLINE $=\mathbf{1 1 2 3}$

\section{Appendix 3. Search terms for Embase}

Database: Embase < 1974 to 2017 Week 38>

1 ((Spine* or spinal or lumbar) adj3 surg $\left.{ }^{\star}\right) . \mathrm{mp}$. or exp spine disease/su or exp spine fusion/ or exp scoliosis/ or scolios*.mp. or thoracolumbar.mp. or (thoraco* adj3 lumbar).mp. or (thoracic adj3 (lumbar or spine)).mp. (115650)

2 epidural analgesia/ or local anesthetic agent/ or narcotic analgesic agent/ or ((local or systemic) adj4 an?esth*).mp. or opioid ${ }^{\star} . \mathrm{mp}^{\star}$ or epidural ${ }^{*}$.mp. or analg*.mp. (430622)

3 exp postoperative period/ or postoperative pain/ or post?operative.mp. or post operative.mp. (1072155)

4 ((crossover procedure or double blind procedure or single blind procedure).sh. or (crossover ${ }^{\star}$ or cross over $^{\star}$ ).ti,ab. or placebo ${ }^{\star}$.ti,ab,sh. or (doubl* adj blind*).ti,ab. or (controlled adj3 (study or design or trial)).ti,ab. or allocat*.ti,ab. or trial*.ti,ab. or randomized controlled trial.sh. or random^.ti,ab.) not ((exp animal/ or animal.hw. or nonhuman/) not (exp human/ or human cell/ or (human or humans).ti.)) (2015360)

51 and 2 and 3 and 4 (1156)

\section{November 2018}

spine AND 'epidural anesthesia' AND ('postoperative period' OR 'postoperative pain') AND [2017-2018]/py = 19

Total Embase $=1175$

Appendix 4. Search terms for CINAHL

\section{September 2017}

\begin{tabular}{lll}
\hline S1 & $\begin{array}{l}\text { (Spine* or spinal or lumbar) N3 surg*) or (MH "Spinal Diseases+") or (MH } \\
\text { "Spinal Fusion") or (MH "Scoliosis+") or scolios* or thoracolumbar or (thoraco* } \\
\text { N3 lumbar) or (thoracic N3 (lumbar or spine)) }\end{array}$ & 20,243 \\
\hline S2 & $\begin{array}{l}\text { (MH "Analgesia, Epidural") or (MH "Anesthetics, Local+") or (MH "Analgesics, } \\
\text { Opioid+") or ((local or systemic) N4 an?esth*) or opioid* or epidural* or analg* }\end{array}$ & 58,832 \\
\hline
\end{tabular}


(Continued)

S3 (MH "Postoperative Period") or (MH "Postoperative Pain") or (MH "Postopera- $\quad$ 66,564 tive Care+") or postoperative or post operative

\begin{tabular}{lll}
\hline S4 & S1 AND S2 AND S3 & 403 \\
\hline S5 & $\begin{array}{l}\text { ((MM "Randomized Controlled Trials") OR (MM "Random Assignment") OR } \\
\text { (MM "Prospective Studies+") OR (MM "Clinical Trial Registry") OR (MM "Dou- } \\
\text { ble-Blind Studies") OR (MM "Single-Blind Studies") OR (MM "Triple-Blind Stud- } \\
\text { ies") OR (MM "Multicenter Studies") OR (MM "Placebos")) OR (random* or } \\
\text { placebo* or trial*) }\end{array}$ & 297,938 \\
\hline S6 & S4 AND S5 & $\mathbf{1 2 3}$ \\
\hline
\end{tabular}

14 November 2018 (2017-2018)

(spine surgery or spinal surgery) AND (epidural analgesia or epidural anesthesia) AND (postoperative pain) $\mathbf{1 6}$

Total CINAHL

\section{Appendix 5. Search terms for ProQuest Dissertations and Theses Global 2 September 2018}

Spine surgery AND epidural = $\mathbf{4}$

14 November 2018

Spine surgery AND epidural $2018=\mathbf{0}$

Total ProQuest Dissertations and Thesis Global $=4$

\section{Appendix 6. Pain scales used in included trials}

Blumenthal 2005; visual analogue scale from 0 to 10

Blumenthal 2006; visual analogue scale from 0 to 10

Cakar Turhan 2011; visual analogue scale from 0 to 10

Cassady 2000; visual analogue scale from 0 to 10

Ezhevskaya 2012a; pain scores not included

Ezhevskaya 2015; pain scores not included

Gauger 2009; pain scale from 0 to 10

Klatt 2013; Wong-Baker system scale from 0 to 10

Malviya 1999; FLACC (Face, Legs, Activity, Cry, Consolability) scale from 0 to 10

O'Hara 2004; visual analogue scale from 0 to 10

Ozturk Mamik 2011: visual analogue scale from 0 to 10

\section{CONTRIBUTIONS OF AUTHORS}

Joanne Guay (JG), Santhanam Suresh (SS), Sandra Kopp (SK), Rebecca L Johnson (RLJ).

Conceiving the review: JG, SS, SK, and RLJ.

Co-ordinating the review: JG.

Undertaking manual searches: JG and RLJ. 
Screening search results: JG and RLJ.

Organizing retrieval of papers: JG.

Screening retrieved papers against inclusion criteria: JG and RLJ.

Appraising quality of papers: JG and SK.

Abstracting data from papers: JG and SK.

Writing to authors of papers for additional information: JG.

Obtaining and screening data on unpublished studies: JG and RLJ.

Managing data for the review: JG.

Entering data into Review Manager : JG.

Analysing Review Manager 5 statistical data: JG.

Performing other statistical analysis not using Review Manager: JG.

Interpreting data: JG, SS, SK, and RLJ.

Making statistical inferences: JG.

Writing the review: JG, SS, SK, and RLJ.

Securing funding for the review: departmental resources only.

Performing previous work that was the foundation of the present review: JG, SS, SK, and RLJ.

Serving as guarantor for the review: JG.

Taking responsibility for reading and checking the review before submission: JG, SS, SK, and RLJ.

\section{DECLARATIONSOF INTEREST}

JG: none.

SS: none.

SK: none.

RLJ: none.

\section{SOURCES OF SUPPORT}

\section{Internal sources}

- University of Sherbrooke, Canada.

University of Sherbrooke provided access to some databases and some articles

- University of Quebec en Abitibi Temiscamingue (UQAT), Canada.

University of Quebec en Abitibi Temiscamingue (UQAT) provided access to some articles

- Cochrane Anaesthesia, Critical and Emergency Care Group, Denmark.

The review authors wish to thank Janne Vendt, Cochrane Information Specialist, who designed the search strategy

- University of Laval, Canada.

University of Laval provided access to some databases and some articles

\section{External sources}

- No sources of support supplied 


\section{DIFFERENCES BETWEEN PROTOCOL AND REVIEW}

We made the following changes to the published protocol (Guay 2017).

1. The study population was specified as being up to 18 years of age in the protocol. Due to the low number of trials available, we included four trials with participants older than 18 years: Blumenthal 2005 (10 to 30 years; mean age 17 years), Ezhevskaya $2012 a$ (12 to 25 years), Klatt 2013 (10 to 21 years) and O'Hara 2004 (13 to 21 years).

2. Due to the high number of trials with zero cells, we analysed complications (respiratory depression, wound infection, epidural abscess and neurological complications) as RDs.

3. For three of the analysis (Analysis 1.1; Analysis 1.2; Analysis 1.4), data included pain measured on different pain scales, although all on scales from 0 to 10. For these three analyses, we gave results both as MDs and SMDs. Analysis in SMD were performed because this is the recommended way to analysis such data (Borenstein 2009b). Analysis in MDs were done to help the readers to interpret our results.

\section{N DEX TERMS}

\section{Medical Subject Headings (MeSH)}

*Analgesia, Epidural [adverse effects]; Analgesia [adverse effects] [*methods]; Early Ambulation [statistics \& numerical data]; Lumbar Vertebrae [* ${ }^{\star}$ surgery]; Operative Time; Pain Measurement; Pain, Postoperative [ ${ }^{\star}$ drug therapy]; Patient Satisfaction; Randomized Controlled Trials as Topic; Thoracic Vertebrae [ ${ }^{\star}$ surgery]; Vomiting [chemically induced]

\section{MeSH check words}

Humans 